Florida International University FIU Digital Commons

FIU Electronic Theses and Dissertations

University Graduate School

2-19-1997

\title{
Influence, policy formation, and higher education in Florida : 1989-94
}

Edward Allen Blackwell

Florida International University

DOI: $10.25148 /$ etd.FI14051163

Follow this and additional works at: https://digitalcommons.fiu.edu/etd

Part of the Education Commons

\section{Recommended Citation}

Blackwell, Edward Allen, "Influence, policy formation, and higher education in Florida : 1989-94" (1997). FIU Electronic Theses and Dissertations. 1684.

https://digitalcommons.fiu.edu/etd/1684

This work is brought to you for free and open access by the University Graduate School at FIU Digital Commons. It has been accepted for inclusion in FIU Electronic Theses and Dissertations by an authorized administrator of FIU Digital Commons. For more information, please contact dcc@fiu.edu. 


\section{FLORIDA INTERNATIONAL UNIVERSITY}

Miami, FL

\section{INFLUENCE, POLICY FORMATION, AND HIGHER EDUCATION IN FLORIDA: 1989-94.}

A dissertation submitted in partial satisfaction of the

requirements for the degree of

DOCTOR OF EDUCATION

IN

EDUCATIONAL ADMINISTRATION AND SUPERVISION

by

Edward Allen Blackwell, Jr. 
To: I. Ira Goldenberg

College of Education

This dissertation, written by Edward A. Blackwell, Jr., and entitled INFLUENCE, POLICY FORMATION, AND HIGHER EDUCATION IN FLORIDA: 1989-94, having been approved in respect to style and intellectual content is referred to you for your judgment.

We have read this dissertation and recommend that it be approved.

\begin{tabular}{l}
\hline John A. Carpenter \\
\hline Ralph L. Lewis \\
\hline Sarah W. I. Pell \\
\hline Peter J. Cistone, Major Professor
\end{tabular}

Date of Defense: February 19, 1997

The dissertation of Edward A. Blackwell, Jr. is approved.

Dean I. Ira Goldenberg

College of Education

Dr. Richard Campbell

Dean of Graduate Studies

Florida International University, 1997 
(C) COPYRIGHT 1997 by Edward A. Blackwell, Jr.

All rights reserved 
I dedicate this dissertation to my parents

\section{Edward Allen Blackwell}

Anne Theresa Keenan Blackwell 


\section{ACKNOWLEDGMENTS}

I wish to thank the members of my committee and the faculty of the College of Education for their helpful comments and patience. I also want to thank my many friends and colleagues at St. Thomas University who have supported me during this entire learning process, especially the staff at the Office of Campus Ministry and the Main Library. In particular, I want to mention Dr. Kenneth Johnson who assisted with the statistical analysis, Dr. James Conley who helped with the final editing, Mary Monaco who assisted with the reference work, and Angela Sims who assisted with the organization of the document. Finally, I would like to acknowledge Sr. Rosemary Winklejohann, O. S. U. and Dr. Norma Goonen whose friendship and support gave me the courage to begin doctoral studies.

A special thanks to my major professor, Dr. Peter J. Cistone, for his ongoing support, encouraging comments, and unflagging confidence in me to complete this research project. 


\section{ABSTRACT OF THE DISSERTATION \\ INFLUENCE , POLICY FORMATION, AND HIGHER EDUCATION}

IN FLORIDA: 1989-94

by

Edward Allen Blackwell, Jr.

Florida International University, 1997

Professor Peter J. Cistone, Major Professor

This study examined the perceptions of state governmental officials and administrators from the state university system, community college system, and independent institutions concerning the ability of various groups to influence state-level higher education policy formation. The study was conducted in Florida for the period 1989-94. Florida has a history of legislative involvement in higher education, an unique system of state universities and community colleges, and a limited number of private institutions of higher education. This study was grounded in the works of Mortimer and McConnell (1978), Millett (1987), Marshall, Mitchell, and Wirt (1989) and Finitfer, Baldwin, and Thelin (1991). 
The study represented the application of an embedded, single-case design. A survey was the primary collection instrument. Respondents were asked questions concerning: (a) personal involvement in higher education, (b) perceptions of the ability of various groups to influence higher education policy, (c) the names of particular individuals considered key players in higher education policy formation, (d) important state-level documents, (e) personal knowledge of key areas of policy formation, and (f) emerging higher education issues in Florida. Quantitative and qualitative methods were used to analyze the different sections of the survey.

The findings indicated that a power and influence hierarchy exists among the various groups that attempt to influence higher education policy and that this hierarchy is recognized by state government officials and higher education administrators. While an analysis of variance of the various groups revealed a few differences between state government officials and higher education personnel, the high overall agreement was an important finding. Leading members of the legislature, especially the Chair of the Senate Higher Education Committee, and key staff members, especially from the Senate Ways \& Means Committee, were considered the most influential. Representatives from higher education institutions and research organizations were considered among the least influential. Emerging issues identified by the respondents included: (a) the political nature of state-level policy formation, (b) the role of legislative staff, (c) the competition for state moneys, (d) legislative concern for state-wide budgetary efficiency, and (e) legislative attempts to define quality and supervise academic program development for higher education. 


\section{TABLE OF CONTENTS}

CHAPTER

PAGE

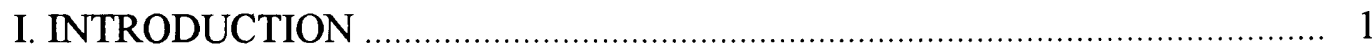

The Research Problem ................................................................... 1

Statement of Purpose ............................................................................ 3

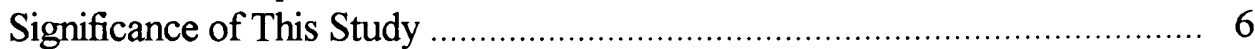

Rationale for the Study of Problem ..................................................... 8

Hypotheses and Research Questions ....................................................... 9

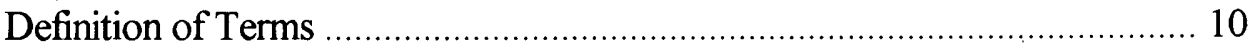

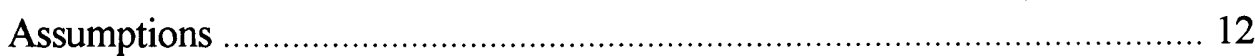

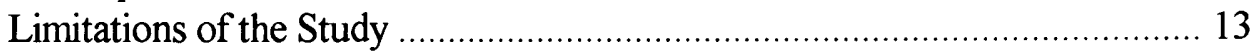

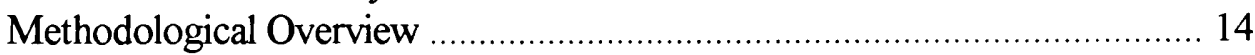

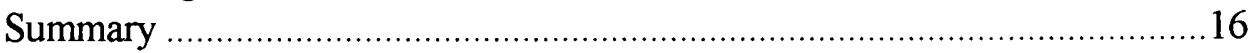

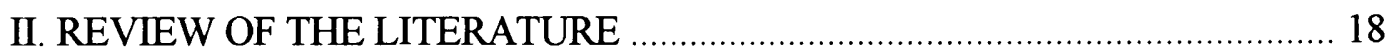

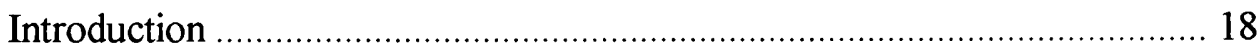

The Politics of Higher Education ........................................................... 19

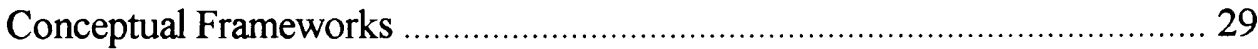

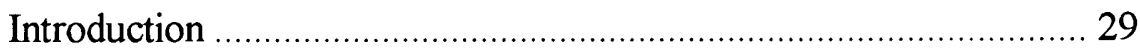

Mortimer and McConnell's Concept of Academic Governance ......... 30

Marshall, Mitchell, and Wirt's Cultural Paradigm ............................. 48

Florida's Higher Education Environment …….......................................... 58

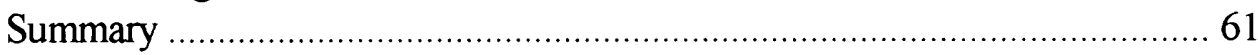

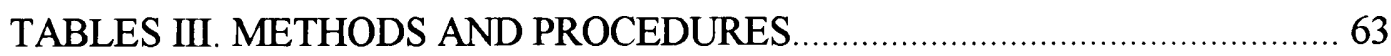

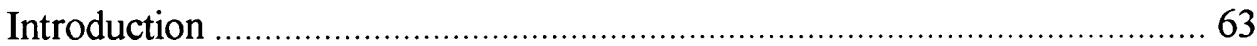

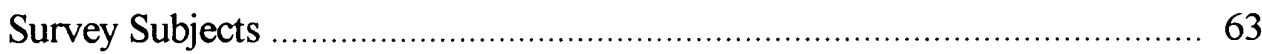

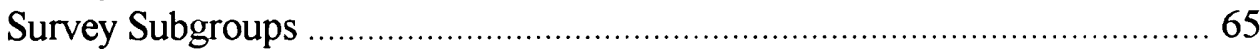

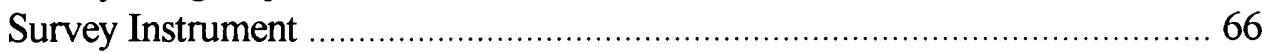

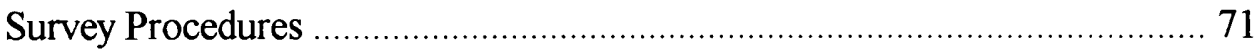

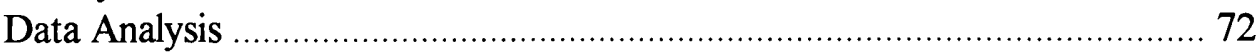

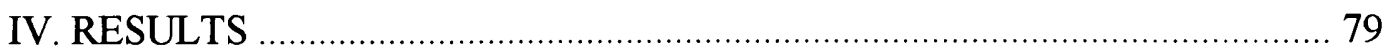

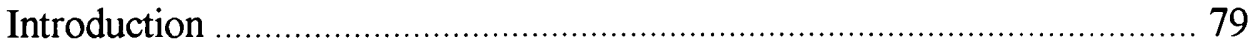

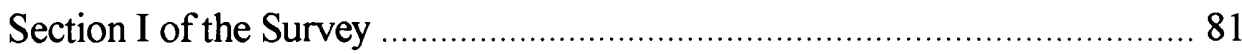

Analysis of Questions .......................................................................... 81

Profile of Florida's Higher Education Leadership ........................... 91

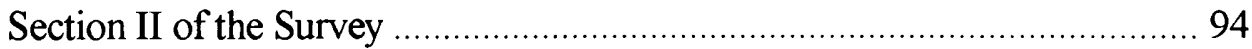

Analysis of 19 Variables ............................................................. 94

Policy Group Rankings for Highest to Lowest .............................. 96 
Analysis of Variance for Each Variable ......................................... 98

The Power and Influence Hierarchy ............................................ 112

Section III of the Survey ................................................................ 132

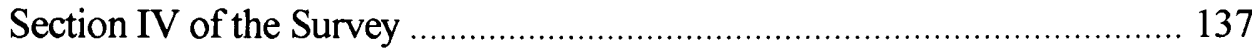

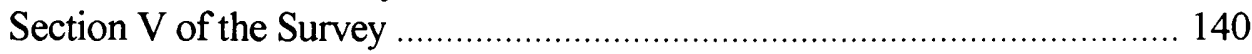

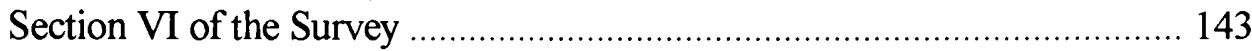

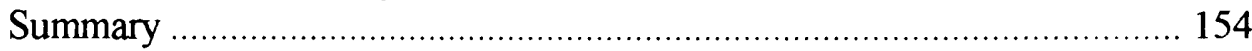

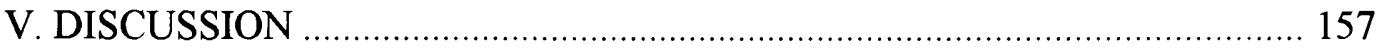

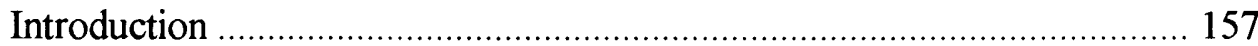

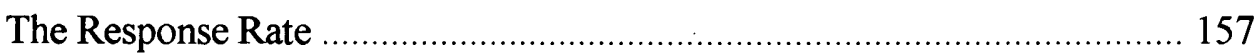

Hypotheses and Research Questions ........................................................ 161

Conclusions and Implications................................................................... 172

Florida's Higher Education Environment .................................... 172

Politics of Higher Education Research ......................................... 175

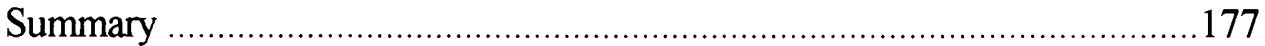

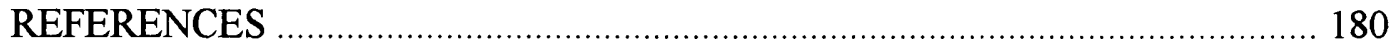

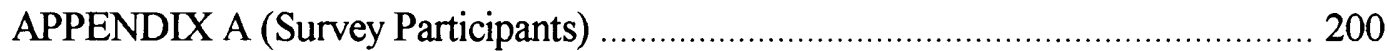

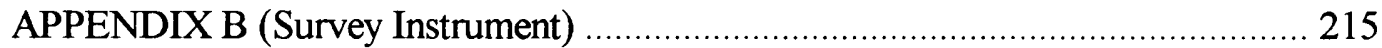

APPENDIX C (Summary of Section III - Key Policy Makers) ............................. 224

APPENDIX D (Summary of Section III - Key Positions or Offices) ..................... 230

APPENDIX E (Summary of Section IV - Relevant Documents) .......................... 233

APPENDIX F (Summary of Section VI - Emerging Issues) ................................ 235

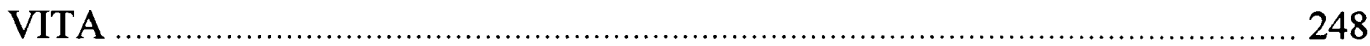




\section{LIST OF TABLES}

Table 1 - Research in Politics and Policy: An Analytical Paradigm

Table 2 - Framework for Assessing the Distribution of Authority in the

Decision-making Process on a Given Issue

Table 3 - A Taxonomy of Higher Education Policy

Table 4 - A Model of a Cultural Paradigm as a Way of Understanding the Public Policy System

Table 5 - Distribution of Returned Surveys by Institutional Affiliation

Table 6 - Respondents' Time in Present Position by Institutional Affiliation

Table 7 - Age of Respondents by Institutional Affiliation

Table 8 - Respondents' Gender by Institutional Affiliation 85

Table 9 - Respondents' Ethnicity by Institutional Affiliation 86

Table 10 - Respondents' Highest Degree Earned by Institutional Affiliation 87

Table 11 - Respondents' Specialized Certification by Institutional Affiliation ......88 88

Table 12 - Respondents' Family Income by Institutional Affiliation 89

Table 13 - Respondents' Political Orientation by Institutional Affiliation 90

Table 14 - Respondents' Political Party Affiliation by Institutional Affiliation 91

Table 15 - Average Background Characteristics of Florida's Higher Education

Leaders 93

Table 16 - Policy Group Rankings from Highest to Lowest TOTAL Mean 96

Table 17 - Policy Group Influence Rankings: Statistical Data

Table 18 - Analysis of Variance 99

a. The Governor and the Executive Staff

Table 19 - Analysis of Variance 100

b. The Chief State School Officer and Senior Staff in the 
State Department of Education

Table 20 - Analysis of Variance 100

c. The State Board of Regents

Table 21 - Analysis of Variance

d. Chancellor of the State University System

Table 22 - Analysis of Variance

e. The State Legislature

Table 23 - Analysis of Variance 103

e1. Leading Members of Legislative Committees

Table 24 - Analysis of Variance 103

e2. Key Legislative Staff Consultants

Table 25 - Analysis of Variance 104

f. All the Education Interests Groups

Table 26 - Analysis of Variance

f1. Faculty Organization(s)

Table 27 - Analysis of Variance 106

f2. Lobbyist from Independent Institutions

Table 28 - Analysis of Variance 107

f3. Lobbyist from Public Institutions

Table 29 - Analysis of Variance 107

f4. Student Organization(s)

Table 30 - Analysis of Variance 108

g. Non-Education Interest Groups

Table 31 - Analysis of Variance 109

h. Producers of Education Related Products

Table 32 - Analysis of Variance 110

i. Direct Referenda Initiated by Citizens

Table 33 - Analysis of Variance 110

j. The Courts (State or Federal) 
Table 34 - Analysis of Variance

k. Federal Policy Mandates to the States

Table 35 - Analysis of Variance

1. Education Research Organizations

Table 36 - Policy Group Influence by Cluster and Ranking

Table 37 - Policy Groups Clusters: Statistical Data 118

Table 38 - Type and Number of Respondents to Section III of the Survey

Table 39 - Number of Respondents by Institutional Affiliation Who Listed the Names of Individuals They Perceived to be Key Policy Makers in Florida Higher Education

Table 40 - Names of Key Policy Makers Mentioned at Least Three Times,

Policy Makers Position in State Government or Higher Education and the Total Number of Times Mentioned by Survey Respondents .... 135

Table 41 - Type and Number of Responses to Section IV of the Survey 138

Table 42 - Source of Materials and Number of Times Mentioned

by Respondents with Documents Origin and Respondents'

Institutional Affiliation

Table 43 - Analysis of Variance

a. Finance

Table 44 - Analysis of Variance

b. Governance

Table 45 - Analysis of Variance

c. Access and Choice

Table 46 - Analysis of Variance

d. Quality and Assessment

Table 47 - Type and Number of Responses by Institutional Affiliation

to Section VI of the Survey 144 


\section{LIST OF FIGURES}

Figure 1 - Four Paradigms for the Analysis of Social Theory

Figure 2 - Assumptive Worlds' Fit with Other Approaches to

Understanding Policy Making

Figure 3 - A Model of Power and Influence in Education Policy Making 55 


\section{INTRODUCTION}

\section{The Research Problem}

New internal realities and external constraints are altering the culture of higher education and its patterns of governance. These patterns evolved prior to World War II and have dominated academic governance for the past forty years. Governing boards, presidents, and faculty will need to develop new patterns of academic governance that respect this cultural shift and maintain a creative tension between the demands of internal and external constituencies. To maintain a cohesive culture, the academy must be able to control and channel the tensions between its various internal and external constituencies or risk inaction and chaos (Whitson \& Hubert, 1982; Schaeffer, 1990). In addition, the various groups that compete for control of the academy must be able to provide the same predictability and stability to their members or risk the same inaction and chaos.

Individuals enter these particular groups with greater or lesser influence and each manipulates interactions in order to gain enough influence to be the individual who dominates the group and whose group dominates academic policy formation. This influence "translates operationally into knowing whose voice will be heard when decisions must be made amid the clamor of demands and complaints" (Marshall, Mitchell \& Wirt, 1989, p. 165).

In investigating the internal and external patterns of academic decision making, Mortimer and McConnell (1978) described the period after World War II to the early 1970s as a period of "faculty power" centered in the academic department. Academic governance during this period can be described as highly decentralized with low levels of 
accountability. However, the growth in the number, size, and complexity of higher education institutions during this period has caused a shift of academic governance away from the faculty and the department.

Other factors are contributing to these unstable conditions in academic governance as various internal and external groups compete for control over the purpose and direction of higher education in the United States. The withdrawal of the federal government from higher education (Robb, 1982; Feller, 1986; Williams, 1991), the growth of state-wide coordinating boards for higher education (Green, 1986), and the shift of faculty interest from institutional concerns to academic disciplines (Austin, 1990) are making new demands on traditional concepts of academic governance and the ability of the internal interests groups to maintain control over academic governance. Mortimer and McConnell (1978) concluded that "higher education is in the throes of a shift from informal and consensual judgments to authority based on formal criteria. Standardization, litigation, and centralization have become the watch-words of college and university governance" (p. 269).

Munitz and Lawless (1986) echoed the same sentiments almost a decade later when they observed: "American colleges and universities are not likely to find much relief from external pressures during the next ten years. Their health will rest on the ability of faculty members and administrators to devise credible and imaginative responses to those pressures" (p. 83). The movement towards centralization and greater accountability is shifting the locus of academic governance. Who will be the new arbitrators of academic matters? Where will the locus or loci of power be? 
One new locus of academic governance may become the state capital (Hook, Kurtz, \& Todorovich, 1978; Green, 1986; "Ten," 1995) where many of the internal and external interests groups debate the issues of quality, diversity, and budgetary efficiency in higher education (Finifter, Baldwin, \& Thelin, 1991) amid the clamor and noise of other interests demanding use of the state's resources and regulatory powers. Slaughter (1990) has suggested that "the state, then, is no longer simply the source of moneys or a policing agency, but is simultaneously a multifaceted source, the arena in which policy formation is played out, and an actor in its own right, with an often unpredictable agenda" (pp. 1-2). The failure of governing boards, administrators and faculty within private and public higher education to negotiate this shift as a political process (Mortimer \& McConnell, 1978; Millett, 1987; Kerr, 1994) could be catastrophic to the academic profession and to the creation of new knowledge by higher education institutions.

\section{Statement of Purpose}

This study seeks a greater understanding of who desires to influence higher education policy formation at the state level and how each individual or group is heard. It also seeks to determine if higher education leaders from private universities and colleges, public community colleges, public universities, and state government have different perceptions of an individual's or a group's ability to influence state-level higher education policy. The ability to compare similarities or differences from an institutional perspective can provide a better understanding of potential areas of conflict or consensus between these constituencies. The study was guided by three hypotheses and seven research 
questions in the examination of the power and influence structures of state-level higher education policy formation in Florida with a particular focus on the period 1989 to 1994.

Both the time frame and the setting for the study are noteworthy. The decade since the release of A Nation at Risk (National Commission on Education, 1983) has seen increased concern about the value and purpose of higher education (Carnegie Foundation, 1988; Aspen Institute, 1992; Bok, 1992; Harvey, 1994; Harvey \& Immerwahr, 1995a, 1995b). These concerns have found outlets in new state-level initiatives and in regional accrediting activities. Increased demands for accountability, and new internal review and reporting activities on college campuses have increased during this period (El-Ehawas, 1995). Revitalized state governments increasingly concern themselves with higher education (Goodall, 1987). The state has become the principle source of higher education funding and policy activity during the 1980s. Social, economic, and political forces (Corey, Jackson, \& Prichtard, 1983; Altbach \& Berdahl, 1987; Tierney, 1988; Gilley, 1991; Cameron \& Tschirhart, 1992) will continue to encourage a substantial shift in higher education policy initiative away from the federal and local (including the institutional) levels into the hands of state policy makers. The state-level context of higher education forms an important and unstable nexus in higher education policy formation.

Not only are most federal mandates directed at the states (Robb, 1982; Feller, 1986) but business interests increasingly are also using state government to discuss economic concerns, and the production and transfer of knowledge (Jones, Oberst, \& Lewis, 1990; Slaughter, 1990). However, four other traditional subgroups who have vital interests in the future of higher education come together at the state level. These four 
groups include: (a) elected or appointed state government officials with an interest in higher education, (b) personnel from the public university system, (c) personnel from the community college system, and (d) personnel from private universities and colleges. At best, these four groups represent a "loosely coupled" system of higher education at the state-level.

From the perspective of state government, higher education is seen as one of many areas that makes demands on public resources and regulation (Easton, 1965). Its representatives are seen as another set of lobbyists attempting to influence policy (Goodall, 1987; Gilley, 1991; Finifter et al., 1991). From the perspective of higher education, state government is seen as one of an increasing number of external constraints on the autonomy and mission of higher education (Fonte, 1989; Volkwein, 1989). From an organizational theory perspective, the state-level context of higher education policy formation raises important issues and concerns about academic governance.

Mortimer and McConnell (1978) outlined a comprehensive understanding of academic governance that included the presence of internal and external interests groups. It is their concept of academic governance that conceptually grounded this study. In addition to providing for various levels of governance and participants, they identified four important variables in academic governance:

1. What issue is to be decided?

2. Who--what persons or groups--should be involved in the decision?

3. When (at what stage of decision-making process) and how should such involvement occur? 
4. Where--at what level in the organizational structure--should such involvement occur? (p. 13).

While Mortimer and McConnell (1978) identified the state level as an arena of academic governance, reviewed the emerging role of state coordinating boards, and outlined the use of faculty bargaining units to articulate faculty interests and concerns at the state level, they did not provide specific answers to their four variables of academic governance at the state level. This study will explore three of their four variables from the cultural perspective of power and influence in its investigation of the "who" and the "what" of the state-level context (the "where") of higher education policy formation. This study does not address the fourth variable of "when and how" participation in policy formation takes place at the state level but assumes that formal and informal consultation processes are present.

\section{Significance of this Study}

Florida's higher education environment makes it an ideal place to study the questions of academic governance (Dye, 1991; Gilley, 1991; Dye 1995). Florida's legislature and governors have taken an active role in the development and coordination of higher education in the state (Gomez, 1982; "Almanac," 1995). In the 1970s, state officials committed themselves to an ambitious plan to provide postsecondary education for every citizen within a 50 mile radius of home. To fulfill this vision of accessible postsecondary education, the state legislature spearheaded the development of a " $2+2$ " system of public community colleges and universities. This system has numerous lower-division institutions 
(28 institutions) offering a variety of community-based continuing education programs and associate degrees. A smaller number of upper-division institutions offer baccalaureate, masters, and doctoral degrees (10 institutions).

These two types of institutions complete Florida's public system of higher education. In addition, the state has a "system" of private universities and colleges with a recent history and limited enrollment. Most of these institutions have enrollments of less than 1,000 and are poorly organized at the state level. Of the 97 private institutions reported in The Chronicle of Higher Education ("Almanac," 1995), only 23 are represented at the state-level by Independent Colleges and Universities of Florida (ICUF).

From a methodological perspective, this study represents the application of Marshall et al.'s (1989) cultural paradigm to answer Mortimer and McConnell's (1978) two variables of "who" and "what" at the state level. Marshall et al.'s cultural paradigm guided the development of the survey instrument that was used for data collection in this research. The survey instrument was designed to surface information concerning who attempts to influence higher education policy formation (Sections I, II, \& III) and what are the emerging issues (Sections IV, V, \& VI). Finally, this research represents the application of an embedded, single-case design (Yin, 1984) as it seeks to understand the perceptions of influence of higher education leaders from four institutional perspectives. While the cultural paradigm of Marshall et al. has been used in K-12 education policy research, this study is the first attempt to apply aspects of their cultural paradigm to the study of the politics of higher education. Tierney (1988) has called for the use of the 
cultural perspective in the study of interorganizational relationships within higher education.

\section{Rationale for the Study of Problem}

This study is of value from both content and methodological perspectives. The hierarchical distinction (Etzioni, 1964) necessary to answer questions of centralization/ decentralization and a hierarchical model's tendency to emphasize "top only" solutions may not be an adequate description of the use of authority in academic governance. The image of the state as "over" higher educational institutions within its jurisdiction is neither an accurate nor appealing image of governance patterns. To counter this image, Mortimer and McConnell (1978) have suggested that patterns of academic governance must develop appropriate consultation processes and maintain appropriate levels of discretion to avoid chaos or inaction.

Attempts to find the appropriate relationships in the patterns of academic governance not only at the state-level but across the higher education environment will be a critical task for all those interested in higher education. Insights into the development of these patterns may have application to non-higher education arenas for the policy researcher, the policy maker, and those who wish to understand patterns of decisionmaking. Insight into the power and influence rankings can be useful to the policy maker, the policy researcher, and those who wish to influence policy. The application of the cultural paradigm of Marshall et al.'s (1989) to state-level questions of higher education 
policy formation can be important as researchers seek new perspectives to study the political aspects of academic governance.

\section{Hypotheses and Research Questions}

The following hypotheses guided this study:

Hypothesis 1: There are statistically significant differences with regard to perceptions of influence among higher education leaders for those groups who seek to influence higher education policy in Florida.

Hypothesis 2: There are statistically significant differences among the clusters of policy actors that form a power and influence hierarchy in the state-level context of higher education policy formation.

Hypothesis 3: There are statistically significant differences among higher education leaders at different types of institutions with respect to the relative ability of various groups to influence in higher education policy formation.

The researcher answered seven exploratory research questions with the information received on the surveys: 
1. Do the higher education leaders agree on the presence of a model of power and influence?

2. How do their perceptions differ based on institutional affiliation?

3. Who are the policy elites that form the "insiders" and members of the "near circle" in this model?

4. Who are the "sometime players" and "often forgotten players" in this model?

5. Do higher education leaders perceive that academic governance is shared in Florida's higher education policy formation?

6. What reports or documents can provide insight into Florida's higher education policy formation?

7. How do personnel from the four types of institutions perceive the various policy issues facing higher education in Florida?

\section{Definition of Terms}

For the purposes of this study, the following definitions will be used: 
1. Policy refers to the programs of action designed to achieve the goals and intentions of the appropriate leaders.

2. Policy Formation refers to the process by which individuals and groups translate values and concerns into policy.

3. Policy Actors refers to those individuals or groups who attempt to influence state level higher education policy formation or implementation.

4. Policy Elites refers to those individuals or groups involved in state level policy formation that perceived as having the most influence in higher education policy.

5. Higher Education Policy Leaders refers to those individuals or groups involved in state-level higher education policy formation or its implementation at the state or institutional level.

6. Culture refers to a group's collection of shared values and legitimating social patterns and practices that support those values and beliefs.

7. System refers to the complex formal and informal relationships through which an institution links itself to other institutions, society in general, and the environment. 
8. Higher Education refers to public community colleges and private and public colleges and universities and their formal and informal relationships with each other and the state government.

\section{Assumptions}

The researcher held the following assumptions:

1. Higher education policy leaders recognize a power and influence hierarchy in their attempts to influence in state-level higher education policy formation.

2. An individual's or group's ability to influence policy may not be expressed in formal organizational arrangements.

3. Administrative or faculty representation on state-level committees or task forces may not be perceived as an adequate voice in state-level policy formation by local or internal institutional leaders.

4. Higher education policy formation at the state level is an element of academic governance. 


\section{Limitations of the Study}

The results of this study should be interpreted with consideration given to the following limitations:

1. There is a potential difference between perceived and actual influence of the various policy actors. In reviewing Marshall et al.'s findings, Richardson (1985) observed that there may be real differences between perceived and actual influence. Based on her experience in Arizona, Richardson has suggested that the influence of legislative staff may be understated and the influence of the legislature or governor may be overstated.

2. Policy actors who attempt to influence policy formation at state level in Florida but were not included in this survey could include: (a) the State Community College Board, (b) the Executive Director of State Community College Board, (c) presidents of individual institutions, (d) local boards of trustees, (e) alumni, and $(f)$ parents.

3. The relative importance of higher education policy issues as they compete with other areas of concern at the state level was not addressed in this study.

4. Although more than $70 \%$ of those surveyed responded, it is not known how the information from non-respondents would have affected the data analysis. 
5. Survey participants were not chosen on a random selection basis but because of their roles in state government or higher education.

\section{Methodological Overview}

The study represents the application of an embedded, single-case design (Yin, 1984 ) in its analysis of the perceptions of influence of Florida's higher education leaders as a group and as members of four distinctive types of institutions. A survey was the primary data collection instrument. While using the cultural paradigm of Marshall et al. (1989) to guide the development of the survey, the data from the survey was used to answer Mortimer and McConnell's (1978) "who" and "what" questions in the state level context of higher education policy formation. The application of Marshall et al.'s cultural paradigm was reflected in the use of two concepts from the paradigm in this research. Their concepts of assumptive worlds and power and influence hierarchy guided the development of this study's data gathering instrument and data analysis.

The survey instrument adapted several interview protocols developed by Marshall et al. (1989) in their work with the policy elites in their six-state study of K-12 policy formation. This study's survey instrument asked higher education policy leaders a series of personal and professional questions. Multiple choice questions were used for personal data. Professional issues were investigated using either a Likert type system or open-ended questions. Questions used to create a higher education leader's profile concerned a participant's institutional role, institutional affiliation, time in present position, age, gender, 
ethnicity, highest degree earned, specialization certification, family income, political orientation, and political party.

A Likert type system was used to rate 19 individuals or groups generally associated with influence in higher education policy formation at the state level and the participant's level of knowledge in the areas of finance, governance, access and choice, and quality and assessment (Millet, 1987). Finally, the survey contained three open-ended questions. The first asked the participants to identify key policy makers in Florida higher education policy formation that should be surveyed. The second question asked the participants if there were any reports or documents that provide a clearer picture of higher education policy formation in Florida. The last question asked participants to comment on the most pressing issues in Millet's four areas of higher policy formation with special reference to Florida.

The study utilized a cultural paradigm in its data collection and analysis. Both quantitative and qualitative methods of data analysis were employed. Quantitative data was analyzed to develop a higher education leader profile, to create a power and influence hierarchy, and to determine if a respondent's institutional affiliation created a difference in the perception of the ability of the various groups to influence higher education policy formation. The qualitative data was used to provide a more precise understanding of who are the policy elites and to surface emerging issues in governance, finance, access and choice, and quality and assessment. 


\section{Summary}

The study examined the "who" and "what" variables of Mortimer and McConnell's (1978) concept of academic governance in the context of state-level higher education policy formation from the perspective of power and influence in Florida with a particular focus on the period 1989-1994. The period was one in which there was a great deal of legislative activity in the area of higher education policy formation. The purpose of the study was to determine if the higher education leaders in Florida recognized a power and influence hierarchy in state-level policy formation and if the perceptions of power and influence varied based on institutional affiliation. It also attempted to identify potential sources of conflict and consensus on emerging issues in higher education. For the purpose of the study, the four subgroups with vital interests in higher education were: (a) private university and college representatives, (b) state university system administrators, (c) public community college personnel, and (d) state government officials.

In addition to determining who are the policy elites in Florida higher education policy formation, the study used Marshall et al.'s (1989) power and influence hierarchy to determine Florida higher education leaders' perceptions of the influence of the various policy actors who attempt to impact higher education policy formation. Finally, the study was used to create a profile of higher education leadership in Florida. This profile could be used to compare the political perspective of higher education leaders to the political culture of the state and to answer questions of gender equality and ethnic diversity within the state's higher education leadership. From a methodological perspective, the study represents the application of the cultural paradigm to questions of academic governance in 
the state-level context of higher education policy formation. The literature suggests that this area of politics of higher education research and the use of the cultural paradigm are important contributions to the field. 


\section{REVIEW OF THE LITERATURE}

\section{Introduction}

The proposed study built upon models and theories from sociology, anthropology, education policy research, and higher education policy research. This review is organized into three major sections: (a) the context of the politics of higher education research, (b) conceptual frameworks, and (c) Florida's higher education environment. The review of the literature on the politics of higher education research will place the current study in the nascent field of the politics of higher education.

The review of conceptual frameworks will place the study within Mortimer and McConnell's (1978) concept of academic governance. Their concept highlighted the various levels of decision making and the groups who wish to influence academic policy as they attempted to move the questions of academic governance from a strictly institutional setting. They argued that the four variables of "what," "who," "when," and "where" must be addressed in any discussion of academic governance. The groups who have an interest in state-level higher education policy formation, especially legislatures, governors, education professionals, state coordinating boards, higher education interest groups, and emerging policy actors will be reviewed in this section.

In addition, the cultural paradigm of Marshall et al.'s (1989) with its concepts of assumptive worlds and the power and influence hierarchy will be reviewed. They developed their cultural paradigm to describe the state-level context of K-12 education policy formation. The last section will focus on the time frame and setting of the study. Relevant features of Florida's higher education environment will be examined. 
The Politics of Higher Education

Edward R. Hines and Leif S. Hartmark have published two important works on the emerging field of the politics of higher education. They authored the monograph, Politics of Education, (1980) to provide "a comprehensive review of the literature of the politics of higher education at the federal, state, and local levels of government." The second work was a chapter in Gove and Stauffer's (1986) Policy Controversies in Higher Education entitled "Politics and Policy in Higher Education: Reflections on the Status of the Field" (Hartmark \& Hines, 1986). In it they attempted to map the field by suggesting a taxonomy of higher education politics and policy, and a paradigm of political research and policy analysis to guide future research efforts. Their two essays will help place this study within the research on the politics of higher education in general and within the state level in particular.

Hines and Hartmark (1980) placed the beginning of politics of higher education research in the late 1960s when Gove and Solomon (1968) published "The Politics of Higher Education: A Bibliographic Essay" in the Journal of Higher Education. The next year, a keynote speaker at a regional political science association meeting outlined a research agenda for inquiry into the state university as a political system. Gove and Floyd (1975) also mentioned the early work of Betty Ann Olive in their review of the research on the politics of higher education. Since that time the Journal of Higher Education has been a leader in publishing work in this field of inquiry. 
Hines and Hartmark (1980) organized their review into four major areas: (a) the politics of higher education at the federal level, (b) the politics of higher education at the state level, (c) the politics of higher education at the local level, and (d) a review of the major conceptual and methodological approaches used in the field. They surfaced several themes in the literature:

1. Politics and higher education are interrelated, and this relationship has a dynamic and fluid quality.

2. As the relationship between higher education and politics evolves, it will become more differentiated.

3. Particular political issues and relationships are evident at each governmental level.

4. It is critical for higher education to make its own case for autonomy and to provide justification in specific areas where its essential character is jeopardized by governmental incursion. (pp. 1-3)

This study explores the particular issues and relationships at the state governmental level from the perspective of power and influence.

In the same review, Hines and Hartmark (1980) surfaced the following themes within the literature concerned with the politics of higher education at the state level: (a) statewide coordination, (b) accountability and institutional autonomy, (c) budgeting for higher education, and (d) interinstitutional relationships. Skolnik and Jones (1992) provided a Canada-United States comparative analysis of state-level coordination that showed that various cultural and institutional differences impact coordination efforts. In 
the area of autonomy, Volkwein (1989) investigated the relationship between the faculty quality, student quality, and external funding. He concluded that state financial policies have a greater impact on quality than do state regulations.

Slaughter (1988) explored the crisis in state funding and its relationship to academic freedom. Levin investigated the issue of productivity in higher education and concluded productivity is "a function of the degree of control given to faculty and administrators to pursue their own interest with the resources of higher education institutions" (1991, p. 243). Morgan (1992) reviewed recent funding efforts to link quality and program initiatives in four states. Berdahl and Studds' (1990) study of sixteen years of quality initiatives in Florida concluded that the legislature has "put categorical strings on otherwise discretionary dollars" (in Morgan, p. 293).

In the area of interinstitutional relationships, Hines and Hartmark (1980) surfaced the following topics: (a) higher education and legislatures, (b) interinstitutional conflict, (c) private or independent higher education, and (d) higher education lobbying. Private or independent higher education has received a great deal of attention. Shulman (1972) provided an early summary of the state's interest in private higher education, methods of aid available to the state, and the problems inherent in the relationship between private higher education and the state.

Breneman and Finn (1978) edited a complete study of the relationship between private higher education and federal and state government. Gardner, Atwell and Berdahl (1985) examined the emerging relationship between private higher education and the state in Pennsylvania, Illinois, Maryland, North Carolina, and New York. They concluded that 
the historical facts, the patterns of politics, and the role of particular personalities impact an individual state's support of private higher education. Levy (1986) investigated the various perspectives of the financial impact of the private-public debate. Ferris (1991) explored the continuing use of contracting of private higher education by state governments as a means of promoting budgetary efficiency. He concluded that the ability to provide contracted services varies greatly on the context in which the service is to provided. Zumeta $(1992,1996)$ has continued to investigate the relationship between budgetary efficiency and private higher education in a series of studies of state policies affecting private higher education.

Gove and Stauffer (1986) argued that a critical area of research in the policy formation process is "the relationship between the internal governance of a university and the decisions that are made by external forces" (p. 264). This study attempts to develop an understanding of the relationships between higher education and state government from the cultural perspective of power and influence.

Hines and Hartmark (1980) also surfaced the following shortcomings in their review of the literature on academic and institutional governance:

1. The literature is replete with prescriptions about how the academic system of government should work under ideal circumstance.

2. The literature focuses on the formal apparatus of academic governance, on the constituent representation on campus wide governance bodies, and on the decisions made by these organs of government. 
3. The literature sheds only dim light on the dynamics of the political process through which these formal structures actually make decisions. (p. 39) However, according to Hartmark and Hines, certain studies did not exhibit these shortcomings. In addition to Mortimer and McConnell's (1978) work on academic governance, the Stanford Project on Academic Governance and Richman and Farmer's examination of power sources and relationships in academic institutions are mentioned. While there have been more recent studies on the current crisis in academic governance (Alpert, 1985; White, 1990; Langenberg, 1992; Benjamin, 1993), this dissertation builds on the work of Mortimer and McConnell.

While Gove and Stauffer (1986) and Slaughter (1990) have reviewed the literature in the politics of higher education, Hines and Hartmark's (1980) monograph remains the most complete review to date. While not attempting to discuss completely the changes in the field since time of their essay, this researcher has noted three developments that are expanding the study of the politics of higher education. The first development is the study of the politics of higher education from an international perspective (Clark, 1981; Premfors \& Wittrock, 1983; Weiler, 1986; Skolnik \& Jones, 1992). The second development is the broadening of themes in the state-level context of higher education. While there is a continued interest in budgetary efficiency at the state level, there is also increased state activity in the areas of quality and diversity. The emergence of these themes at the state level is raising questions about the relationship between state legislative initiatives and institutional autonomy (Fisher, 1988; Finifter et al., 1991). 
The third area of development has been in methodology. Researchers have begun to use a variety of perspectives in investigating the field. This shift is best understood as the introduction of a multiparadigm perspective into the study of the politics of higher education. Burrell and Morgan (1988) created a continuum between the sociology of radical change and the sociology of regulation and a continuum between the subjective and the objective to create four paradigms for the analysis of social theory. They labeld the four quadrants of their model: (a) the "radical humanist," (b) the "radical structuralist," (c) the "interpretive," and (d) the "functionalist" (Figure 1). These paradigms represent the four paradigms that are available for contemporary research. The implications and application of these perspectives have been more fully developed elsewhere in the literature (Sergiovanni \& Corbally, 1984; Popkewitz, 1984; Lincoln, 1985; Foster, 1986; Sirotnik \& Oakes, 1986; Cherryholmes, 1988; Burrell \& Morgan, 1988; Gioia \& Pitre, 1990; Tierney; 1990; Hassard, 1991; Parker \& McHugh, 1991; Tierney, 1991a, 1991b; Capper; 1992). The current study used the "interpretive" or cultural paradigm (Marshall et al., 1989) to explore the issue of power and influence at the state level in higher education policy formation.

Six years after their Politics of Education (1980), Hartmark and Hines (1986) provided a taxonomy of higher education politics and policy as "a heuristic device for mapping the field, suggesting both the range of topical diversity and its boundaries and outlining some of the relationships between higher education systems and public policy structures" (p. 5). They also developed their analytical paradigm for research in politics and policy. Building on the works of Crosson and Adams and Robert Spadaro, their 
Figure 1

Four Paradigms for the Analysis of Social Theory

THE SOCIOLDG OF RADICAL CHANGE

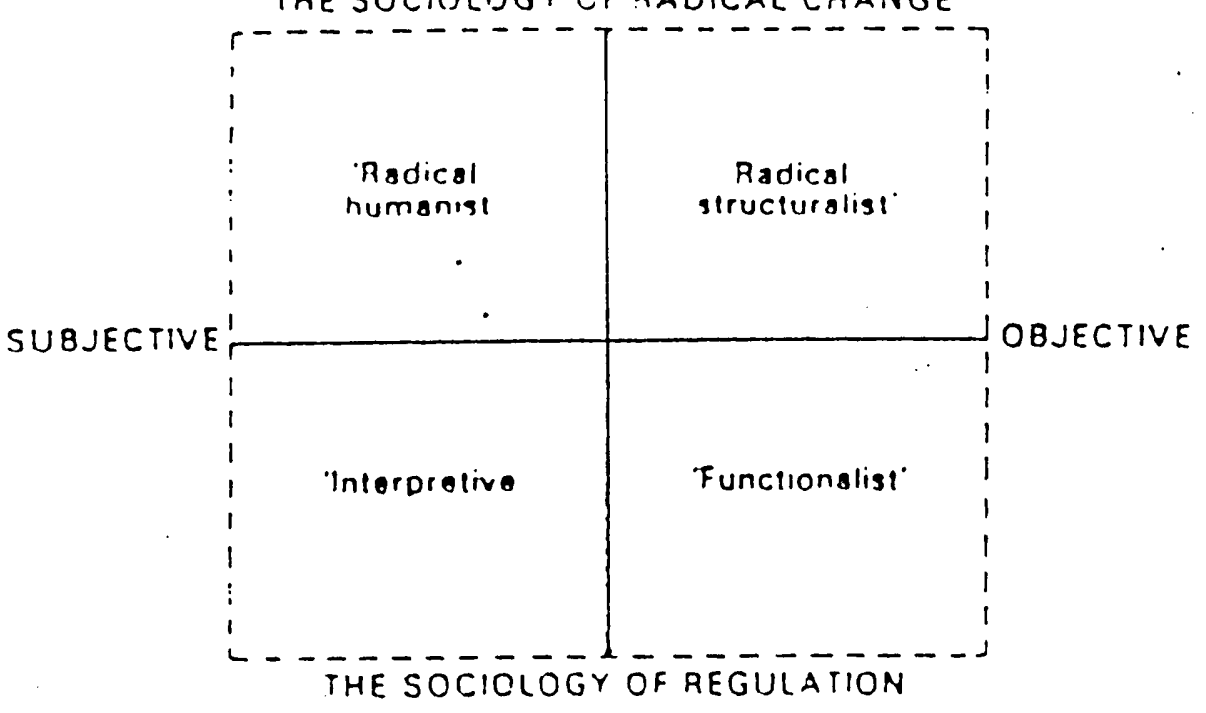

Source: Burrell, G. \& Morgan, G. (1988). Sociological paradigms and organizational analysis. Portsmouth, NH: Heinemann Educational Books, Inc., p. 22. 
analytical paradigm's two dimensions are the focus of research and the level of analysis (Table 1).

The levels of analysis are applied, disciplinary, and evaluative. Each level has a different mode of analysis, objective and actors. In their paradigm, the focus of research is either substantive policy (impact) or policy context (process). Their two dimensions of analysis and focus produced six different types of research: (a) policy analysis, (b) policy research, (c) evaluative research, (d) political feasibility analysis, (e) process research, and (f) meta-policy analysis. The current study is located in the second level of analysis or the disciplinary level where the focus of research is either on substantive policy or policy research.

Disciplinary research develops and tests theory by seeking "general patterns of behavior" either through policy research (substantive policy) or process research (policy context). Disciplinary research does not have the goal of participating in the decisionmaking process (third order or applied analysis) or of "reflecting on the conduct of policy and policy research" (first order or evaluative analysis).

The current study fits their category of policy research that they define as follows: "Policy research is the study of policy for the purpose of explaining the policy system" (Hartmark \& Hines, 1986, p. 19). In their discussion of policy research, they suggested that Thomas Dye's definition of policy analysis is similar to their understanding of policy research. For Hartmark and Hines suggested that process research's focus is on the "how" of policy, most especially how the policy impacts its environment or implementation. They echoed Robert Spadaro's plea that "it is equally important to know or to try to know also 


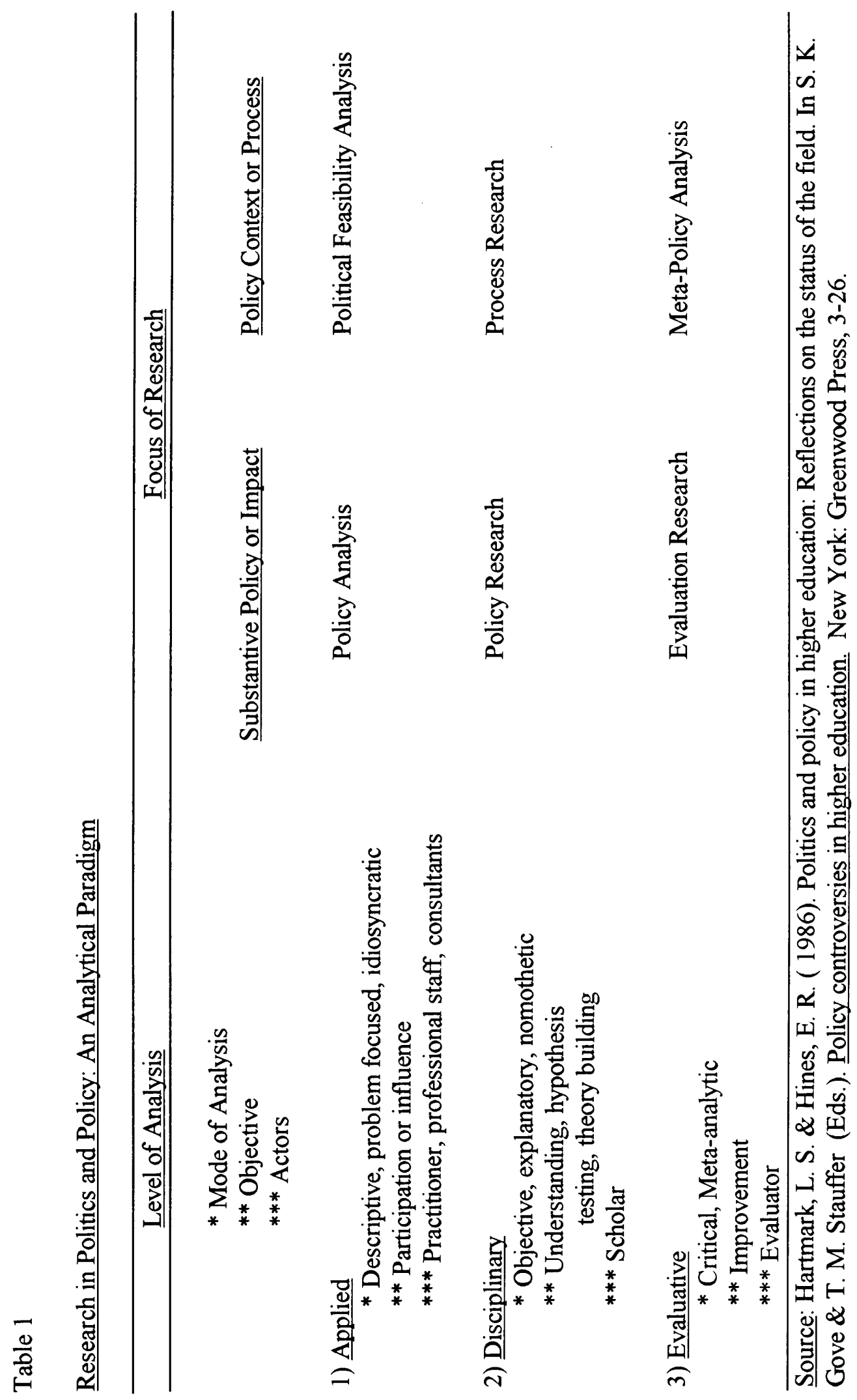


the impact and success of the policy, the symbolic or intangible results of that policy in perceptions and expectations, and the function of feedback" (in Hartmark \& Hines, 1986, p. 19).

Hartmark and Hines concluded that the development of disciplinary or secondorder literature in the field of higher education research is critical to its continued growth and health. They argued that second-order research can assist the field in four ways. The research could provide more reflective research that would focus on the nature of the field, its relationship to other disciplines, and its potential contributions to scholarship and practice. Secondly, the research could provide a more synthetic research that brings together the growing body of material found in dissertations and case studies with the goal of creating a more useful knowledge base.

A third contribution of this research to the field is the development of better theory to structure, organize, and guide future research efforts. Hartmark and Hines cautioned that this "theory" should never become monolithic but should take multiple frameworks and perspectives. Finally, this literature should be concerned with defining the boundaries of the field and additional conceptual problems. The current reserach is located in this area of second-order literature. It is a contribution to the area of policy research as it seeks a better understanding of state-level context of academic governance from the perspective of power and influence. It is concerned with the "who" and the "what" of this state-level context. 


\section{Conceptual Frameworks}

\section{Introduction}

With growth in the size, complexity and number of higher education institutions since World War II, the notion that higher education exists in an ivory tower divorced from politics has become a cherished myth about the "good old days" with little claim on reality. A central issue in the debate is what Hartmark and Hines called "the accountability problem" (1986). They argued that "the accountability problem" should be viewed from a political rather than a moral perspective.

The moral perspective views the relationship between higher education and government as either an intrusion on the part of government into academe or the erosion of institutional autonomy. This moral perspective does not take into account the changed context of the contemporary world in which higher education and other institutions find themselves. It can also foster a "victim perspective" that fails to take advantage of higher education's ability to influence regulation. Finally, it can fail to promote an atmosphere in which higher education can make "its own case for autonomy and to provide justification in specific areas where its essential character is jeopardized by governmental incursion" (Hines \& Hartmark, 1980, p. 2).

An important assumption of this study is that higher education policy formation at the state level is an expression and form of academic governance. Slaughter (1990) argued that state government can no longer be seen as merely the source of regulation and fiscal resources but as a legitimate partner in the development and maintenance of higher 
education. Kean (1991) has suggested that a new relationship between state government and higher education needs to be developed.

\section{Mortimer and McConnell's Concept of Academic Governance}

Introduction

Mortimer and McConnell's (1978) concept of academic governance attempted to capture the complexity of a decision-making process that can no longer be confined to or isolated in the halls of academe. Their framework for academic governance (Table 2) suggests that academic governance is a political process with nine decision-making levels ranging from the national level to the individual. Their matrix included six types of

participants: (a) government, (b) governing boards, (c) academic administrators, (d) faculty, (e) students, and (f) others.

In addition, they concluded that there are four important variables that must be addressed in the debate about the appropriate distribution of academic authority:

1. What issue is to be decided?

2. Who--what persons or groups--should be involved in the decision?

3. When (at what stage of decision-making process) and how should such involvement occur?

4. Where--at what level in the organizational structure--should such involvement occur? $(1978$, p. 13).

A similar conclusion is reached by Hartmark and Hines (1980) who asserted that the meaningful questions in the area of accountability are "what decisions are made, by 


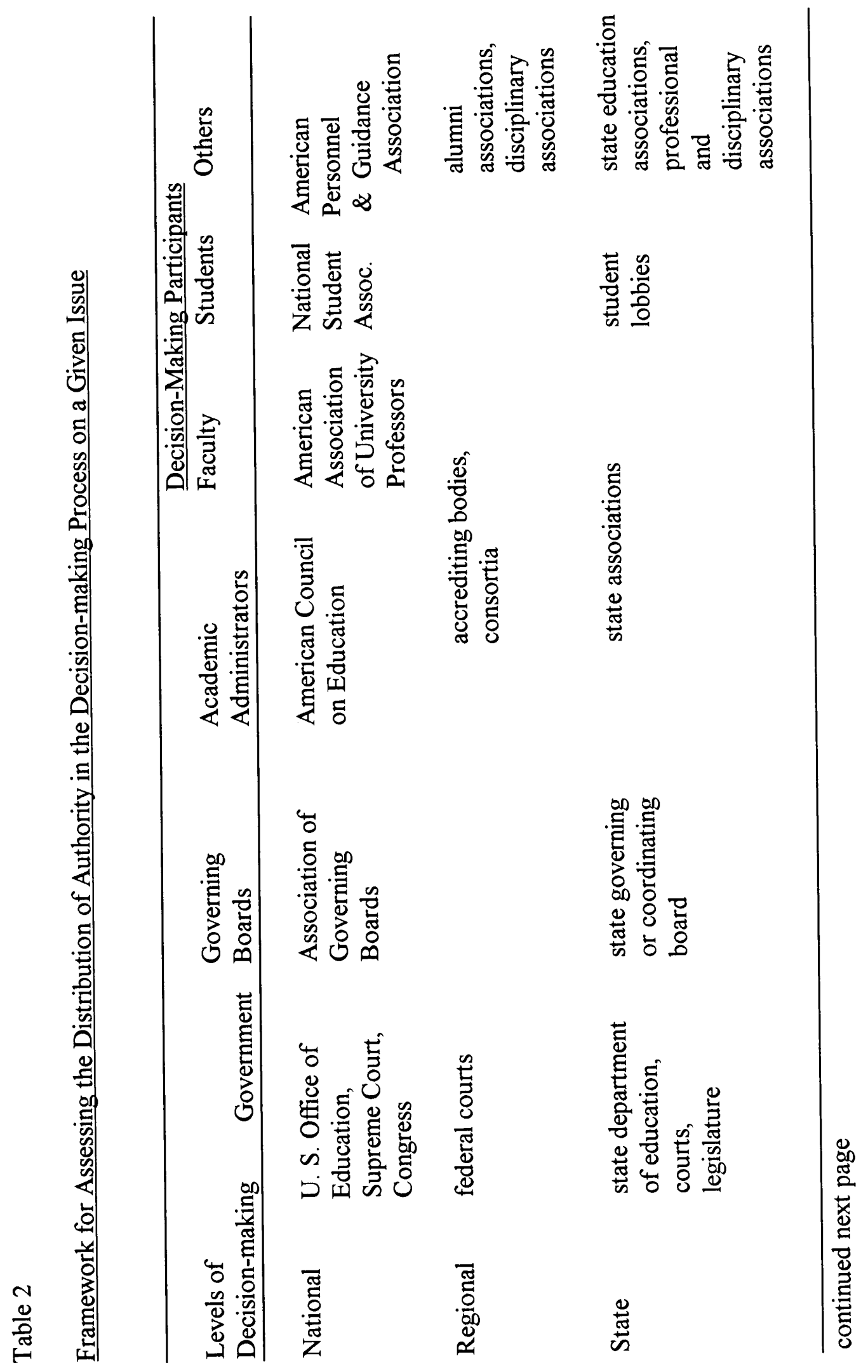




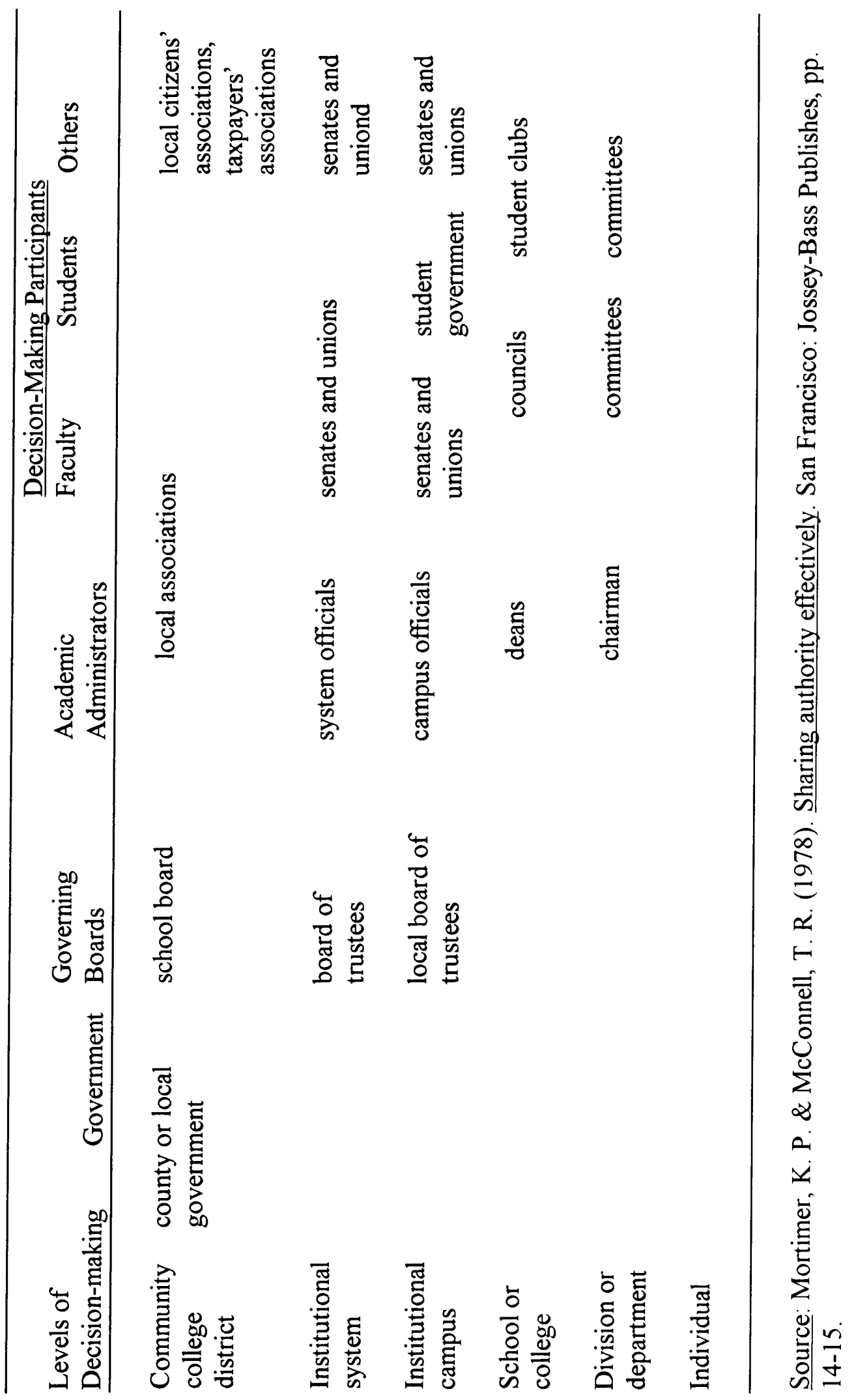


whose authority, at what level of detail, and with what effect on the perquisites of either the university or the state" (p. 13). Mortimer and McConnell concluded that most studies of academic governance have remained focused on the internal relationships between administrators and faculty. Only recently have studies investigating the role of marginal groups in academic governance at the institutional level and across the decision-making spectrum begun to emerge (Tierney, 1991; Lincoln, 1991; Foster, 1991; Capper, 1992).

It is Mortimer and McConnell's three variables of "who," "what," and "where" that provided the conceptual framework for this study of power and influence in the statelevel context of higher education policy formation. The state-level context provides the answer to the "where" question. The "who" question will be explored from a cultural perspective using Marshall et al.'s (1989) concepts of assumptive worlds and the power and influence hierarchy. Finally, the "what" question will be explored using Millet's (1987) four areas of state involvement and Finifter et al.'s (1991) uneasy triangle of quality, diversity, and budgetary efficiency. For the purposes of this study, it is assumed that formal constitutional and structural arrangements and informal processes guide policy formation activities and would provide answers to "when" and "how." The following review will discuss the state-level context for Mortimer and McConnell's four variables.

What issues are to be decided?

Hartmark and Hines (1986) and Millett (1987) have provided various answers to the question of what issues are to be decided at the state level. Hartmark and Hines provided a taxonomy (Table 3) that moves from general to specific policy areas and 


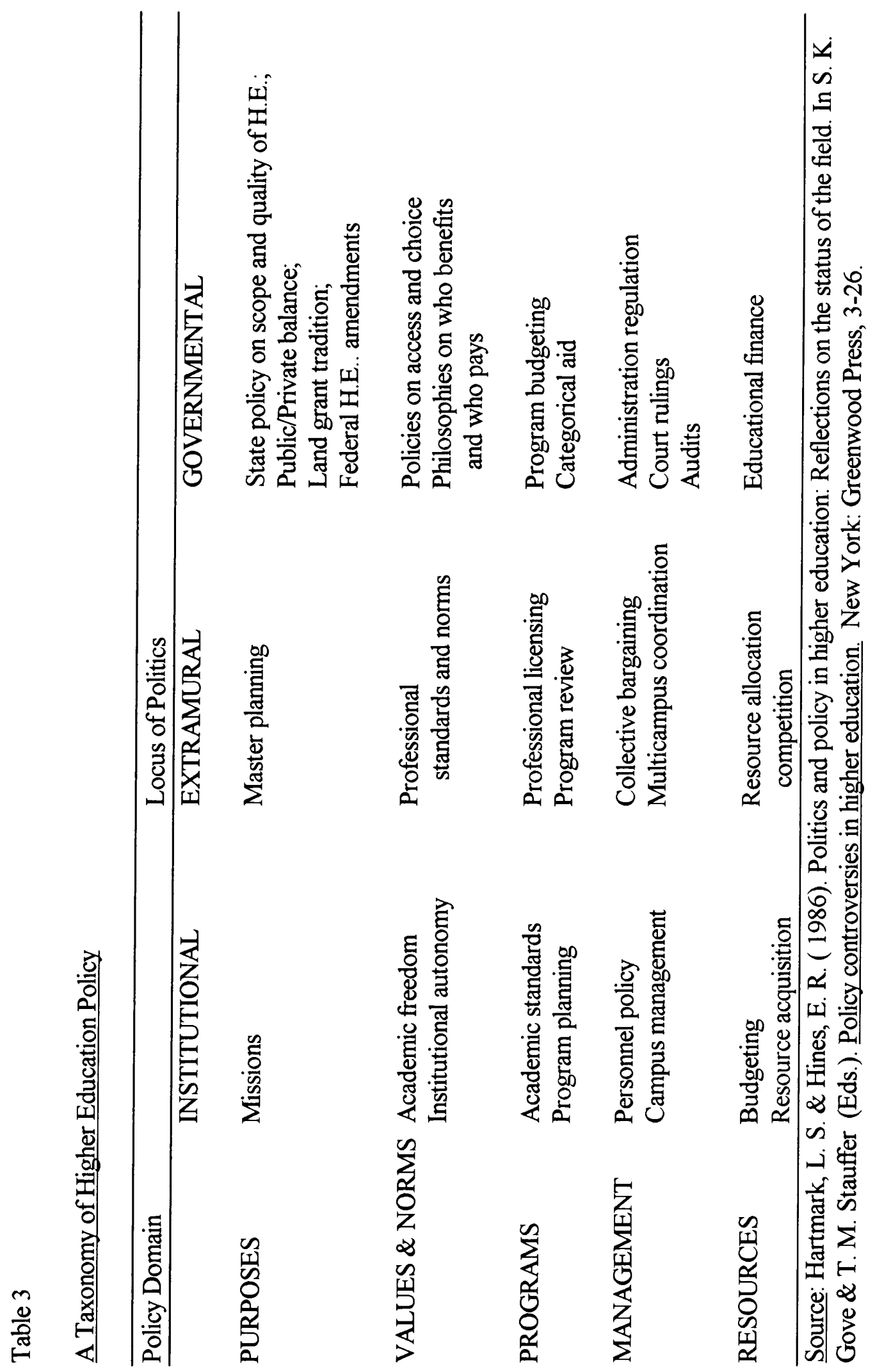


across the three levels of institutional, extramural, and governmental. At the governmental level, they found policies involved with a variety of issues that included: (a) scope and quality of higher education, (b) public/ private balance, (c) land grant tradition, (d) federal higher education amendments, (e) policies on access and choice, (f) philosophies on who benefits and who pays, (g) program budgeting, (h) categorical aid, (i) administration regulation, (j) court rulings, (k) audits, and (l) educational finance. Their list demonstrates the extent and complexity of governmental involvement in higher education governance.

Millett (1987) provided a descriptive summary of the four areas of finance, governance, access and choice, and quality and assessment where state governments seem to pursue policy initiatives. Finifter et al. (1991) argued that the three goals of quality, diversity, and budgetary efficiency drive federal and state policy formation. St. John's (1991) investigation of resource management strategies in higher education suggested that state policies should focus on the three goals of equity, quality, and economic development. Aper and Hinkle (1991) explored Virginia's state policies on student outcomes. Morgan (1992) reviewed the quality incentive programs in New Jersey, Ohio, Tennessee, and Florida. The literature suggests that there is little consensus about the issues proper to the state-level context of higher education policy formation.

Who--what persons or groups--should be involved in the decision?

The "who" question has received varied attention in the literature. Mortimer and McConnell (1978) suggested six groups of participants: (a) government, (b) governing boards, (c) academic administrators, (d) faculty, (e) students, and (f) others. They argued 
"colleges and universities are not only pressed to be accountable for efficient and effective operation; external agencies now hold them accountable for how well they achieve the social goals of equal access and nondiscrimination" (p. 195). They also suggested that "accountability to the public is mediated by the existence of several layers of representation between the people and its institutions ... judicial, legislative, and executive agencies of federal and state governments exert varying degrees of control over, and demand accountability from, colleges and universities" (pp. 195-196).

The Courts. In addition to the public demands for accountability, Mortimer and McConnell (1978) observed "the process of displacing decision making onto external agencies" by internal interest groups is another threat to higher education's autonomy. The increasing role of federal and state courts in higher education is an excellent example of this shift of authority (Kaplin, 1989; Kaplin \& Lee, 1990; McKinnon, 1995). Mortimer and McConnell made seven observations concerning the increasing role of the courts in internal affairs:

1. Institutions are using the courts to protect themselves against external groups.

2. There is a price to institutional autonomy when administrations and faculty resort to judicial authority.

3. The distinction between public and private institutions is blurred.

4. With increasing success faculty and students are using the judicial process to protect their rights. 
5. The courts may increase their jurisdiction as they become familiar with higher education.

6. The threat of judicial action can begin to modify institutional policies and procedures.

7. A judicial ruling in one case or jurisdiction may have unintended consequences throughout the nation or state.

They argued that the reality of "unintended consequences" is the most dangerous when administrators or faculty choose judicial redress for internal disputes.

The Executive Agencies of State Government. While many studies in this area combine federal and state government activities, this review will focus on the state-level context of policy formation. Mortimer and McConnell (1978) concluded that "the demands [from these groups] take forms ranging from direct attempts to influence institutional and individual behavior to subtle attempts to influence the direction of institutional policy" (p. 201). Federal mandates in nondiscrimination, equal employment, and affirmative action; and federal funding requirements have had a profound impact on higher education. According to most authors, Glenny has provided the best analysis of the federal impact on higher education. The recent federal decision to withdraw from higher education may relieve some of this pressure but will also create a funding vacuum.

Mortimer and McConnell (1978) concluded that several tendencies are emerging in the relationship between higher education and state government: 
1. The state appropriations process is the most visible form of control of higher education by the state.

2. Institutional budget requests are impacted by political realities as institutional leaders build their budgets based on their need to defend them in a budget process.

3. State legislatures support procedural controls including program planning, budgeting, and cost formulas.

4. State legislatures see higher education as only one of many areas making demands on state resources.

Hines and Hartmark (1980) observed that "the missions, structure, and governance of higher education institutions are inextricably related to the politics and public policy of state governments" (p. 12). They concluded that much of the literature in the early 1970 s dealt with state universities and their contribution to the state with little attention to the relationship between higher education and state politics. Their assessment of the emerging body of case study and comparative literature on the politics of higher education at the state level included the following material: (a) statewide coordination efforts, (b) accountability and institutional autonomy, (c) budgeting for higher education, and (d) interinstitutional relationships.

The continued growth of multi-campus systems and increased statewide coordination are impacting institutional autonomy and are causing instability in the accountability-autonomy dichotomy. In addition, Hines and Hartmark (1980) reported that two other factors have also contributed to this instability: (a) The growth in the scope and size of higher education has made increased demands on the state's fiscal resources 
and (b) the need for more specific, detailed, and comparative information to justify the purpose and value of higher education. In the early 1970s, the Carnegie Commission made a series of recommendations that attempted to respect the need for institutional autonomy in this more complex and political environment. The Commission suggested that states should: (a) use broad instruments for coordination, (b) preserve independent board of trustees, and (c) delegate influence over academic matters to the faculty to preserve a proper balance at the statelevel (in Hines \& Hartmark, p. 18).

Case and comparative studies of statewide coordination have focused on the practical organizational issues of function, roles, and processes of statewide coordination with a emphasis on the need to determine the appropriate or most effective structures and processes (Hines \& Hartmark, 1980). More recent studies have continued to focus on these themes (Greer, 1986; Martorana \& Nespoli, 1986; Moos \& Rourke, 1987; Gilley, 1991; Skolnik \& Jones, 1992).

An additional area in the literature has been the role of higher education in state constitutional revision activity. Mautz (1982) provided a case study of the failed attempt of the Florida's Board of Regents to gain constitutional status in 1978 and the impact of its failure on the relationships between the legislature, the Board of Regents, and individual institutions. Gove and Welch (1987) reviewed the efforts of higher education leaders to impact state constitutions. They concluded that there are four opinions concerning the relationship between higher education and state government reflected in these efforts: (a) higher education does not belong in a modern state constitution, (b) legislatures should have strict control over public universities because they are funded by state funds and are 
state agencies, (c) parochial interests such as geographical limitations or curricular restrictions have a place in state-level activity, or (d) private higher education may oppose public institutions.

The role of the governor has received attention in Gove (1987) and Gilley (1991). Gove concluded that "the relationship of the governor to higher education varies from one state to another; it has varied over time and within a state from one governor to another" (p. 41). Gilley reported that governors do not rely on higher education leaders but on their "own people" and other governors for ideas, issues, and programs. He provided eight suggestions on how higher education leaders can better engage the political process at the state level. In addition, Gilley reported on the reform activities of Thomas Kean of New Jersey, Lamar Alexander of Tennessee, Bill Clinton of Arkansas, and Robert Graham of Florida.

In addition, several governors have written on the role of state government in higher education. Charles Robb (1982), who was governor of Virginia, reflected on the changing state realities caused by the new federalism of the Regan administration. Thomas Kean (1991), the former governor of New Jersey, noted at the opening of the conference that preceded Finifter et al.'s (1991) book that " having been on both sides of the handshake, I know that higher education and government need to reexamine their relationship if we are to remain a competitive, compassionate, and forward-looking nation" (p. vii). 
The State Legislature. The relationship between the state legislature and higher education continues to be an important area of research in the politics of higher education (Hines \& Hartmark, 1980; Eulau \& Quinley, 1987). Hines and Hartmark (1980) suggested that Eulau and Quinley's earlier study of level of satisfaction among legislators, executive officials, and staff in nine states is the landmark work in this area. In addition, they mentioned the work of Nowlen in Illinois; Smoot in Ohio; Borgestad and Phillips in Minnesota; and a comparative study in New York, California, Illinois, Pennsylvania, and Texas by Worthley and Apfel. Worthley and Apfel's study is also important because they outlined some of barriers to better cooperation between higher education and state government. More recently, Floyd (1985), Sederburg (1989), and Gilley (1991) have discussed barriers to cooperation between higher education and state government from various perspectives.

While state legislatures influence higher education through planning and coordination, appropriations, and regulations, it is the budgetary process that "may very well be the most significant in its impact on the status and viability of higher education institutions." (Hines \& Hartmark, 1980, p. 21). Wildavsky observed "in the most integral sense, the budget lies at the heart of the political process" (in Hines \& Hartmark, 1980, p. 21) and reflects the relative position of higher education within the distribution of political power within a state. They observed that studies of the budgetary process have focused either on the amount of appropriations or the decision-making process. They report that these studies have found that population, demographic variables, legislative professionalism, and political competitiveness can affect the appropriations process. The 
cultural paradigm (Marshall et al., 1989) with its emphasis on the assumptive worlds of the legislature with its power and influence hierarchy and operational code may also be a good candidate for explaining these processes.

In addition to these studies, Hines and Hartmark (1980) reported a significant body of literature on the agencies involved in the budgetary process, their functions and roles in budgeting, the budgetary formulas used by the states, the presence of rationality in the budgetary process, and the role of information and rationality in decision making. They concluded "the relationship of information to political decision making appears to be multifaceted and indirect" (p. 27). They reported that Craven argued that the three factors of demands, supports, and constraints impinge on the use of information in the decision making process.

While state legislatures have continued to focus on budgetary issues (Fonte, 1989; Fischer, 1990; Karelis, 1991), they also have turned their attention to issues of quality (Conrad \& Blackburn, 1985; Morgan \& Mitchell, 1985; Volkwein, 1989; Banta \& Fisher, 1990; Davies, 1991; Gutmann, 1991; Doyle, 1991; Morgan, 1992), diversity (Greene, 1991; Zemsky, 1991, Wilson, 1991, Ginsburg \& McLaughlin, 1991), and assessment (Englert, 1986; Ewell, 1990; Satterlee, 1992; Schmitz, 1993). With this increased legislative activity, some authors have begun to investigate the relationship between state legislative activity to institutional autonomy (Fisher, 1988; Volkwein, 1989). The review of the literature indicates that the instability and shifts in the patterns of academic governance that began in the 1970s will continue with increasing attention and focus on the state-level context of policy formation, most especially within the legislature 
and the state-wide coordinating boards. Marshall et al. (1989) have suggested that a state's background variables of political culture (Freeman, 1992), recent history, current fiscal status, and hierarchies of power and influence have a profound impact on policy formation.

Higher Education Lobbying and Emerging Actors. Hines and Hartmark (1980) observed that attempts to understand how educational policy is influenced at the state level are beginning to emerge in the literature about lobbying efforts. They cited Gove and Carpenter's study as the most important work on higher education lobbying efforts. Gove and Carpenter reviewed the research on the activities of lobbying groups from faculty, students, institutional associations, and university officials. They saw the emergence of a higher education lobby as a result of the increased complexity of higher education and state government. They concluded that the type of lobbying and the target varied by state but that the most often targets were the governor, the governor's fiscal staff, the legislative leadership and members, opinion leaders, the general public, and the state coordinating board.

Hines and Hartmark (1980) reported on Anderson's study in Florida that used an analysis of critical incidents to determine the effectiveness of lobbying efforts. Sandage's study used factor analysis to determine the level of consensus between legislators and higher education lobbyists on a broad range of issues. Goodall (1987) reviewed higher education lobbying efforts at the state-level that included efforts to influence state constitutions, governors, legislators, and state coordinating boards. 
Mortimer and McConnell (1980) saw faculty influence at the state level as a function of faculty collective bargaining activity. They argued that faculty collective bargaining was the result of legislative activity that produced the legislative framework for collective bargaining, determined who participated in contract ratification, controlled the fiscal arrangements of bargaining agreements, and attempted to standardized personnel policies for public employees.

Floyd (1985) has reviewed faculty participation in decision making across the institutional, system, and state levels. Slaughter (1993), Gumport (1993), Rhoades (1993), and Kerlin and Dunlap (1993) provided a series of studies on the impact of retrenchment during the 1980 s on faculty from a variety of perspectives. Each of these studies concluded that the power and influence of the various groups was a critical factor in eventual retrenchment decisions.

Mortimer and McConnell (1980) reviewed the emergence of student lobbies at the federal and state level. Henderson provided an early study of student lobby efforts in California, New York, and Illinois. In the same year, Shark released a study on student lobbying efforts in Montana and Oregon. While student lobbies can support institutional goals at the state level, they tend to address student-related financial and academic issues.

Since the Southern Association of Colleges and Schools introduced the concept of institutional effectiveness into its reaffirmation and accrediting processes, the level of reporting and accountability has increased at universities and colleges throughout the country. The argument for regional and professional accreditation bodies is they preserve peer review and professional determination while addressing the emerging issue of 
accountability. More recently, Penney (1986) and Simmons (1986) addressed the issue of accreditation. The Chronicle of Higher Education reported new efforts to link federal government funding to the regional accrediting activities. If this trend continues and impacts state funding decisions, the role of regional and professional accrediting bodies could become even more critical for local institutions.

While much of the research activity in higher education has been funded by the federal government, its gradual withdrawal from these funding programs is creating a resource vacuum in higher education (Feller, 1986). This vacuum is being filled by business interests who seek to link the academy's ability to produce and transfer new knowledge with economic issues. State governments have been quick to respond to the potential connections between higher education institutions and economic development. Solomon and Zumeta (1986) address this tension as an emerging issue in higher education. Slaughter $(1988,1990)$ has continued to explore the emerging role of business in higher education who argued that a three-way relationship between state government, business, and higher education has begun to emerge for a variety of reasons. The increased importance to business of technology production and transfer is causing this shift in relationship. Buchbinder (1993) deals with the corporate-university relationship and the transfer of knowledge. 
When (at what stage of decision-making process) and how should such involvement $\underline{\text { occur? }}$

This question concerns the type and process of consultation and level of discretion provided for the various issues and groups interested in academic governance. While this study does not investigate the "when" and "how" of higher education policy formation at the state level, some conclusions from the literature can be suggested. Mortimer and McConnell (1978) concluded that shared authority is an ideal that has not been achieved in academic governance in spite of the importance placed on it in academic governance statements. Floyd (1985) outlined three types of consultation within academic governance: (a) separate jurisdictions, (b) shared authority, and (c) joint participation. Building on the work of Berdhal, Hartmark and Hines (1986) have suggested five different types of accountability: (a) systematic, (b) substantive, (c) programmatic, (d) procedural, and (e) fiduciary. These different forms of accountability might suggest the implementation of different consultative processes. Several authors have described ideal forms of consultation that might occur (Mortimer \& McConnell, 1978). Other authors have described some of the barriers to academic consultation (Floyd, 1985; Feller, 1986).

Where--at what level a policy should be formulated.

While not suggesting a hierarchical model, Mortimer and McConnell (1978) have included the levels of national, regional, state, community college, institutional system, institutional campus, school or college, division or department, and individual in their 
framework for assessing the distribution of authority. Hartmark and Hines (1986) include the three levels of institutional, extramural, and governmental (state and federal). Their extramural setting corresponds to Mortimer and McConnell's category of state governing boards. In dealing with the issues of quality, diversity, and budgetary efficiency, Finifter et al. (1991) blended the discussion of federal and state issues.

Etzioni (1964) has suggested that questions framed in terms of centralization and decentralization arise when organizational units are viewed as hierarchical with one superior to another and questions about "where" a decision should be made arise. In this frame, one answer is to provide a highly centralized system with decisions made at "the top" and communicated to the subordinates "at the bottom." In this solution, the state is seen as "the top" and the higher education institutions are seen as the "subordinates." Higher education becomes another state agency that can be regulated like any other public utility.

Another solution is to provide a highly decentralized system of governance in which each institution is provided with the greatest amount of freedom and there is limited accountability to the state. While higher education has flourished in the highly decentralized period after World War II, several commentators have suggested that pure decentralization is not an ideal situation for higher education (Mortimer \& McConnell, 1978; Floyd, 1985). While the current study focuses on the state-level context using a model of power and influence, it is not suggesting that the hierarchical model is either an appropriate or accurate description of academic governance at the state level. 


\section{Marshall, Mitchell and Wirt's Cultural Paradigm of Education Policy Making}

\section{Introduction}

In their review of methodology, Hines and Hartmark (1980) concluded that the most influential conceptual framework in higher education is Easton's system theory. In addition, they reported that the relationship between higher education and the state has been investigated from the perspective of Warren's interorganizational theory that attempts to focus on the "space" between organizations. Warren argued that there are several contexts for decision making between organizations. Hines and Hartmark also reported on Helsabeck's study that found a combination of contexts was most effective in academic decision making and on Perucci and Pilisuk's study that saw interorganizational ties as a variant of social ties.

\section{The Cultural Paradigm}

This study applies the cultural paradigm suggested by Marshall et al. (1989) to the study of the emerging relationship between state government and higher education. They developed the cultural paradigm (Table 4) and its related artifacts during their six-state study of K-12 education policy formation. The paradigm is organized into three main sections: (a) cultural variables affecting policy; (b) the subculture of the state capital; and (c) policy as a reflection of cultural values and choices. Each of these areas contain the various artifacts of the cultural paradigm. The subculture of the state capital reflects the policy-makers' shared understanding about: (a) what is desirable in their political culture, (b) policy alternatives available to them, (c) policy priorities (individual and generalized), 


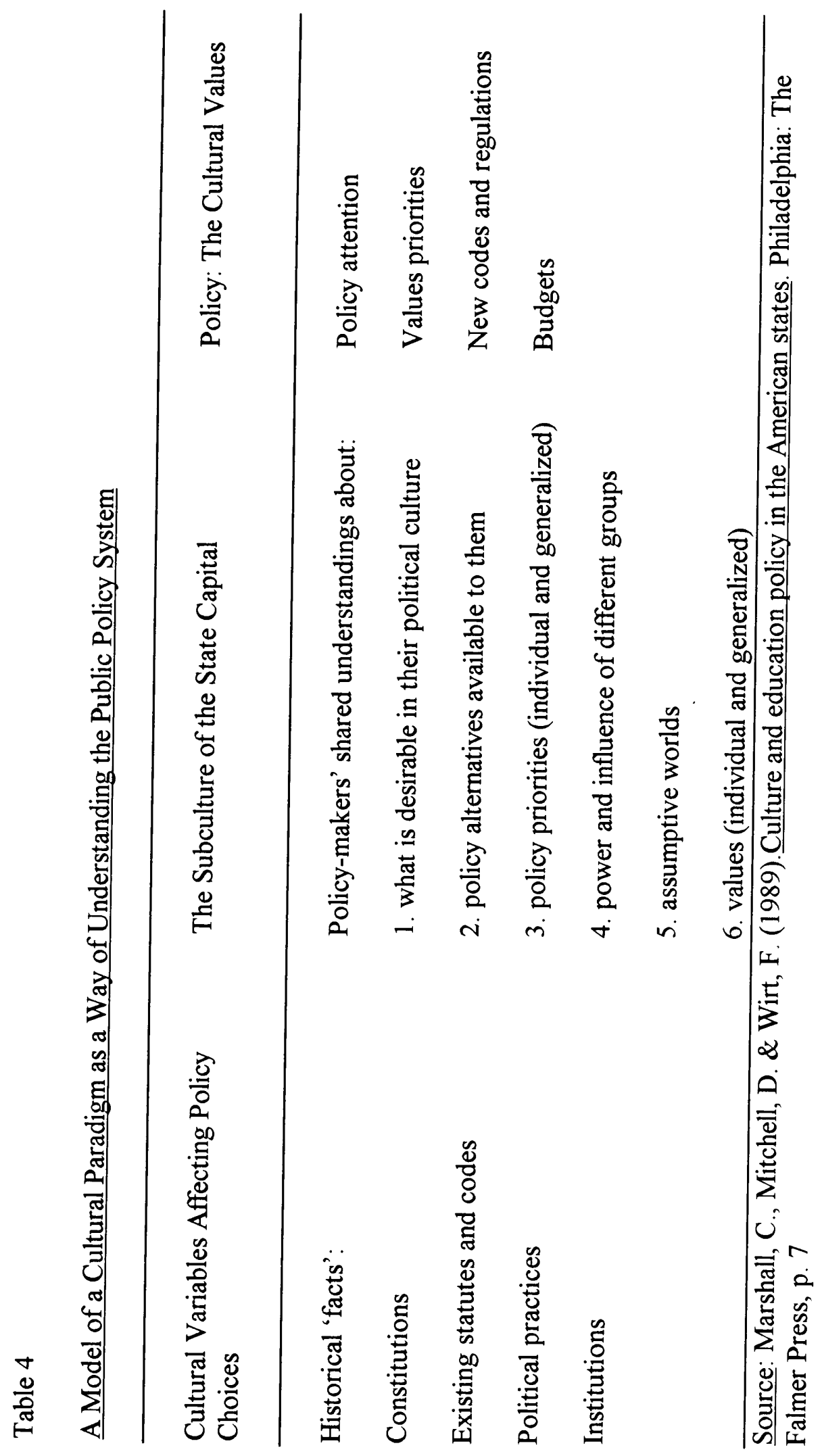


(d) power and influence of different groups, (e) assumptive worlds, and (f) values

(individual and generalized). The current study will focus on the ability of various groups to influence higher education policy and emerging issues at the state-level. Data about these two areas will be used to answer to Mortimer and McConnell's "who" variable in investigating the relative influence of various individuals and groups in the state-level context of higher education policy formation. While various components of Marshall et al.'s cultural paradigm have been used in other K-12 policy studies, this dissertation is the first to use it in a topic related to the politics of higher education.

Their cultural paradigm grew out of an investigation of the complex process of contemporary education policy formation using the methodology and tools suggested by anthropologists and sociologists: "Like structural anthropology, structural policy analysis rests on discovering the patterns of order and contrast in policy in order to derive an abstract meaning that encompasses both the order and the contrast" (Marshall et al., 1989, p. 166). Building on the work of Levi-Strauss who saw the work of culture as a process of mediation that involved conflict-dialectic-consensus, the insights of Mary Douglas into social regulation, and Aaron Wildavsky's (1987) understanding that conflict between the individual and the group as the primary conflict, Marshall et al. (1989) developed the cultural paradigm to provide a better understanding of state-level K-12 education policy formation.

An important conclusion of Marshall et al.'s (1989) investigation was their realization that the polarities that cause conflict between individuals and groups within a society are essential to a society's vitality. The polarities reflected in these conflicts are in 
essence the framework of cultural identity. Without these polarities a culture would no longer be able to define itself. Within their cultural paradigm, they created the concepts of assumptive worlds and of the power and influence hierarchies to surface these polarities and to understand how a group manages the conflict between them. Their concept of assumptive worlds helped them to identify those forces for cohesion within the subculture of the state capital. Their power and influence hierarchy helped them to identify important polarities within subculture of K-12 state-level policy formation.

\section{The Assumptive Worlds Concept}

Building on the work of Young (1977), Marshall et al. (1989) suggested in the concept of assumptive worlds that "policy conflict drives the participants to set out agreed upon ways of ordering conflict in the form of decisional rules--even before decisions are confronted" (p. 163). They concluded (Figure 2) that "any model or theory of education policy-making must incorporate the assumptive world concept" (p. 53). Like Bronfenbrenner's ecology of human development (Bronfenbrenner \& Hamilton, 1978) and Giddens' duality of structure (in Foster, 1991), their concept of assumptive worlds stresses the importance of a particular policy culture to maintain the power of the elites, to provide predictability, and to build cohesion for its members through its social interactions. The values of individuals, especially those of the policy elites with respect to public policy, are filtered through the "perceptual screen" of "expected behaviors, rituals and judgments about feasible policy options." 
Figure 2

Assumptive Worlds' Fit with Other Approaches to Understanding Policy Making

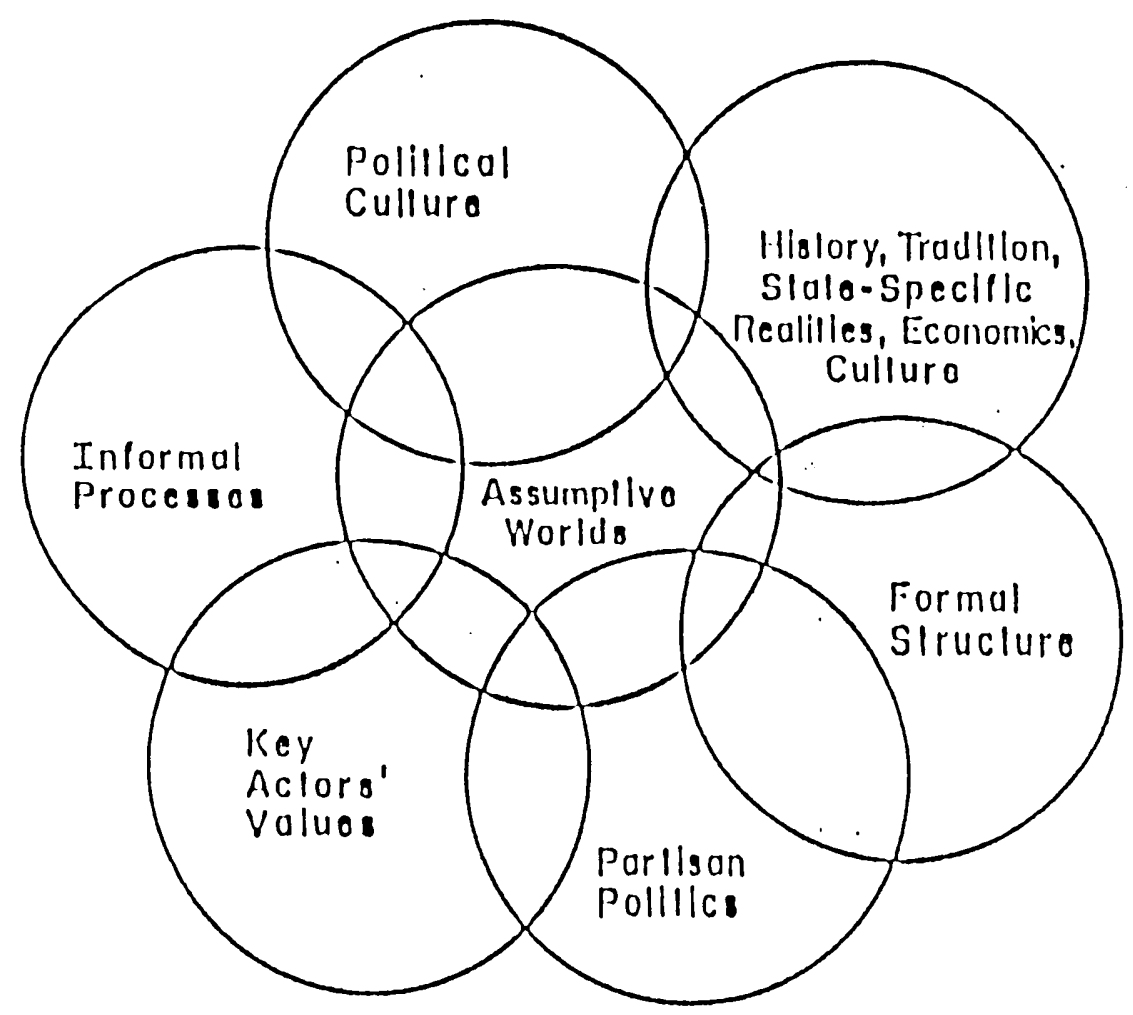

Source: Marhsall, C., Mitchell, D., \& Wirt, F. (1989). Culture and education policy in the American states. Philadelphia, PA: The Falmer Press, p. 15. 
Individuals who wish to influence policy have two choices. They can reword, translate, and alter their positions "by modifying their behaviors and constraining their preferences to work within the assumptive worlds of a particular policy culture;" or they can upset the assumptive worlds of that culture's policy elites (Marshall et al., 1989, p. 53). Marshall and her colleagues also observed that "policy changes arise not from objective criteria of need but from changes in the assumptive worlds" $(1989$, p. 52). Their concept of assumptive world contains the two elements of a recognized power and influence hierarchy and an operational code. The policy elites are aware of the operational code and power and influence hierarchy that they use to maintain power and to provide stability and cohesion. The operational code assists the policy elites in understanding the "when" and "how" of policy formation. The current study will use the concept of a power and influence hierarchy from Marshall et al. because it can provide an understanding of "who."

The Concept of a Power and Influence Hierarchy

Mortimer and McConnell (1978) reviewed the various definitions of "power," "influence," and "authority" that sociologists and organizational theorist working in higher education have used in their works. They concluded that there is no consensus on the meaning or use of these words in the literature. Recent literature has not clarified the situation. Parsons (1992) has provided important insights into power and higher education policy formation in a study of the federal-level student financial aid reauthorization 
process. Clegg (1994) has explored the relationship between power and democracy. His study has implications for the relationship between higher education, government bodies and the public. Griffin (1991) provided a summary of Sherif's, Festinger's, and Petty and Cacioppo's theories of influence and concluded "no one set of theories has emerged as the best way to view the persuasion process." (p.177)

While Marshall et al. (1989) did not provide definitions of "power" or "influence" in outlining their concept of a power and influence hierarchy but developed the concept in three different articles. In their first article (Marshall et al., 1985), they established their two working assumptions for the development of their model. Their first assumption was that "state constitutions and formal mechanisms of policy formation do not portray the entire picture of influence" (p. 61). Their second assumption was that their investigation would reveal the influence patterns recognized by the policy elites who participated in their study. National and state patterns would be developed using data from their study. These patterns became the basis for their power and influence hierarchy model. While the data in their initial report is presented in a hierarchical fashion using a rank order, their model is a series of circles (Figure 3).

In their first article, they provided names for the sections of their model:

1. The Insiders. The most influential individuals or groups are called the "insiders" who are considered the policy elites in their particular subculture. At the state level, the constitutionally mandated policy makers, especially the legislature, occupy this cluster. 
Figure 3

A Model of Power and Influence in Education Policy making

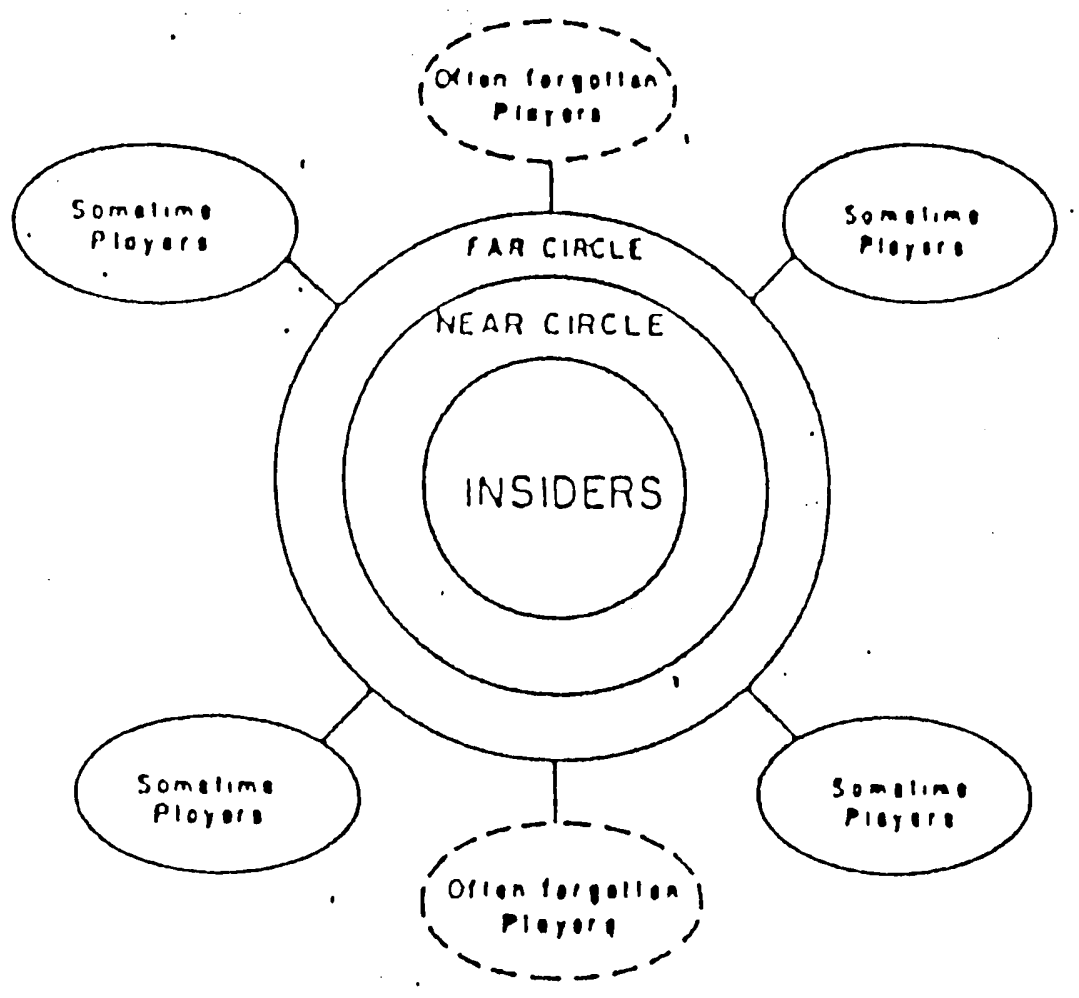

Source: Marhsall, C., Mitchell, D., \& Wirt, F. (1989). Culture and education policy in the American states. Philadelphia, PA: The Falmer Press, p. 15. 
2. The Near Circle. This cluster is contains the second most influential groups. Professionals whose full-time occupation is policy formation often form this group.

3. The Far Circle. This third cluster contains policy actors whose influence is not considered crucial to the policy formation process.

4. The Sometime Players. The fourth cluster contains policy actors who are involved in policy formation but have little influence.

5. The Often Forgotten Players. The last cluster contains policy actors who have little influence on policy formation or are perceived as having little influence. (1985, pp. 62-67)

In their second article, Marshall et al. (1986) outlined the various models of political decision making found in the literature ranging from Easton's systems model to Thompson's framework for policy analysis in American education and provided a summary of the quantitative methods used to create the national and state models of the power and influence hierarchy. It was this article that provided the information that was used in this study to determine the statistical operations that would be utilized to create the initial ranking of policy actors and the power and influence hierarchy model. 
In Culture and education policy in the American states, Marshall et al. (1989)

integrated their concept of assumptive worlds and the power and influence hierarchy model into their large research effort. In this third work, they argued that "each policy actor enters the policy subculture with standing in an influence hierarchy, and each manipulates interactions in order to gain enough influence to be the group whose values dominate" (p. 17). In a democratic policy-making culture, deference is given to those with "more power and expertise, or more commitment and interest" (p. 163). These policy elites recognize this model and use it as the basis for an operational code. This code determines: "(a) who initiates policy action, (b) what ideas are acceptable, (c) what activity is fit, and (d) what special conditions will affect the policy process" (p. 157). An understanding of this operational code would be important especially in developing a clearer understanding of "when" and "how" policy formation takes place at the state level.

The concept of a power and influence hierarchy developed by Marshall and her colleagues (1989) can provide an important research tool to explore higher education policy formation at the state level. Their hierarchy with its five different clusters of policy actors who are "stratified in a fashion that filters policy demands from external constituencies" (p. 157) away from the policy elites on the inside. This stratification is an important element in their model that has received little attention in the literature. If elites of a policy culture recognize varying degrees of influence among the policy actors, do the non-elites interested in a particular policy area also recognize the same power and influence hierarchy? Whose demands do the policy elites filter out? Who is considered an "outsider" to the higher education policy formation process at the state level? 
Marshall et al.'s (1989) contribution can be seen as part of the emerging body of literature in educational anthropology (Eddy, 1985). While others (Fetterman, 1987; Wiedman, 1990, 1992; Tierney, 1992) have applied anthropological concepts in the study of the institutional environment of higher education, the current study uses Marshall et al.'s concepts to explore Mortimer and McConnell's (1978) two academic governance variables of "who" and "what" at the state level. Marshall et al. (1989) encouraged policy researchers to use the methods of data collection and analysis they developed in future studies. Stout (1985) also suggested that future policy research needed to build on the contributions of the past if the disciplined study of the politics of education and policy research is to mature. A review of dissertation abstracts showed that various elements of Marshall et al.'s cultural paradigm have been used in recent research (Spears, 1989; Johnson-Howard, 1991; Carson, 1992; George, 1992; Webb, 1992; Ah Nee-Benham, 1993; Atkinson, 1995; Klebs, 1995). This dissertation on of higher education policy formation at state level using the concepts of assumptive worlds and a power and influence hierarchy constituted such an application.

Florida's Higher Education Environment

While the publicly elected Commissioner of Education has formal authority over all education in the state, state-level higher education policy formation can be described as fragmented with two legislative committees and three state-level coordinating boards competing for power and influence (Mautz, 1982; Kimbrough, Alexander \& Wattenbarger, 1984). The Chancellor and Board of Regents represent the ten institutions 
in the state university system. The Community College Board and its Director represent the community and junior colleges in the state's community college system. Finally, the Postsecondary Education Planning Commission has been charged to provide systematic planning and to review for all postsecondary institutions within the state including private universities and colleges.

The time period of the study between 1989 and 1994 is significant. In 1989, the legislature appointed a Structure Commission to review the current $2+2$ system and to make recommendations ("Structure," 1990). While the final report reaffirmed the $2+2$ system of lower-division community colleges and upper-division universities, consultants who organized its initial draft reported there appeared to be confusion and mistrust among the various policy actors attempting to direct higher education policy in the state (Augenblick, Van De Water \& Associates, 1990). At that time the state committed itself to a system of higher education that would be at odds with the organizational thinking and culture of U.S. higher education, a culture into which administrators and faculty have been formed through postgraduate studies, and numerous academic and administrative appointments within higher education.

During the period between 1989 and 1994, state-sponsored higher education institutions would experience a decline in their portion of the state budget with the community college system experiencing the most severe decline in funding (Cobb \& Edmonds, 1995, p. 60). The Planning Commission also released a new master plan ("Challenges," 1993). Private institutions would lobby to retain their tuition voucher. At the same time enrollment across the public system would continue to expand. By 1995, six 
of the 28 community colleges and five of the ten public universities would be listed among the 120 schools nation-wide with enrollments over 20,000 students ("U. S. Department of Education," 1995). The state's higher education environment can be characterized as tense and unstable as administrators and faculty attempted to deal with the combination of declining resources and increasing demands. Throughout this period, local institutions appear to have had little impact on state-level policy formation.

During the 1995 legislative session, the state legislature passed Senate Bill 2330 (Laws of Florida, Chapter 95-243). While the intent of the bill was to provide for a more efficient management of state moneys, the bill mandated changes to undergraduate curriculum by limiting the numbers of hours for graduation to 60 hours in the lower division schools and 120 hours in the upper division schools. The bill also strengthened the work of the Articulation Coordinating Committee that (a) supervises the transfer of students and credits from the lower division schools to upper division institution's or to the state's private universities and colleges and (b) promotes the use of the same course numbering in all lower and upper division institutions. In the same legislative session, the legislature provided some financial relief for higher education. The legislature also broadened the passing methods for the College-Level Academic Skills Test (CLAST) that had been mandated for all students receiving state financial aid to complete an associate degrees or to transfer to an upper-division university. The legislature had made the CLAST mandatory in 1984 over the objections of higher education professionals. 


\section{Summary}

As higher education moves into the postmodern period and prepares for the twenty-first century, it is undergoing a profound period of instability. With the growth in the size and number of higher education institutions dedicated to the transmission and creation of new knowledge and the shifts in the political and economic realities from a national to a global perspective, the locus of academic governance can no longer be found in the informal procedures of faculty working within the context of academic departments protected from the outside environment by governing boards and presidents. Academic governance has become more fragmented as numerous internal and external groups using different sets of political and academic prerogatives compete for the control and direction of the academy. In this respect, the assumptive worlds of administrators and faculty have been disrupted.

While the academy has always been a collection of internal and external interest groups and periods of instability have been followed by periods of stability, the answers to this moment's critical questions of who will decide what issues may determine if a significant shift in the patterns of academic governance away from the internal interests groups will take place. A critical polarity in higher education is this tension between these two groups of policy actors. If the shift is too great and the academy becomes another public utility, it will lose its ability to transmit or to create new knowledge. While the image of the academy as an "ivory tower" is a myth, such a powerful image reflects the need for the academy to remain some distance from the larger political processes of the 
state. Elected and appointed state officials must recognize this need, or in their efforts to achieve budgetary efficiency and protect the common good they may destroy inadvertently one of the great contributions of the United States to the world community.

The academy must once again make its case for appropriate and responsible autonomy to the general public and its public representatives or it may unwittingly destroy one of the critical polarities that has contributed to the growth of modern higher education. The state has become the arena in which many of the internal and external interests of the academy compete among themselves and with others for financial resources and regulation. In recent years, state government has become a critical and unpredictable participant in higher education policy initiatives as it pursues its own political and economic agendas.

This study explores the state-level context of higher education policy formation from the cultural perspective of power and influence. While this review of the literature on politics of higher education research has suggested a great deal of research activity at the state level, the need to explore from a cultural perspective the relationships among those wish to influence policy formation remains. State level higher education policy formation can be considered an important expression of academic governance. It is critical to establish appropriate answers to the questions of who participates and what decisions are made in academic governance at this level. For the vitality of higher education, answers to these questions must preserve the polarity between the internal and external interests groups who seek to govern the academy. 


\section{METHODS AND PROCEDURES}

Introduction

The individuals surveyed in this study were leaders in higher education and state government in Florida who were considered knowledgeable about the groups and individuals who attempt to influence higher education policy formation at the state level. The survey was sent to the presidents, academic vice presidents, and administrative vice presidents of 61 independent colleges and universities, community colleges, and state universities in Florida. State government leaders included in the survey were elected and appointed state government officials, lobbyists for higher education institutions, and newspaper reporters accredited to the Florida legislature. The purpose of the study was to determine if Florida's higher education and governmental leaders perceive any difference in the relative influence of the various groups and individuals who attempt to shape higher education policy. For the purposes of this study, survey participants were divided into two based on role and institutional affiliation. It was hoped that comparative analysis based on these subgroups could provide a richer understanding of who is perceived to influence higher education policy formation and implementation in Florida.

\section{Survey Subjects}

The survey was sent to 290 individuals (Appendix A). Presidents (61), academic vice presidents (61), and administrative vice presidents (60) from the ten state universities, twenty-eight community colleges, and twenty-three member institutions of ICUF were 
included in the survey. In September 1995, during the time of the survey, the University of Miami withdrew from ICUF but its personnel were included in this study. At the time of the survey, Webber College did not have an administrative affairs professional to whom the survey could be sent. Finally, Central Florida Community College did not have an academic affairs professional to whom the survey could be sent and Valencia Community College listed two professionals who were considered equivalents to an academic affairs professional for the purpose of this study.

The variety of organizational arrangements and the institutions with multiple campuses within the community college system made some of the researcher's choices concerning the equivalent administrative or academic vice president difficult.

One hundred and eight individuals involved in Florida state government including members of the executive branch (6), legislators (57), legislative staff (6), and journalists (1) were drawn from the 1995 Know Your Legislators (1995). Accredited lobbyists (38) were drawn from the Registered Legislative Lobbyists 1992-1994 Biennium (Joint Legislative Management Committee, u.n.). The Governor, the Governor's Acting Advisor on Education, the Commissioner of Education, the Director of Post Secondary Education, the Chancellor of the State University System, and the Executive Director of the Division of Community Colleges were chosen to represent the executive branch.

The fifty-seven legislators who were sent surveys included members of the Senate and House Higher Education and Education Committees, the President of the Senate, the Speaker of the House, the Chair and Vice-Chair of the Senate Ways \& Means Committee, 
and the Chair and Vice-Chair of the House Appropriations Committee. The staff directors (6) of the Senate and House Higher Education and Education Committees, the Senate Ways \& Means Committee and the House Appropriations Committee were also sent surveys. Thirty-eight accredited lobbyists represented higher education institutions, faculty groups, student groups, or other higher education interests groups.

\section{Survey Subgroups}

The survey subjects were divided by (a) their various roles within Florida higher education or state government and (b) their institutional affiliation. Seven different roles were identified by the researcher as representing individuals who are knowledgeable about who influences policy formation at the state level in Florida (Section I, Question a). The roles included president (61), academic vice president (61), administrative vice president (60), executive branch (6), legislators (57), legislative staff (6), and accredited lobbyists or journalists (39).

Institutional affiliation represented the second and primary subgrouping of the survey participants (Section I, Question b). Personnel from independent colleges and universities (68), the community college system (84), the state university system (30), and state government officials and accredited lobbyists and newspaper reporters (108) were sent the survey. Collectively, these four groups have created a web of relationships that form a loosely connected system of influences that attempt to shape higher education policy in Florida. 


\section{Survey Instrument}

The instrument used in this research was a four-page survey with a title page and three pages for data. The pages for data were divided into six sections (see Appendix B). The first section of the survey included 11 questions concerning personal data. The first question concerned the participants administrative role and listed the seven choices of president, academic vice president, administrative vice president, executive branch, legislator, legislative staff, or interest group representative. The second question concerned the participants institutional affiliation and included the four choices of Private University/College, Florida Community College System, State University System of Florida, or Other. The responses to these first two questions on role and institutional affiliation became the basis for the comparative analysis of the data from sections two through six of the survey instrument.

The third question asked the respondent's time in present position and had four choices. The fourth question asked the respondent's age and had five choices. The fifth question asked the respondent's gender and had two choices. The sixth question asked the individual's ethnicity and had five choices with the option to write in another. The seventh question asked the highest degree earned and had three choices. In addition, each respondent was asked to write in the particular degree earned. The eighth question had three parts that asked if the individual had teacher's certification, administrator's certification, and/or a law license. Respondents could answer "yes" or "no" to each. The 
ninth question concerned family income and listed three income ranges. The tenth question concerned political orientation and listed the choices of liberal, moderate, or conservative. The eleventh question concerned the respondent's political party affiliation and listed the three choices of Democrat, Republican, or independent with a place for the participants to write in another designation.

The second section of the survey listed 19 individuals or groups that could have influence on policy formation in higher education for Florida. These groups were selected based on information derived from Marshall et al. (1989) and a review of the literature on state-level higher education policy formation. The first six variables included elected or appointed state government officials (a, b, c, d, e, el, e2). These variables were the governor and the executive staff, the chief state school officer and senior staff in the state department of education, the state board of regents, the chancellor of the state university system, the state legislature, leading members of legislative committees, and key legislative staff consultants.

The next six variables included various interest groups that would lobby on higher education policy issues ( $\mathrm{f}, \mathrm{fl}, \mathrm{f} 2, \mathrm{f} 3, \mathrm{f} 4, \mathrm{~g}$ ). These groups included all education interests groups, faculty organization(s), lobbyist from independent institutions, lobbyist from public institutions, student organization (s), and non-educator interest groups (business leaders, taxpayers groups, etc.) The next six variables were unrelated groups or activities (h, i, j., k, l) that might influence higher education policy formation. These variables included producers of education related products, direct referenda initiated by citizens, the 
courts (state or federal), federal policy mandates to the states, and education research organizations. The last variable $(\mathrm{m})$ was "any other" and gave the respondents an opportunity to add additional individuals, groups or activities to the list. Survey participants were asked to evaluate the importance of the 19 variables on the survey using a Likert type scale from "very low" to "very high."

The third section was an open-ended question that asked survey participants to name "key policy-makers in Florida higher education policy formation" that they felt should be surveyed. Like the second section, this section provided the researcher with information to determine who is perceived to influence higher education policy formation in Florida.

The fourth through sixth sections of the survey contain requests for additional information that focused on the issues in higher education policy formation or implementation confronting policy makers in Florida. The fourth section was an openended question asking the survey participants to list any documents that might be helpful in understanding higher education policy formation. The fifth section contained four areas of policy based on Millet's (1987) research. Survey participants were asked to indicate their level of knowledge in finance, governance, access and choice, and quality and assessment using a Likert type scale from "least" to "most." The sixth section was an open-ended question asking survey participants to comment on the area(s) from section five they felt most knowledgeable. 
In addition to the survey instrument, the packet included several letters of introduction (Appendix B). A letter from Dr. Peter J. Cistone, the major professor for the research project and a representative of the state university system, introduced the researcher and topic to survey participants. A letter of introduction from the researcher who is from an independent Florida university gave the survey participants information on the purpose of the study and the method of return. As a result of a visit from Senator George Kirkpatrick, Chair of the Florida Senate Higher Education Committee, to St. Thomas University during the Fall 1995 Semester, he provided a letter of support to his colleagues in the Florida legislature. This letter was sent from his office at the time of the fourth mailing to the state legislators and staff directors who had not returned the survey by late December 1995 .

The survey was reviewed by four individuals involved in Florida educational policy formation. They suggested only minor changes to the list of variables and no changes to the open-ended questions. One reviewer suggested that accredited lobbyists and newspaper reporters might provide an additional perspective to the research question. Two professors who have expertise in survey research also reviewed the instrument. One professor had concerns about achieving an adequate response rate due to the nature of the survey's anticipated population and the content of the survey. A second professor suggested helpful changes to the format of the personal data questions concerning time in present office, gender, and ethnicity. This professor also suggested using the more typical 5-point Likert type scale in the instrument. The researcher did not follow this suggestion 
because the 7-point scale gave the respondents a greater range of variation. The design had been used in Marshall et al.'s six-state study of policy formation at the K-12 level. No pilot study was done because the basic format used to create the instrument had been developed by Marshall and her colleagues in interviews with policy elites during their sixstate study of K-12 policy formation. In addition, the survey received only minor adaptations for its use in this study after having been reviewed by professionals in the field. The survey was designed to be as "user friendly" as possible. The survey itself used one sheet of paper folded into four letter-size pages. The researcher was sensitive to the fact that respondents prefer to spend a minimal amount of time completing such documents. The researcher was also concerned that the respondents have an opportunity to provide written answers. This concern was addressed by the inclusion of three openended questions. The survey was printed on off-white or white paper with an attractive title page that included the title of the study and a silhouette map of Florida. A letter of introduction from the researcher on St. Thomas University letterhead was included. The letter of support from Dr. Peter J. Cistone was on Florida International University letterhead.

The first mailing of the complete packet was posted on August 20, 1995. Ninetynine were returned for a response rate of $31.0 \%$. A second mailing of a reminder postcard was posted on October 3,1995. Only fourteen surveys were returned for a response rate of $38.6 \%$. The third mailing that included the complete packet was posted on 
November 16, 1995. Sixty-five more surveys were returned for a total response rate at the time of $61.3 \%$. The fourth mailing of a complete packet was sent certified mail. It was mailed on two different occasions. The mailing to higher education personnel occurred on December 15,1995 . The mailing to state legislators and legislative staff was mailed on January 6, 1996. The delay was due to the need to coordinate the mailing of Senator Kirkpatrick's letter of support to his colleagues in the legislature with the survey materials. Thirty-one additional surveys were collected for a total of 209 surveys or $72.1 \%$.

\section{Survey Procedures}

As indicated, four mailings were made. A self-addressed stamped envelope was enclosed with each survey to expedite its return to the researcher. A self-addressed, stamped postcard indicated, on the message side, the name of the surveyed individual, title, institution or legislative committee, and a place to mark if the survey participant would like to receive a summary of the results after the study was completed. Participants in the survey were asked to mail the survey in the enclosed stamped envelope to the researcher's work address. A postcard with the participant's name and positions was to be mailed separately from the survey to the researcher's home address. This procedure was used so that researcher would know who had completed surveys, but not which survey belonged to whom. It was noted by the researcher that more surveys were returned than postcards. It is not known if the postcards were lost in the mail or if the participants chose not to return the postcards. Some participants returned the postcard in the same envelope 
with the survey. This action may indicate that they did not feel it was necessary to keep

their answers anonymous.

\section{Data Analysis}

\section{Personal Data from Section I}

Section I of the survey instrument consisted of eleven questions about the individuals completing the survey. The information obtained by the questions in this section of the survey would be most important to understand the differences in perceptions of influence and to anticipate potential areas of cooperation or conflict based on the similarities and differences among the various groups concerned with higher education policy formation. Descriptive statistics including percentages and cross tabulations were conducted on the information received.

\section{Hierarchical Clustering and Correlated T-tests from Section II}

Section II of the survey instrument listed 19 groups who attempt to influence higher education policy at the state level with a Likert type scale for each variable. To answer hypothesis one concerning the perceived difference of influence, descriptive statistics including the mean and standard deviation for each variable were used to determine a descending rank order among the variables. Correlated t-tests were then used pairwise beginning with the two variables with the highest means to determine the level of 
significance between each pair of variables. Any difference at the .05 level of significance was considered an indication of perceived difference of influence between variables.

To answer hypothesis two concerning the presence of a power and influence hierarchy, cluster analysis was used to generate a five segment influence hierarchy. The means of each variable in each segment were than regrouped and a correlated t-test was run pairwise between the segments to determine the level of difference. The hypothesis, as stated in chapter 1, was that statistically significant differences would exist among the five clusters of the power and influence hierarchy. Any difference at the .05 level of significance was considered an indication of perceived difference in influence either between variables or between clusters.

\section{Analysis of Variance and Post Hoc Tests from Section II}

To answer hypothesis three concerning the difference of perception among higher education leaders from different types of institutions, univariate ANOVAs were used to compare the different institution affiliations for each variable. A Wilk's test (MANOVA) was performed on the responses from Section II. The Wilk's gave an approximate F $(81.361)=2.900, \mathrm{p} \leq .000$ indicating that at least two types of institutional affiliations differed on at least one of the 19 variables surveyed. Tukey's HSD was also performed for each variable to determine if differences based on instititutional affiliation were signficant at .05 level. The results of these various tests will be presented here for each variable. 


\section{Qualitative Analysis of Section III}

Section III of the survey instrument provided respondents with an open-ended question concerning the key policy makers that should be interviewed by this researcher. It was hoped that the answers would provide the researcher with the names of key policy makers who might be considered the policy elites in Florida higher education. The question was followed by a 2 " blank space to be used for written comments by the survey participants. The information from this section was coded by respondent's identification number, role, institutional affiliation, and complete comment. Any case where the respondent did not complete the questions on role or institutional affiliation, this information was left blank in the coding system. In a few cases, the writing was illegible to the researcher and the respondent's information was not included in the analysis.

After the initial entry and proper coding of each respondent's written comments, the material was divided into two groups. The first group of comments included the names of specific individuals. This list of individuals was considered the most important group by the researcher. A second analysis divided this list of names by the role and institutional affiliation of the respondent. In the last analysis, the number of times mentioned by the survey participants, membership in a particular policy group and cluster group was included for each name that was mentioned more than 3 times by the survey participants. This final list of names can be considered a potential list of names for an interview protocol in future research. 
Written comments that only mentioned a particular office (e.g., the Governor) or position (e.g., Senate Higher Education Staff) within state government or higher education were placed in a second group. This group of comments provided additional support for concerns data found in Section II of the survey or the names mentioned by respondents in Section III of the survey.

\section{Qualitative Analysis of Section IV}

Section IV of the survey instrument contained an open-ended question to determine which documents are important in the process of higher education policy formation. The section contained the question and a 2 " blank space for the written comment. It was hoped that the answers to this question would provide the researcher with the names of important documents that might assist in developing a list of higher education policy elites for Florida. The information from this section was coded by respondent's identification number, role, institutional affiliation, and complete comment. If the respondent failed to complete the questions on role or institutional affiliation, then that respondent's information was not analyzed. In a few cases, the writing was illegible to the researcher, and the respondent's comments were not included in the analysis.

After the initial entry, each respondent's comments were divided by the origin of the document (e.g., the State University System or the Postsecondary Education Planning Commission). The researcher hoped that the types of documents mentioned, the number of times a document was mentioned, and which respondent mentioned it would provide 
supporting information in answering the primary research question of who has influence in Florida higher education policy formation.

\section{Areas of Policy Formation from Section V}

Section $\mathrm{V}$ of the survey instrument listed four areas of higher education policy formation. These areas were based on a review of the literature and included (a) finance, (b) governance, (c) access and choice, and (d) quality and assessment. Each respondent was asked to self-report a level of expertise for each area by using Likert scale. The researcher did not define any of the policy areas or the words "least" or "most" for the survey participants. It was hoped that the answers to these questions would be helpful in understanding the general level of expertise among the respondents within each area of higher education policy formation. It was also hoped that the information from this section, section four and section six could be used to complete an interview protocol for future research. The information obtained by the answers in this section of the survey would be most important in developing an understanding of the potential areas of cooperation or conflict based on the ability of leaders in higher education and state government to understand and to communicate with each other using a common language and frame of reference for the different areas of policy formation.

Univariate ANOVAs were conducted comparing institutional affiliation for each variable in Section V. The ANOVA for finance provided a F Ratio $=4.4299$ and probability $\leq .0182$. The ANOVA for governance provided a F Ratio $=8.8751$ and 
probability $\leq .0000$. The ANOVA on access and choice provided a F Ratio $=2.4877$ and probability $\leq .0618$. The ANOVA on quality and assessment provided a $\mathrm{F}$ Ratio $=1.2267$ and probability $\leq .3014$. Because the researcher was interested in differences based on institutional affiliation for (a) access and choice and (b) quality and assessment and these did not appear significant, no additional analysis was done.

\section{Qualitative Analysis of Section VI}

Section VI of the survey instrument provided respondents with an open-ended question concerning the most pressing issues in higher education policy formation. The section contained the question and a 4" blank space for the written comment. The responses were coded and analyzed for significant trends. The material was used to help identify the emerging trends in Florida higher education. The researcher hoped that the material might reveal something of the quality of the relationships among the state's higher education leaders.

The comments from this section were coded by respondent's identification number, role, and institutional affiliation If the respondent failed to complete the questions on role or institutional affiliation, then the respondent's information was not analyzed. In a few cases where the writing was illegible to the researcher, the comment was not included in the analysis.

After the initial entry and proper coding of each respondent's written comments, the material was divided by the role and institutional affiliation of the respondent. In the 
last analysis, each comment was coded with one of six designations. The designations included culture, system, finance, governance, access, and quality. The researcher hoped that this analysis by type of comment and the respondent's role or institutional affiliation might provide information on the pressing issues in Florida higher education as well as any differences in institutional perspective on these issues. To protect the anonymity of the survey participants only the respondent's case number and comments have been included in Appendix F. 


\section{RESULTS}

\section{Introduction}

The data for this study was gathered using a survey instrument. Surveys were mailed to 290 individuals associated with public and private colleges and universities and state government officials in Florida. Surveys were sent to the presidents, the vice presidents for academic affairs, and the vice presidents for administrative affairs of 61 public and private colleges and universities in Florida that included were institutions from ICUF, the community college system, and the state university system. In addition, 19 senators, 38 representatives, three Senate staff directors, and three House staff directors were sent surveys as representatives of the Florida legislature and legislative staff. Six members of the executive branch, including the governor, were sent surveys. Finally, 38 accredited higher education lobbyists and one journalist were asked to participate in the study.

Quantitative and qualitative data was gathered in this study. The data was used to increase understanding of the perceptions of power and influence in higher education policy formation among the higher education leaders in Florida. The way the data was analyzed depended on the type of data and the most effective form of analysis.

The first mailing of the complete packet was posted on August 20, 1996. Ninetynine were returned for a response rate of $31.0 \%$. A second mailing of a reminder postcard was posted on October 3, 1996. Only fourteen surveys were returned for a response rate of $38.6 \%$. The third mailing that included the complete packet was posted on November 
16,1996 . Sixty-five more surveys were returned for a total response rate at the time of $61.3 \%$. The fourth mailing with a complete packet was sent certified mail. It was mailed on two different occasions. The mailing to higher education personnel occurred on December 15,1995 . The mailing to state legislators and legislative staff was mailed on January 6,1996 . The delay was due to the need to coordinate the mailing of Senator Kirkpatrick's letter of support to his colleagues in the legislature with mailing of the survey materials. Senator Kirkpatrick's letter of support was sent separately to his colleagues at approximately the time the certified mailing was received by them. Thirty-one additional surveys were collected for a total of 209 surveys or $72.1 \%$.

In addition, seven individuals responded to the request for information but did not complete the survey for various reasons. One Representative responded that his office received too many survey requests and that his policy was not to respond to any request. A Senator responded that it was important to have a full and open dialogue with all parties involved before making a decision and to have completed the survey would be inappropriate.

One Vice President for Administration declined to complete the survey because he felt that his major areas of interest were national and local issues. As an administrator at a private institution, he felt that state policy initiatives had little impact on his institution. Another two administrators from public institutions responded that they had taken new positions in the state and that it would be difficult for them to comment on policy formation. 
The most interesting response to the survey came from three individuals at one institution. They had received the request to complete the survey on four separate occasions. After the last certified mailing was sent to them, they discussed the survey and decided not to complete it. They had an administrative assistant call the researcher's office to convey their regrets. They thought the survey was important but that the researcher had not done enough to protect their anonymity. Their response suggests that there is a great deal of suspicion and fear in the current state political environment surrounding higher education policy issues. If the fears of these respondents are accurate, the corresponding atmosphere could make adequate and appropriate dialogue among those responsible for policy formation and implementation difficult or impossible.

Section I of the Survey

\section{Analysis of Individual Questions}

\section{Section I, Question b.: Institutional Affiliation}

Because of the limited number of responses for several of the categories based on role (Section I, Question a), the researcher based the comparisons in the study on institutional affiliation (Section I, Question b). In addition to the distribution difficulties in the category of professional role, the subgroup of institutional affiliation best represented the notion of a higher education "system" at the state level.

Table 5 shows the distribution of returned surveys by institutional affiliation. The patterns shows that the best response rate was from the Community College System with 
78 of the 84 potential surveys returned $(93 \%)$. The smallest response rate was from the State Government Officials with 44 of the 108 potential surveys returned (41\%). The distribution pattern of returned surveys shows that the Community College System has the highest number of returned surveys (78) included in the study (37\%). While the State University System had the smallest number of returned surveys (27) included in the study (13\%), the number (27) was considered sufficient for analysis as a separate subgroup.

Table 5

Distribution of Returned Surveys by Institutional Affiliation

\begin{tabular}{|c|c|c|c|c|}
\hline Institutional Affiliation & $\begin{array}{l}\text { Surveys } \\
\text { Sent }\end{array}$ & $\begin{array}{l}\text { Surveys } \\
\text { Returned }\end{array}$ & P1 & P2 \\
\hline Private Universities/ Colleges & 68 & 58 & $85 \%$ & $29 \%$ \\
\hline Community College System & 84 & 78 & $93 \%$ & $37 \%$ \\
\hline State University System & 30 & 27 & $90 \%$ & $13 \%$ \\
\hline $\begin{array}{l}\text { State Government Officials } \\
\text { and Accredited Lobbyists }\end{array}$ & 108 & 44 & $41 \%$ & $21 \%$ \\
\hline Institutional Affiliation Missing & -- & 2 & -- & $1 \%$ \\
\hline TOTAL & 290 & 209 & --- & $72 \%$ \\
\hline
\end{tabular}

\section{Section I, Question c.: Time in Present Position}

The third question of the section asked each respondent to indicate time in the present position. Table 6 shows the number of years in the present position according to institutional affiliation. 
The pattern of distribution shows that a majority of respondents $(66 \%)$ fall into the two categories of $1-3$ years $(34 \%)$ or $10+$ years $(32 \%)$ in present position. The pattern may indicate either a great deal of stability in the higher education leadership or a new cycle is beginning in higher education in Florida as the individuals who have been in their present positions either retire or move to other positions.

Table 6

Respondent's Time in Present Position By Institutional Affiliation

\begin{tabular}{llllll}
\hline $\begin{array}{l}\text { Years in } \\
\text { Positions }\end{array}$ & $\begin{array}{l}\text { Private } \\
\text { Institutions }\end{array}$ & $\begin{array}{l}\text { Community } \\
\text { Colleges }\end{array}$ & $\begin{array}{l}\text { State } \\
\text { Universities }\end{array}$ & $\begin{array}{l}\text { Government } \\
\text { Officials }\end{array}$ & TOTAL \\
\hline 1-3 Years & 19 & 20 & 10 & 20 & 69 \\
4-6 Years & 7 & 11 & 7 & 10 & 35 \\
7-9 Years & 14 & 15 & 5 & 0 & 34 \\
10+ Years & 17 & 30 & 5 & 13 & 65 \\
TOTAL & 57 & 76 & 27 & 43 & 203 \\
\hline
\end{tabular}

Note. Missing Observations $=6$.

\section{Section I, Question d.: Age}

The fourth question of the section asked each respondent to indicate his/ her age.

Table 7 shows the age of the respondents according to institutional affiliation. The pattern of distribution shows that a majority of respondents (71\%) fell into the two categories of $40-49(25 \%)$ or $50-59$ years $(46 \%)$ of age. The pattern may indicate that there will be 
some stability in higher education leadership over the next decade as individuals remain in their present positions.

Table 7

Age of Respondents By Institutional Affiliation

\begin{tabular}{llllll}
\hline Age & $\begin{array}{l}\text { Private } \\
\text { Institutions }\end{array}$ & $\begin{array}{l}\text { Community } \\
\text { Colleges }\end{array}$ & $\begin{array}{l}\text { State } \\
\text { Universities }\end{array}$ & $\begin{array}{l}\text { Government } \\
\text { Officials }\end{array}$ & TOTAL \\
\hline Under 29 & 0 & 0 & 0 & 4 & 4 \\
$30-39$ & 1 & 2 & 0 & 6 & 9 \\
$40-49$ & 15 & 19 & 3 & 14 & 51 \\
$50-59$ & 26 & 36 & 12 & 17 & 91 \\
$60-69$ & 13 & 19 & 9 & 1 & 42 \\
$70+$ & 2 & 0 & 0 & 0 & 2 \\
TOTAL & 57 & 76 & 24 & 42 & 199 \\
\hline Not & & & & & \\
\hline
\end{tabular}

Note. Missing Observations $=10$.

\section{Section I, Question e.: Gender}

The fifth question of the section asked the respondents to indicate their gender.

Only 188 respondents completed this question. The low number may indicate that individuals consider questions about gender inappropriate in survey material. Table 8 shows the gender of the respondents according to institutional affiliation.

The pattern of distribution shows that a majority of respondents (90\%) were male. The pattern may also indicate that the representation of females in leadership positions 
across the higher education system in Florida continues to be small. Of the 18 women who returned the survey, five were academic vice presidents, five were administrative vice presidents, and four were legislators. Only two of the 47 presidents who responded to this question indicated that they were female.

Table 8

Respondent's Gender By Institutional Affiliation

\begin{tabular}{llllll}
\hline Gender & $\begin{array}{l}\text { Private } \\
\text { Institutions }\end{array}$ & $\begin{array}{l}\text { Community } \\
\text { Colleges }\end{array}$ & $\begin{array}{l}\text { State } \\
\text { Universities }\end{array}$ & $\begin{array}{l}\text { Government } \\
\text { Officials }\end{array}$ & TOTAL \\
\hline Female & 4 & 5 & 3 & 6 & 18 \\
Male & 50 & 67 & 19 & 34 & 170 \\
TOTAL & 54 & 72 & 19 & 40 & 188 \\
\hline
\end{tabular}

Note. Missing Observations $=21$.

Section I, Question f.: Ethnicity

The sixth question of the section asked the respondents to indicate their ethnicity. There was confusion on the correct ascription for African-Americans. Several respondents changed the category to read "Black-American." Table 9 shows the ethnicity of the respondents according to institutional affiliation.

While the category of White/ Non-Hispanic dominates the answers to the question, the overall pattern indicates an even distribution by ethnicity across institutional affiliation. Eleven respondents indicated that they were Hispanic with two from a private university or college, two from community colleges, three from the state universities and four from governmental circles. Nine respondents indicated that they were African- 
Table 9

Respondents' Ethnicity By Institutional Affiliation

\begin{tabular}{|c|c|c|c|c|c|}
\hline Ethnicity & $\begin{array}{l}\text { Private } \\
\text { Institutions }\end{array}$ & $\begin{array}{l}\text { Community } \\
\text { Colleges }\end{array}$ & $\begin{array}{l}\text { State } \\
\text { Universities }\end{array}$ & $\begin{array}{l}\text { Government } \\
\text { Officials }\end{array}$ & TOTAL \\
\hline \multicolumn{6}{|c|}{ White/Non-Hispanic } \\
\hline & 53 & 74 & 18 & 35 & 182 \\
\hline \multicolumn{6}{|l|}{ Hispanic } \\
\hline & 2 & 2 & 3 & 4 & 11 \\
\hline \multicolumn{6}{|c|}{ African-American } \\
\hline & 2 & 0 & 5 & 4 & 9 \\
\hline \multicolumn{6}{|c|}{ Black/ Other } \\
\hline & 0 & 1 & 0 & 0 & 0 \\
\hline \multicolumn{6}{|c|}{ Asian-American } \\
\hline & 0 & 0 & 0 & 0 & 0 \\
\hline Other & 0 & 0 & 0 & 1 & 1 \\
\hline TOTAL & 57 & 77 & 26 & 44 & 204 \\
\hline
\end{tabular}

Note. Missing Observations $=5$.

American with two from a private university or college, five from state government. While no respondent from the community colleges chose African-America, one respondent from the community college chose the category of "Black/ Other." No respondent chose the category of Asian-American.

\section{Section I, Question g.: Highest Degree Earned}

The seventh question of the section asked the respondents to indicate the highest degree earned. They could mark bachelors, masters, or doctorate. When a respondent marked more than one category, the category indicating the highest degree was placed in 
the data. Table 10 shows the highest degree earned by the respondents according to institutional affiliation. One respondent stated that he was self-educated. His response was

Table 10

Respondents' Highest Degree Earned by Institutional Affiliation

\begin{tabular}{llllll}
\hline Degree & $\begin{array}{l}\text { Private } \\
\text { Institutions }\end{array}$ & $\begin{array}{l}\text { Community } \\
\text { Colleges }\end{array}$ & $\begin{array}{l}\text { State } \\
\text { Universities }\end{array}$ & $\begin{array}{l}\text { Government } \\
\text { Officials }\end{array}$ & TOTAL \\
\hline Bachelor & 5 & 7 & 2 & 10 & 24 \\
Masters & 15 & 15 & 7 & 18 & 55 \\
Doctorate & 37 & 55 & 18 & 15 & 125 \\
TOTAL & 57 & 77 & 27 & 43 & 204 \\
\hline
\end{tabular}

Note. Missing Observations $=5$.

coded as "other" in the data and is included in the missing observations in Table 10.

The pattern of distribution shows that a majority of respondents $(61 \%)$ have earned a doctorate degree.

Section I, Question h.: Specialized Certification

The eighth question of the section asked the respondents to indicate if they had a specialists certification as a teacher or administrator or a law license. The question was phrased "Do you possess one of the following?" Each respondent could mark "yes" or "no" to each of the categories. Table 11 shows the specializations of the respondents according to institutional affiliation. 
Table 11

Respondents' Specialized Certification By Institutional Affiliation

\begin{tabular}{|c|c|c|c|c|c|}
\hline Specialization & $\begin{array}{l}\text { Private } \\
\text { Institutions }\end{array}$ & $\begin{array}{l}\text { Community } \\
\text { Colleges }\end{array}$ & $\begin{array}{l}\text { State } \\
\text { Universities }\end{array}$ & $\begin{array}{l}\text { Government } \\
\text { Officials }\end{array}$ & TOTAL \\
\hline \multicolumn{6}{|c|}{ Teacher Certificate } \\
\hline Yes & 8 & 26 & 7 & 6 & 47 \\
\hline No & 46 & 49 & 16 & 38 & 149 \\
\hline TOTAL & 54 & 75 & 23 & 44 & 196 \\
\hline \multicolumn{6}{|c|}{ Administrator's Certification } \\
\hline Yes & 1 & 5 & 1 & 2 & 9 \\
\hline No & 53 & 67 & 22 & 39 & 181 \\
\hline TOTAL & 54 & 72 & 23 & 41 & 190 \\
\hline \multicolumn{6}{|l|}{ Law License } \\
\hline Yes & 6 & 2 & 1 & 4 & 13 \\
\hline No & 48 & 69 & 22 & 37 & 176 \\
\hline TOTAL & 54 & 71 & 23 & 41 & 189 \\
\hline
\end{tabular}

The pattern of distribution shows that a majority of respondents do not possess either an administrator's certification (95\%) or a law license (93\%) and less than one quarter possess a teacher's certificate $(23 \%)$. 
Section I, Question i.: Family Income

The ninth question of the section asked the respondents to indicate their family income. Table 12 shows the family income of the respondents according to institutional affiliation. The pattern of distribution shows that a majority of respondents $(86 \%)$ reported a family income greater than $\$ 65,000$.

Table 12

Respondents' Family Income By Institutional Affiliation

\begin{tabular}{|c|c|c|c|c|c|}
\hline $\begin{array}{l}\text { Family } \\
\text { Income }\end{array}$ & tions & $\begin{array}{l}\text { Community } \\
\text { Colleges }\end{array}$ & $\begin{array}{l}\text { State } \\
\text { Universities }\end{array}$ & $\begin{array}{l}\text { Government } \\
\text { Officials }\end{array}$ & TOTAL \\
\hline Less than $\$ 49,000$ & 3 & 1 & 0 & 4 & 8 \\
\hline$\$ 50,000-\$ 65,000$ & 3 & 6 & 2 & 9 & 20 \\
\hline Greater than $\$ 65,000$ & 50 & 70 & 24 & 30 & 174 \\
\hline TOTAL & 56 & 77 & 26 & 43 & 202 \\
\hline
\end{tabular}

Note. Missing Observations $=7$.

Section I, Question j.: Political Orientation

The tenth question of the section asked the respondents to indicate their political orientation. Table 13 shows the political orientation of the respondents according to institutional affiliation. Thirty respondents $(15 \%)$ reported a liberal orientation with the community college system reporting the fewest liberals (1\%) and state government reporting the most liberals (25\%). One hundred and sixteen respondents (58\%) reported a moderate political orientation. Fifty-four respondents (27\%) reported a conservative 
political orientation. While 16 respondents (29\%) from the private universities and colleges, 22 respondents from community colleges (29\%) and 13 respondents from state government (30\%) indicated a conservative orientation, only three respondents $(12 \%)$ from the state university system identified themselves as conservative in political orientation.

Table 13

Respondents' Political Orientation By Institutional Affiliation

\begin{tabular}{llllll}
\hline $\begin{array}{l}\text { Political } \\
\text { Orientation }\end{array}$ & $\begin{array}{l}\text { Private } \\
\text { Institutions }\end{array}$ & $\begin{array}{l}\text { Community } \\
\text { Colleges }\end{array}$ & $\begin{array}{l}\text { State } \\
\text { Universities }\end{array}$ & $\begin{array}{l}\text { Government } \\
\text { Officials }\end{array}$ & TOTAL \\
\hline Liberal & 8 & 7 & 4 & 11 & 30 \\
Moderate & 30 & 47 & 19 & 20 & 116 \\
Conservative & 16 & 22 & 3 & 13 & 54 \\
TOTAL & 54 & 76 & 26 & 44 & 200 \\
\hline Note. Missing Observations $=9$. & & &
\end{tabular}

\section{Section I, Question k.: Political Party Affiliation}

The eleventh question of the section asked the respondents to indicate their political party. They could choose between Democrat, Republican, Independent, or Other. Table 14 shows the political orientation of the respondents according to institutional affiliation.

The pattern of distribution shows a slight majority of the respondents $(63 \%)$ reported affiliation with the Democratic Party. When choosing the Republican Party, 
respondents from the private universities or colleges (30\%), community college system $(26 \%)$, and state government (32\%) show a similar response rate. However, respondents from the state university system had a response rate of only $9 \%$ when choosing the Republican Party.

Table 14

Respondents' Political Party Affiliation By Institutional Affiliation

\begin{tabular}{llllll}
\hline $\begin{array}{l}\text { Political } \\
\text { Party }\end{array}$ & $\begin{array}{l}\text { Private } \\
\text { Institutions }\end{array}$ & $\begin{array}{l}\text { Community } \\
\text { Colleges }\end{array}$ & $\begin{array}{l}\text { State } \\
\text { Universities }\end{array}$ & $\begin{array}{l}\text { Government } \\
\text { Officials }\end{array}$ & TOTAL \\
\hline Democrat & 28 & 52 & 16 & 26 & 122 \\
Republican & 16 & 20 & 2 & 14 & 52 \\
Independent & 8 & 4 & 3 & 2 & 17 \\
Other & 0 & 0 & 1 & 1 & 2 \\
TOTAL & 52 & 76 & 22 & 43 & 193 \\
\hline
\end{tabular}

Note. Missing Observations $=16$.

\section{Profile of Florida's Higher Education Leadership}

At the beginning of the study, the researcher believed that the personal data would be a valuable part of the study. This information helped to develop a more comprehensive understanding of background characteristics of higher education leaders in Florida. The personal data suggested some areas of commonality and some potential areas of conflict between the four traditional institutional subgroups that attempt to influence higher 
education policy at the state level. When the distribution patterns for ethnicity, gender and age are combined, they indicate that higher education leadership in Florida is dominated by White/ Non-Hispanic males between 40 and 59 years of age. When the data from questions ten and eleven are combined a pattern of moderate to liberal Democrats within the leadership of the state university system emerges. In contrast, when the data from questions ten and eleven are combined for the private universities and colleges, community colleges and state government, a pattern of moderate to conservative Democrats and Republicans emerges.

Table 15 represents a composite profile of the Florida's higher education leadership based on the participants' responses to the survey's personal questions. The survey's composite profile indicates great similarity among Florida's higher education leaders. However, the gender and ethnicity patterns are at odds with Florida's overall population pattern and increasing ethnic diversity. 
Table 15

Average Background Characteristics of Florida's Higher Education Leaders

\begin{tabular}{ll}
\hline Characteristic & Average \\
\hline Time in & Under 3 yrs. (34\%) \\
Present Position & $\begin{array}{l}\text { 4-9 yrs. (34\%) } \\
\text { Over } 10 \text { yrs }(32 \%)\end{array}$ \\
& Under $40(7 \%)$ \\
Age & $40-59(66 \%)$ \\
& Over $60(22 \%)$ \\
& Male (90\%) \\
Gender & Female (10\%) \\
& White/ Non-Hispanic (89\%) \\
Ethnicity & Hispanic (5\%) \\
& African- American (4\%) \\
& Other (1\%)
\end{tabular}

Educational Level $\quad$ Bachelor (12\%)

Masters (27\%)

Doctorate $(61 \%)$

Teaching Certificate $\quad$ Yes $(24 \%)$

No $(76 \%)$

Administrator's $\quad$ Yes $(5 \%)$

Certificate No $(95 \%)$

Law License $\quad$ Yes (7\%)

No $(93 \%)$

Family Income $\quad$ Over $\$ 65,000(86 \%)$

Political Orientation Liberal (15\%)

Moderate (58\%)

Conservative (27\%)

Political Party Democrat (63\%)

Republican (27\%)

Independent (9\%) 


\section{Analysis of 19 Variables}

The heart of the survey was Section II. While 19 variables were listed on the survey, only 18 variables were included in the analysis. The survey's last variable of "other" was either left unmarked by the respondents (188) or information provided by the respondents (21) was so fragmented that it could not be used. The other 18 groups have been associated with attempts to influence higher education policy formation. The individuals completing the survey were asked to circle one of a series of numbers to the right of each variable. The numbers represented Likert type rating starting with "very low" at 1 and ending with "very high" at 7 (see Appendix B for a copy of the survey form).

This section was the most important part of the survey. It was anticipated that differences in perceptions of influence would emerge and that some of them would be significant at the .05 level. In addition, the means and standard deviations for each variable would become the basis for the formation of a power and influence hierarchy. It was anticipated that the various clusters of the power and influence hierarchy would show significant differences at the .05 level.

Surveys with missing data were eliminated from this analysis, 129 complete surveys were used to establish between group significance and between cluster significance in the development of the model of a power and influence hierarchy. Finally, the Wilk's test (MANOVA) was performed on the responses from Section II based on a respondent's institutional affiliation to determine if there were differences of perceptions of 
influence based on institutional affiliation. Univariate ANOVAs were conducted on each variable by institutional affiliation. In addition, Tukey's HSD was performed at the $p \leq .05$ level of significance for pairwise comparisons. The results of these tests are presented for each variable.

\section{Policy Group Rankings from Highest To Lowest}

Table 16 shows the policy groups rankings from highest to lowest overall TOTAL mean. The differences between these means gives the first indication that higher education leaders do perceive a difference in the ability of the various groups to influence higher education policy formation at the state level.

\section{Policy Group Influence Rankings: Statistical Data}

Correlated $\mathrm{t}$-tests were performed on the adjacent pairs in the ranking beginning with the two groups with the highest means and working down the order to determine if any of the differences between means was at a level of significance based on a $p \leq .05$ (Table 17). This level of significance is more conservative than Marshall et al.'s (1986) original work that reported significant differences at the .10 level. Of the 17 pairs tested for differences at the .05 level, three of the pairs were statistically significant: (a) the legislature (ranked 3) and the Chancellor of the State University System (ranked 4), (b) 
Policy Group Rankings from Highest to Lowest TOTAL Mean

\begin{tabular}{|c|c|c|}
\hline \multicolumn{2}{|c|}{ Ranking Policy Group } & \multirow{2}{*}{$\underline{\underline{M}}$} \\
\hline 1 & Leading Members of Legislative Committees & \\
\hline 2 & Key Legislative Staff Consultants & 5.8915 \\
\hline 3 & The State Legislature & 5.8915 \\
\hline 4 & Chancellor of the State University System & 5.4574 \\
\hline 5 & The State Board of Regents & 5.2791 \\
\hline 6 & The Governor and the Executive Staff & 4.7829 \\
\hline 7 & Federal Policy Mandates to the States & 4.7132 \\
\hline 8 & Lobbyist for Public Institutions & 4.6279 \\
\hline \multirow[t]{2}{*}{9} & The Chief State School Officer and Senior & \\
\hline & Staff in the State Department of Education & 4.5039 \\
\hline 10 & Non-Educator Interest Groups & 4.2326 \\
\hline 11 & Lobbyist for Independent Institutions & 4.1705 \\
\hline 12 & The Courts (State or Federal) & 4.1473 \\
\hline 13 & All the Education Interest Groups & 4.1240 \\
\hline 14 & Faculty Organization(s) & 3.5814 \\
\hline 15 & Direct Referenda Initiated by Citizens & 3.3798 \\
\hline 16 & Student Organization(s) & 3.1628 \\
\hline 17 & Education Research Organizations & 3.0620 \\
\hline 18 & Producers of Education Related Materials & 2.9767 \\
\hline
\end{tabular}

Note. $n=129$ cases. ---- denotes statistically significant (at .05 ) difference between policy groups. 
Table 17

Policy Group Influence Rankings: Statistical Data

\begin{tabular}{|c|c|c|c|c|c|}
\hline Policy Group & $\underline{\mathrm{M}}$ & $\underline{\mathrm{SD}}$ & $\begin{array}{l}\text { Between Mean } \\
\text { Difference }\end{array}$ & 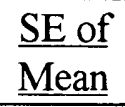 & $\begin{array}{c}\text { 2-tail } \\
\text { Probability }\end{array}$ \\
\hline \multirow[t]{2}{*}{ Leading Members } & 5.9457 & 1.307 & & & \\
\hline & & & .0543 & .089 & .543 \\
\hline \multirow[t]{2}{*}{ Key Staff } & 5.8915 & 1.245 & & & \\
\hline & & & .0000 & .088 & 1.000 \\
\hline \multirow[t]{2}{*}{ State Legislature } & 5.8915 & 1.220 & & & \\
\hline & & & .4341 & .137 & .002 \\
\hline \multirow[t]{2}{*}{ Chancellor } & 5.4574 & 1.452 & & & \\
\hline & & & .1783 & .097 & .070 \\
\hline Board of Regents & 5.2791 & 1.452 & & & \\
\hline \multirow[t]{2}{*}{ The Governor } & 4.7829 & 1.447 & .4901 & .152 & .000 \\
\hline & & & .0698 & .158 & .659 \\
\hline \multirow[t]{2}{*}{ Federal Policy } & 4.7132 & 1.547 & & & \\
\hline & & & .0853 & .153 & .579 \\
\hline Lobbyists, Public & 4.6279 & 1.160 & & & \\
\hline \multirow[t]{2}{*}{ CSSO } & 4.5039 & 1.511 & .1240 & .158 & 435 \\
\hline & & & .2713 & .157 & .087 \\
\hline \multirow[t]{2}{*}{ Non-Educator Groups } & 4.2326 & 1.338 & & & \\
\hline & & & .0620 & .125 & .622 \\
\hline \multirow[t]{2}{*}{ Lobbyists, Private } & 4.1705 & 1.572 & & & \\
\hline & & & .0233 & .153 & .879 \\
\hline The Courts & 4.1473 & 4.1473 & & & \\
\hline \multirow[t]{2}{*}{ All Education } & 4.1240 & 1.139 & .0233 & .160 & .884 \\
\hline & & & .5426 & .104 & .000 \\
\hline \multirow[t]{2}{*}{ Faculty Groups } & 3.5814 & 1.279 & & & \\
\hline & & & .2016 & .149 & .180 \\
\hline Direct Referenda & 3.3798 & 1.611 & & & \\
\hline \multirow{2}{*}{ Student Groups } & 3.1628 & 1.255 & 2171 & . 158 & .171 \\
\hline & & & .1008 & .124 & .418 \\
\hline \multirow[t]{2}{*}{ Education Research } & 3.0620 & 1.267 & & & \\
\hline & & & .0853 & .110 & .438 \\
\hline Education Materials & 2.9767 & 1.290 & & & \\
\hline
\end{tabular}

Note. $\mathrm{n}=129$ cases 
the Board of Regents (ranked 5) and the Governor and the Executive Staff (ranked 6), and (c) all the education interest groups combined (ranked 13) and faculty organization(s) (ranked 14).

\section{Analysis of Variance for Each Variable}

Introduction

An analysis of variance was used to determine the between groups differences for each of the survey's variables. In spite of general agreement on the presence and relative distribution of the various groups in the power and influence hierarchy, the researcher anticipated differences in perception of a particular variable's ability to influence between the four subgroups in the survey's population would occur. Where statistically significant differences were revealed in the analysis, Tukey's HSD test was used to determine which subgroups differed.

The Governor and the Executive Staff

Table 18 shows the computed means for perception of the importance of the Governor and the Executive Staff at the four types of institutions. The Governor and the Executive Staff had their highest mean at Private Universities/ Colleges and their lowest mean at the State University System. 
Table 18

Analysis of Variance - a. The Governor and the Executive Staff

\begin{tabular}{llllll}
\hline Institutional Affiliation & $\underline{\mathrm{n}}$ & $\underline{\mathrm{M}}$ & $\underline{\mathrm{SD}}$ & $\underline{\text { F Ratio }}$ & $\underline{\text { F Prob }}$ \\
\hline Private Universities/ Colleges & 58 & 5.19 & 1.42 & & \\
Community College System & 78 & 4.62 & 1.45 & & \\
State University System & 27 & 4.44 & 1.53 & & \\
$\begin{array}{l}\text { State Government Officials } \\
\text { and Accredited Lobbyists }\end{array}$ & 44 & 4.55 & 1.61 & & \\
TOTAL & 207 & 4.74 & 1.50 & 2.557 & .056 \\
\hline
\end{tabular}

Note. Tukey's HSD test showed no significant differences at the $p \leq .05$ level between the means of any two types of institutional affiliation.

The Chief State School Officer and Senior Staff in the State Department of Education

Table 19 shows the means for the Chief State School Officer and the Senior Staff in the State Department of Education. This policy group had the highest mean at Private Universities/Colleges and its lowest mean at the State University System.

\section{The State Board of Regents}

Table 20 shows the computed means for the State Board of Regents. The Regents had the highest mean from the State University System and their lowest mean at Private Universities/ Colleges. 
Table 19

Analysis of Variance - b. The Chief State School Officer and Senior Staff in the State Department of Education

\begin{tabular}{llllll}
\hline Institutional Affiliation & $\underline{\mathrm{n}}$ & $\underline{\mathrm{M}}$ & $\underline{\mathrm{SD}}$ & $\underline{\text { F Ratio }}$ & $\underline{\text { F Prob }}$ \\
\hline Private Universities/ Colleges & 57 & 4.81 & 1.41 & & \\
Community College System & 78 & 4.45 & 1.40 & & \\
State University System & 27 & 4.15 & 1.54 & & \\
$\begin{array}{l}\text { State Government Officials } \\
\text { and Accredited Lobbyists }\end{array}$ & 44 & 4.23 & 1.65 & & \\
TOTAL & 206 & 4.46 & 1.49 & 1.813 & .146 \\
\hline
\end{tabular}

Note. Tukey's HSD test showed no significant differences at the $p \leq .05$ level between the means of any two types of institutional affiliation.

Table 20

Analysis of Variance - c. The State Board of Regents

\begin{tabular}{llllll}
\hline Institutional Affiliation & $\underline{\mathrm{n}}$ & $\underline{\mathrm{M}}$ & $\underline{\mathrm{SD}}$ & $\underline{\text { F Ratio }}$ & $\underline{\text { F Prob }}$ \\
\hline Private Universities/ Colleges & 57 & 5.16 & 1.29 & & \\
Community College System & 76 & 5.28 & 1.33 & & \\
State University System & 27 & 5.33 & 1.54 & & \\
$\begin{array}{l}\text { State Government Officials } \\
\text { and Accredited Lobbyists }\end{array}$ & 44 & 5.18 & 1.62 & & \\
TOTAL & 204 & 5.23 & 1.41 & .141 & .935 \\
\hline
\end{tabular}

Note. Tukey's HSD test showed no significant differences at the $p \leq .05$ level between the means of any two types of institutional affiliation. 


\section{Chancellor of State University System}

Table 21 shows the computed means for the Chancellor of the State University

System. The Chancellor had his highest mean at the State University System and his lowest mean at Private Universities/Colleges.

Table 21

Analysis of Variance - d. Chancellor of State University System

\begin{tabular}{|c|c|c|c|c|c|}
\hline Institutional Affiliation & $\underline{\mathrm{n}}$ & $\underline{\mathrm{M}}$ & $\underline{\mathrm{SD}}$ & F Ratio & $\underline{\text { F Prob }}$ \\
\hline Private Universities/ Colleges & 57 & 5.18 & 1.45 & & \\
\hline Community College System & 76 & 5.59 & 1.38 & & \\
\hline State University System & 27 & 5.63 & 1.52 & & \\
\hline $\begin{array}{l}\text { State Government Officials } \\
\text { and Accredited Lobbyists }\end{array}$ & 43 & 5.47 & 1.40 & & \\
\hline TOTAL & 203 & 5.51 & 1.43 & 1.586 & .194 \\
\hline
\end{tabular}

\section{The State Legislature}

Table 22 shows the computed means for the State Legislature. The Legislature had its highest mean from State Government and Lobbyists and its lowest mean from Private Universities/ Colleges. 
Table 22

Analysis of Variance - e. The State Legislature

\begin{tabular}{|c|c|c|c|c|c|}
\hline Institutional Affiliation & $\underline{\mathrm{n}}$ & $\underline{\mathrm{M}}$ & $\underline{\mathrm{SD}}$ & F Ratio & F Prob \\
\hline Private Universities/Colleges & 48 & 5.56 & 1.17 & & \\
\hline Community College System & 62 & 6.11 & 1.24 & & \\
\hline State University System & 23 & 6.13 & 1.32 & & \\
\hline $\begin{array}{l}\text { State Government Officials } \\
\text { and Accredited Lobbyists }\end{array}$ & 35 & 6.14 & 1.00 & & \\
\hline TOTAL & 168 & 5.96 & 1.20 & 2.573 & .056 \\
\hline
\end{tabular}

\section{Leading Members of Legislative Committees}

Table 23 shows the computed means for the Leading Members of Legislative Committees. The Leading Members had their highest mean from the State University System and their lowest mean at the Private Universities/Colleges.

\section{$\underline{\text { Key Legislative Staff Consultants }}$}

Table 24 shows the means for Key Legislative Staff. The highest mean was from the State University System and their lowest mean was from Private Universities/ Colleges. Tukey's HSD test showed that the means of Community College System and 
the State University were significantly higher than the Private Universities/ Colleges and

State Government Officials.

Table 23

Analysis of Variance - e1. Leading Members of Legislative Committees

\begin{tabular}{llllll}
\hline Institutional Affiliation & $\underline{\mathrm{n}}$ & $\underline{\mathrm{M}}$ & $\underline{\text { SD }}$ & $\underline{\text { F Ratio }}$ & F Prob \\
\hline Private Universities/ Colleges & 58 & 5.69 & 1.20 &
\end{tabular}

Community College System $\quad 78 \quad 6.19 \quad 1.20$

$\begin{array}{llll}\text { State University System } \quad 27 \quad 6.15 & 1.10\end{array}$

State Government Officials

and Accredited Lobbyists $\quad 43 \quad 6.00 \quad 1.25$

TOTAL

$\begin{array}{llll}206 & 6.00 & 1.21 & 2.104\end{array}$
.101

Note. Tukey's HSD test showed no significant differences at the $p \leq .05$ level between the means of any two types of institutional affiliation.

Table 24

Analysis of Variance - e2. Key Legislative Staff Consultants

\begin{tabular}{llllll}
\hline Institutional Affiliation & $\underline{\mathrm{n}}$ & $\underline{\mathrm{M}}$ & $\underline{\underline{\mathrm{SD}}}$ & $\underline{\text { F Ratio }}$ & $\underline{\text { F Prob }}$ \\
\hline Private Universities/ Colleges & 55 & 5.40 & 1.21 & & \\
Community College System & 77 & 6.40 & 1.08 & & \\
State University System & 24 & 6.42 & .93 & & \\
$\begin{array}{l}\text { State Government Officials } \\
\text { and Accredited Lobbyists }\end{array}$ & 44 & 5.51 & 1.24 & & \\
TOTAL & 197 & 5.94 & 1.24 & 11.526 & .000 \\
\hline
\end{tabular}

Note. Tukey's HSD test showed significant differences at the $p \leq .05$ level among institutional affiliation. 


\section{$\underline{\text { All Education Interests Groups }}$}

Table 25 shows the means for All the Education Interest Groups. The highest mean was from the State Government Officials and the lowest mean was from the Community College System. Tukey's HSD test showed the mean of the State Government Officials was significantly higher than the mean for the Community College System.

Table 25

Analysis of Variance - $\mathrm{f}$. All the Education Interests Groups

\begin{tabular}{llllll}
\hline Institutional Affiliation & $\underline{\mathrm{n}}$ & $\underline{\mathrm{M}}$ & $\underline{\mathrm{SD}}$ & $\underline{\text { F Ratio }}$ & $\underline{\text { F Prob }}$ \\
\hline Private Universities/ Colleges & 48 & 4.13 & 1.00 & & \\
Community College System & 70 & 3.84 & .94 & & \\
State University System & 24 & 4.00 & 1.18 & & \\
$\begin{array}{l}\text { State Government Officials } \\
\text { and Accredited Lobbyists }\end{array}$ & 39 & 4.67 & 1.28 & & \\
TOTAL & 181 & 4.12 & 1.11 & 5.045 & .002 \\
\hline
\end{tabular}

Note. Tukey's HSD test showed significant differences at the $p \leq .05$ level among institutional affiliation. 


\section{Faculty Organization(s)}

Table 26 shows the computed means for Faculty Organization(s). The Faculty Organization(s) received their highest mean at Private universities/ colleges and their lowest at the State Government Officials.

Table 26

Analysis of Variance - fl. Faculty Organization(s)

\begin{tabular}{|c|c|c|c|c|c|}
\hline Institutional Affiliation & $\underline{\mathrm{n}}$ & $\underline{\mathrm{M}}$ & $\underline{\mathrm{SD}}$ & F Ratio & F Prob \\
\hline Private Universities/ Colleges & 56 & 3.79 & 1.28 & & \\
\hline Community College System & 78 & 3.49 & 1.19 & & \\
\hline State University System & 27 & 3.67 & 1.24 & & \\
\hline $\begin{array}{l}\text { State Government Officials } \\
\text { and Accredited Lobbyists }\end{array}$ & 44 & 3.45 & 1.62 & & \\
\hline TOTAL & 205 & 3.59 & 1.32 & .749 & .524 \\
\hline
\end{tabular}

Lobbyist from Independent Institutions

Table 27 shows the computed means for Lobbyists from Independent Institutions. These lobbyists had their highest mean at the State Government Officials and their lowest mean at the Community College System. 
Table 27

Analysis of Variance - $f 2$. Lobbyist from Independent Institutions

\begin{tabular}{|c|c|c|c|c|c|}
\hline Institutional Affiliation & $\underline{\mathrm{n}}$ & $\underline{\underline{M}}$ & $\underline{\mathrm{SD}}$ & F Ratio & F Prob \\
\hline Private Universities/ Colleges & 58 & 4.16 & 1.23 & & \\
\hline Community College System & 77 & 3.99 & 1.22 & & \\
\hline State University System & 27 & 4.04 & .81 & & \\
\hline $\begin{array}{l}\text { State Government Officials } \\
\text { and Accredited Lobbyists }\end{array}$ & 43 & 4.37 & 1.11 & & \\
\hline TOTAL & 205 & 4.12 & 1.15 & 1.089 & .355 \\
\hline
\end{tabular}

\section{Lobbyist from Public Institutions}

Table 28 shows the computed means for Lobbyist from Public Institutions. These lobbyists had the highest mean at the State Government Officials and the lowest means with the Community College System. Tukey's HSD showed that the mean of State Governmental Officials was significantly higher than the mean from the Community College System.

\section{Student Organization(s)}

Table 29 shows the means for Student Organization(s). The highest mean was from the State University System and the lowest mean was from the Community College System. Tukey's HSD test showed that the mean of the State University System was significantly higher than the mean of the Community College System. 
Table 28

Analysis of Variance - $\mathrm{f} 3$. Lobbyist from Public Institutions

\begin{tabular}{llllll}
\hline Institutional Affiliation & $\underline{\mathrm{n}}$ & $\underline{\mathrm{M}}$ & $\underline{\text { SD }}$ & $\underline{\text { F Ratio }}$ & $\underline{\text { F Prob }}$ \\
\hline Private Universities/Colleges & 57 & 4.67 & 1.02 & & \\
Community College System & 76 & 4.17 & 1.28 & & \\
State University System & 26 & 4.62 & .94 & & \\
$\begin{array}{l}\text { State Government Officials } \\
\text { and Accredited Lobbyists }\end{array}$ & 44 & 4.98 & .98 & & \\
TOTAL & 203 & 4.54 & 1.14 & 5.376 & .001 \\
\hline
\end{tabular}

Note. Tukey's HSD test showed significant differences at the $p \leq .05$ level among institutional affiliations.

Table 29

Analysis of Variance - $\mathrm{f} 4$. Student Organization(s)

\begin{tabular}{llllll}
\hline Institutional Affiliation & $\underline{\mathrm{n}}$ & $\underline{\mathrm{M}}$ & $\underline{\mathrm{SD}}$ & $\underline{\text { F Ratio }}$ & $\underline{\text { F Prob }}$ \\
\hline Private Universities/ Colleges & 57 & 3.16 & 1.31 & & \\
Community College System & 76 & 2.76 & 1.22 & & \\
State University System & 27 & 3.74 & 1.32 & & \\
$\begin{array}{l}\text { State Government Officials } \\
\text { and Accredited Lobbyists }\end{array}$ & 44 & 3.18 & 1.21 & & \\
TOTAL & 204 & 3.09 & 1.29 & 4.271 & .006 \\
\hline
\end{tabular}

Note. Tukey's HSD test showed significant differences at the $p \leq .05$ level among institutional affiliations. 
Non-Education Interest Groups

Table 30 shows the means for Non-Education Interest Groups. The highest mean was from the Community College System and the lowest mean was from State Government Officials.

Table 30

Analysis of Variance - g. Non-Education Interest Groups (business leaders, taxpayer groups, etc.)

\begin{tabular}{llllll}
\hline Institutional Affiliation & $\underline{\mathrm{n}}$ & $\underline{\mathrm{M}}$ & $\underline{\text { SD }}$ & $\underline{\text { F Ratio }}$ & $\underline{\text { F Prob }}$ \\
\hline Private Universities/ Colleges & 58 & 4.03 & 1.46 & & \\
Community College System & 77 & 4.42 & 1.39 & & \\
State University System & 26 & 4.23 & 1.14 & & \\
$\begin{array}{l}\text { State Government Officials } \\
\text { and Accredited Lobbyists }\end{array}$ & 44 & 3.91 & 1.27 & & \\
TOTAL & 205 & 4.18 & 1.36 & 1.589 & .193 \\
\hline
\end{tabular}

Note. Tukey's HSD test showed no significant differences at the $p \leq .05$ level between the means of any two types of institutional affiliation.

Producers of Education Related Products

Table 31 shows the means for Producers of Education Related Products. The highest mean was from the Community College System and the lowest was from the State University System. 
Table 31

Analysis of Variance - h. Producers of Education Related Products (textbook manufacturers, test producers, etc.)

\begin{tabular}{llllll}
\hline Institutional Affiliation & $\underline{\mathrm{n}}$ & $\underline{\mathrm{M}}$ & $\underline{\mathrm{SD}}$ & $\underline{\text { F Ratio }}$ & $\underline{\text { F Prob }}$ \\
\hline Private Universities/ Colleges & 57 & 3.00 & 1.16 & & \\
Community College System & 77 & 3.05 & 1.32 & & \\
State University System & 27 & 2.14 & 1.01 & & \\
$\begin{array}{l}\text { State Government Officials } \\
\text { and Accredited Lobbyists }\end{array}$ & 43 & 2.49 & 1.33 & & \\
TOTAL & 204 & 2.83 & 1.26 & 3.296 & .022 \\
\hline
\end{tabular}

Note. Tukey's HSD test showed no significant differences at the $p \leq .05$ level between the means of any two types of institutional affiliation.

\section{Direct Referenda Initiated by Citizens}

Table 32 shows the means for Direct Referenda Initiated by Citizens. The highest mean was from State Government Officials and the lowest mean was from the State University System.

\section{The Courts}

Table 33 shows the means for The Courts (State or Federal). The highest mean was from the Community College System and the lowest mean was from the State University System. 
Table 32

Analysis of Variance - i. Direct Referenda Initiated by Citizens

\begin{tabular}{llllll}
\hline Institutional Affiliation & $\underline{\mathrm{n}}$ & $\underline{\mathrm{M}}$ & $\underline{\mathrm{SD}}$ & $\underline{\text { F Ratio }}$ & $\underline{\text { F Prob }}$ \\
\hline Private Universities/ Colleges & 57 & 3.35 & 1.47 & & \\
Community College System & 76 & 3.58 & 1.83 & & \\
State University System & 27 & 3.04 & 1.58 & & \\
$\begin{array}{l}\text { State Government Officials } \\
\text { and Accredited Lobbyists }\end{array}$ & 41 & 3.54 & 1.83 & & \\
TOTAL & 201 & 3.43 & 1.70 & .766 & .515 \\
\hline
\end{tabular}

Note. Tukey's HSD test showed no significant differences at the $p \leq .05$ level between the means of any two types of institutional affiliation.

Table 33

Analysis of Variance - j. The Courts (State or Federal)

\begin{tabular}{llllll}
\hline Institutional Affiliation & $\underline{\mathrm{n}}$ & $\underline{\mathrm{M}}$ & $\underline{\mathrm{SD}}$ & $\underline{\text { F Ratio }}$ & $\underline{\text { F Prob }}$ \\
\hline Private Universities/ Colleges & 58 & 4.26 & 1.60 & & \\
Community College System & 78 & 4.22 & 1.61 & & \\
State University System & 27 & 3.37 & 1.04 & & \\
$\begin{array}{l}\text { State Government Officials } \\
\text { and Accredited Lobbyists }\end{array}$ & 43 & 3.81 & 1.89 & & \\
TOTAL & 206 & 4.03 & 1.63 & 2.514 & .060 \\
\hline
\end{tabular}

Note. Tukey's HSD test showed no significant differences at the $p \leq .05$ level between the means of any two types of institutional affiliation. 


\section{Federal Policy Mandates to the States}

Table 34 shows the computed means for Federal Policy Mandates to the States. The highest mean for this variable was from the Community College System and the lowest mean for it was from the State University System. Tukey's HSD test showed that the Community College System has a significantly higher mean than the State University System and State Government Officials and that the Private Universities/ Colleges had a significantly higher mean than the State University System.

Table 34

Analysis of Variance - $k$. Federal Policy Mandates to the States

\begin{tabular}{llllll}
\hline Institutional Affiliation & $\underline{\mathrm{n}}$ & $\underline{\mathrm{M}}$ & $\underline{\mathrm{SD}}$ & $\underline{\text { F Ratio }}$ & $\underline{\text { F Prob }}$ \\
\hline Private Universities/ Colleges & 58 & 4.95 & 1.42 & & \\
Community College System & 78 & 5.22 & 1.30 & & \\
State University System & 27 & 3.89 & 1.25 & & \\
$\begin{array}{l}\text { State Government Officials } \\
\text { and Accredited Lobbyists }\end{array}$ & 43 & 4.30 & 1.93 & & \\
TOTAL & 206 & 4.78 & 1.55 & 7.292 & .000 \\
\hline
\end{tabular}

Note. Tukey's HSD test showed significant differences at the $p \leq .05$ level among institutional affiliations.

\section{Education Research Organizations}

Table 35 shows the means for Education Research Organization. The highest mean was from State Government Officials and the lowest mean was from the State University System 
Table 35

Analysis of Variance - 1. Education Research Organizations

\begin{tabular}{llllll}
\hline Institutional Affiliation & $\underline{\mathrm{n}}$ & $\underline{\mathrm{M}}$ & $\underline{\mathrm{SD}}$ & $\underline{\text { F Ratio }}$ & $\underline{\text { F Prob }}$ \\
\hline Private Universities/Colleges & 58 & 3.09 & 1.27 & & \\
Community College System & 78 & 2.92 & 1.16 & & \\
State University System & 27 & 2.44 & .80 & & \\
$\begin{array}{l}\text { State Government Officials } \\
\text { and Accredited Lobbyists }\end{array}$ & 43 & 3.12 & 1.68 & & \\
TOTAL & 206 & 2.95 & 1.29 & 1.874 & .135 \\
\hline
\end{tabular}

Note. Tukey's HSD test showed no significant differences at the $p \leq .05$ level between the means of any two types of institutional affiliation.

\section{The Power and Influence Hierarchy}

Introduction

The policy groups that were chosen for this study were selected by a review of the literature. In previous research on the politics of higher education, the relationship between state government and higher education has been treated from an "interest group" perspective with a focus on either how state government officials viewed higher education or how various higher education "lobbying" groups attempted to influence the policy formation process. In this study the various groups who attempt to influence state policy formation efforts were included in the state-level context of academic governance. From this perspective, higher education leaders from the state and local levels were asked their 
perceptions of the ability of various groups to influence state policy formation and what emerging issues are present at the state level.

In Section II of the survey instrument, nineteen variables were listed in three groupings of state government officials, interest groups and unrelated groups. The lack of randomness of the variables on the survey instrument was a concern to the researcher but it appeared that the respondents considered each policy group separately and deliberately rated them. It is unclear why the survey participants did not respond at the same level to the two variables of "the state legislature" and "all the education interest groups." There may have been some difficulty following the survey instrument. The instrument might have given the impression that these variables were "headings" and not separate variables.

It must be conceded that an individual's interpretation of words "very low" and "very high" is difficult to predict. In addition, it is difficult to interpret an individual's understanding of historical reference. The study asked individuals to rate the level of influence of various individuals or groups between 1989 and 1994. The responses were used to create an overall ranking of the groups based on TOTAL means and a power and influence hierarchy. Marshall et al.'s (1989) research provided the frame of reference for this analysis. In addition, an analysis of variance for eighteen of the variables was performed to determine if differences of perceptions of influence based on institutional affiliation among Florida's higher education leaders existed. The following discussion will be limited to the first 18 variables of the survey. The last variable of the survey, "Other," was dropped from the analysis because most respondents did not complete the item. 
The following presentation of the power and influence hierarchy is divided into two sections. In the first section, the formation of the power and influence hierarchy and its statistical significance using the survey's data will be discussed. In the second section, each variable will be discussed beginning with the "insiders" of the hierarchy. An individual policy group's place in the power and influence hierarchy, its statistical significance, data from the analysis of variance of these variables, information from Section IV, V or VI of this survey, and appropriate conclusions from previous research will be discussed. The reader is reminded that the "rating" of each policy group by analysis of variance and the formation of the influence hierarchy were done using the Likert ratings made by the respondents.

Seven of the policy groups in this survey represented state government officials and included the governor and the executive staff, the chief state school officer and senior staff in the state department of education, the state board of regents, the chancellor of the state university system, the state legislature, leading members of the legislative committees, and key legislative staff consultants. As the analysis was completed state government personnel would be perceived as most influential in higher education policy formation with the leading members of the state legislature receiving the highest mean. Another set of individuals interested in influencing higher education policy were considered interest groups. While many interests groups are accredited to the Florida legislature ("Joint Legislative," u. n.), six general headings were used in this survey. They included all the education interests groups, faculty organization(s), lobbyists from 
independent institutions, lobbyists from public institutions, student organization(s) and non-education interest groups (business leaders, taxpayers, etc.). A review of the literature had indicated that education interest groups were not influential in Florida's legislature (Dye, 1995). The analysis of data confirmed this impression among Florida's higher education leaders and state officials.

The last five policy groups were unrelated and included direct referenda initiated by citizens, the courts (state or federal), federal policy mandates to the states, and education research organizations. The researcher was curious about the place education research would take in the overall data analysis. The literature had suggested that research has little impact on federal or state policy formation (Premfors \& Wittrock, 1983; Lynn, 1987). The researcher also felt that the strength or weakness of this variable's mean would be an indication of the value placed of the reports and recommendations of the Postsecondary Education Planning Commission, the system-wide and local five-year plans, and other research mandated by the state legislature.

The Creation of a Power and Influence Hierarchy

To establish the power and influence hierarchy, SPSS was used to form a hierarchical cluster. In this calculation, the various groups are treated as variables. The policy groups of each cluster were created through hierarchical clustering (Table 36) and correlated t-tests were used to determine the level of significance between each cluster (Table 37). The cluster analysis resulted in five clusters. The five clusters were labeled 
“insiders," "near circle," "far circle," "sometime players," and "often forgotten players" (Table 36).

\section{Policy Groups Clusters: Statistical Data}

Correlated t-tests were performed on the adjacent circles of the power and influence hierarchy beginning with the "insiders" and moving out towards the "often forgotten players" to determine it any of the differences between cluster means was at a level of significance based on a $p \leq .05$. This level of significance is more conservative that Marshall et al.'s (1986) original work that reported significant differences at the .10 level. Of the four pairs tests for differences at the .05 level, two of the pairs were statistically significant: (a) the "insiders" and the "near circle" and (b) the "sometime players" and the “often forgotten players" (Table 36).

The Power and Influence Hierarchy: The Insiders

Leading Members of Legislative Committees. The leading members of legislative committees received the highest TOTAL mean of the groups on the survey. Leading members of legislative committees are perceived to be the most influential of the eighteen policy groups in higher education policy formation. The committees mentioned by the survey respondents in Section III included the Senate Ways and Means, Higher Education, and Education Committees and the House Appropriations, Higher Education, and Education Committees. 
Table 36

Policy Group Influence by Cluster and Ranking

\begin{tabular}{|c|c|c|}
\hline Cluster & Policy Group & Rank \\
\hline Insiders & $\begin{array}{l}\text { Leading Members of Legislative Committees } \\
\text { The State Legislature } \\
\text { Key Legislative Staff Consultants } \\
\text { Chancellor of the State University System } \\
\text { The State Board of Regents }\end{array}$ & $\begin{array}{l}1 \\
2 \\
3 \\
4 \\
5\end{array}$ \\
\hline Near Circle & $\begin{array}{l}\text { The Governor and the Executive Staff } \\
\text { The Chief State School Officer and Senior } \\
\text { Staff in the State Department of Education }\end{array}$ & $\begin{array}{l}6 \\
9\end{array}$ \\
\hline Far Circle & $\begin{array}{l}\text { The Courts (State or Federal) } \\
\text { Federal Policy Mandates to the States }\end{array}$ & $\begin{array}{r}7 \\
12\end{array}$ \\
\hline $\begin{array}{l}\text { Sometime } \\
\text { Players }\end{array}$ & $\begin{array}{l}\text { Lobbyists from Public Institutions } \\
\text { Non-Education Interest Groups } \\
\text { All Education Interest Groups } \\
\text { Lobbyists from Private Institutions }\end{array}$ & $\begin{array}{c}8 \\
10 \\
13 \\
11\end{array}$ \\
\hline $\begin{array}{l}\text { Often } \\
\text { Forgotten } \\
\text { Players }\end{array}$ & $\begin{array}{l}\text { Faculty Organizations } \\
\text { Direct Referenda Initiated By Citizens } \\
\text { Student Organizations } \\
\text { Education Research Organizations } \\
\text { Producers of Education Related Products }\end{array}$ & $\begin{array}{l}14 \\
15 \\
16 \\
17 \\
18\end{array}$ \\
\hline
\end{tabular}

Note. ----- denotes statistically significant (at .05) difference between clusters. denotes no significance difference (at .05 ) between clusters. 
Table 37

Policy Groups Clusters: Statistical Data

\begin{tabular}{lcllll}
\hline Cluster & $\begin{array}{c}\text { Cluster } \\
\mathrm{M}\end{array}$ & $\begin{array}{l}\text { Cluster } \\
\text { SD }\end{array}$ & $\begin{array}{l}\text { Differences } \\
\text { Between } \\
\text { Clusters }\end{array}$ & $\begin{array}{l}\text { Cluster } \\
\text { SE }\end{array}$ & $\begin{array}{l}\text { 2-tail } \\
\text { Prob- } \\
\text { ability }\end{array}$ \\
\hline Insiders & 5.6930 & 1.036 & 1.0496 & .116 & .000 \\
Near Circle & 4.6434 & 1.317 & .2132 & .138 & .124 \\
Far Circle & 4.4302 & 1.411 & .1415 & .121 & .245 \\
$\begin{array}{l}\text { Sometime } \\
\text { Players }\end{array}$ & 4.288 & .870 & 1.0562 & .067 & .000 \\
$\begin{array}{l}\text { Often } \\
\text { Forgotten } \\
\text { Players }\end{array}$ & 3.2326 & .961 & & & \\
\hline Note. $\mathrm{n}=129$ cases & & & & & \\
\hline
\end{tabular}

The leading members of legislative committees were listed in the cluster analysis as part of the "insiders" of the power and influence hierarchy. There was no significant difference between its mean and the mean of the next closest variable (key legislative staff consultants) when paired t-tests were performed. The Tukey's HSD showed no significant differences between the means of this variable based on institutional affiliation. This ranking was consistent with Porter's study of influence in the Michigan legislature (in Hines \& Hartmark, 1980) and Marshall et al.'s (1989) observation that deference is given to elected individuals who specialize in a particular area as determined by their peers. 


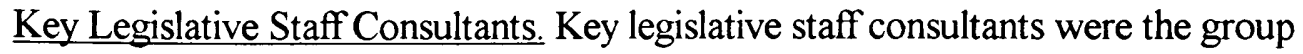
that received the second highest TOTAL mean of the groups on the survey. Key legislative staff consultants are perceived to be more influential than the state legislature in higher education policy formation. This ranking in the survey may indicate a subtle but important shift of influence away from constitutionally elected officials to the professional full-time staff of the state capital. The staff consultants mentioned in Section III included the staff consultants for the Senate Ways and Means, Higher Education, and Education Committees and the House Appropriation, Higher Education, and Education Committees. However, the individuals named most in Section III were staff consultations from the Senate Ways \& Means Committee.

This variable was listed in the cluster analysis as part of the "insiders" of the power and influence hierarchy. The means for this variable and the state legislature were exactly the same. There was only slight difference in the their respective standard deviations. Tukey's HSD showed the means of Community College System and the State University were significantly higher than the Private Universities/ Colleges and State Government Officials. This difference is an indication that community college and state university personnel think that Key Legislative Staff are more influential This perception of the influence of key legislative staff by community college and state university personnel was reinforced by written comments made by respondents throughout the survey. Several respondents suggested that the ability of staff "to influence proviso language" was the source of this influence. The overall tone of these written 
comments suggested that the legislative staff is perceived with some mistrust by higher education personnel. Augenblick et al. (1990) had commented on the mistrust between the legislature, state officials and local institutional leaders in their report to the Structure Committee. They made a series of recommendation to improve this situation. This study suggests that the mistrust may have increased and become more focused during the early 1990s. However, the state government officials ranked the legislative staff lower in perceived influence. Two research questions are suggested by this information. Why does the consultation process used by the legislature encourage conflict instead of cooperation among higher education leaders? How does the legislative staff influence higher education policy?

The State Legislature. The state legislature was the group that received the third highest TOTAL mean of the groups on the survey. The state legislature is perceived to be influential in higher education policy formation but only after the leading members of legislative committees and key staff consultants. The researcher's review of the literature (Fisher, 1988; Marshall et al., 1989; Volkwein, 1989) had suggested that the state legislature would be ranked first in the TOTAL means. This ranking of third may indicate that individuals are more influential in the formation of higher education policy than the legislature as a whole.

The legislature was listed in the cluster analysis as an "insider" in the power and influence hierarchy. The mean for this variable and the next variable (i.e., Chancellor of the 
State University System) were statistically significant in their t-test. This difference is the first statistically significant difference in the pairwise analysis and suggests the survey participants perceive some difference in influence between of the state legislature and the chancellor. However, Tukey's HSD showed no significance difference between the means based on institutional affiliation and the cluster analysis did not break the variables at this point.

Chancellor of the State University System. The fourth variable, the Chancellor of the State University System, was the first variable to be ranked that is not part of the state legislature. Dr. Charles Reed, the Chancellor of the State University System, was mentioned 27 times in Section III of the survey. Only Senator George Kirkpatrick, Chair of the Senate Higher Education Committee and Executive Director of ICUF, who was mentioned 24 times, had the same level of support from survey participants.

The Chancellor was listed in the cluster analysis as an "insider" of the power and influence hierarchy. This ranking is consistent with the research on the emergence of the state coordinating board in higher education mentioned by Mortimer and McConnell (1978) and Hines and Hartmark (1980). The means for this variable and the next variable, the State Board of Regents, were not statistically significant in their t-test. Tukey's HSD showed no significant difference for this variable between the means based on institutional affiliation. Information from Section III of this survey indicates that there is tension between the Board of Regents and Florida's two other state-level coordinating boards 
(i.e., The State Board of Community Colleges and the Postsecondary Education Planning Commission).

The State Board of Regents. The State Board of Regents received the fifth highest TOTAL mean of the variables in the survey. The survey results revealed that the Board of Regents is perceived as very influential and part of the "insiders" in the power and influence hierarchy. The correlated t-test for this variable when paired with the next variable (i.e., the Governor and the Executive Staff) showed a significant difference. In addition, the correlated t-test for "insiders" cluster and the next cluster (the "near circle") also showed a significant difference. However, the analysis of variance based on institutional affiliation showed no difference.

This pattern may indicate that there is a high level of agreement on the relative influence of the Board of Regents among the state's higher education leaders. While the Board is perceived as not as influential as the leading members of legislative committees, key staff consultants, and the state legislature, it is perceived as influential as the Chancellor of the State University System and more influential than the Governor and the Executive Staff.

The statistical evidence from Section II of the survey is not supported in Section III where two members of the Board of Regents are mentioned by only two survey participants. These instances are the only times that members of the Board are mentioned specifically. The Board of Regents and its staff are mentioned more frequently in a generic 
manner in Section III of the survey. When information from Sections II and III is combined the question of the relative ability of the three state-level coordinating boards to influence policy formation emerged from the data.

While the Board of Regents is an agent of the Legislature, a review of the literature (Mautz, 1982) had indicated there was a struggle for influence between the legislature, the Board of Regents and the local institutions. The researcher had suggested that the Board of Regents would be clustered in the far circle of the influence hierarchy because of Mautz's research. The data indicates that Board of Regents and the Chancellor continue to exercise great influence in higher education policy formation.

\section{The Power and Influence Hierarchy: The Near Circle}

The Governor and the Executive Staff. The Governor and the Executive Staff received the sixth highest of the TOTAL means of the survey. While the office of the governor was mentioned in Section III, neither Governor Chiles or any of the executive staff were mentioned by name. This position in the TOTAL ranking of means is consistent with the research that has suggested that the Florida's constitutional arrangements have created a weak governor (Kimbrough et al., 1984). Several commissions have been created to study the problem and to suggest a constitutional solution (Wolfe \& Jreisat, 1995).

This ranking supports Marshall et al.'s (1989) argument that the development of a power and influence hierarchy can help reveal how influence from external constituencies 
is filtered away from the "insiders." Even though Florida's governor is weak, the office serves as a screen to protect the influence of the state legislature in higher education policy formation from the representatives of local institutions of higher education within the state.

The Governor and the Executive Staff was one of two variables listed in "near circle" in the cluster analysis. The Governor and the next variable, federal policy mandates, in the ranking based on highest TOTAL means showed no significant difference in their ttest. Tukey's HSD showed no significant difference for this variable between the means based on institutional affiliation. The governor's influence on higher education policy is perceived to be the same regardless of institutional affiliation.

\section{The Chief State School Officer and Senior Staff in the State Department of}

Education. The other variable in the near circle of the power and influence hierarchy was the Chief State School Officer and Senior Staff at the Department of Education. The Chief State School Officer and Senior Staff were placed ninth in the ranking based on TOTAL means of the survey. It was the last of the state government groups to be ranked. This ranking was consistent with the literature and comments made by survey participants in other parts of the survey. In the paired t-test between of the means of variables in the "near circle" and "far circle" there was no significant difference. In the paired t-test with the next variable (i.e., non educator interest groups) in the overall ranking there was also 
no significant difference. One respondent commented "the Commissioner of Education is really a K-12 office--could care less about higher education!" (097).

The Power and Influence Hierarchy: The Far Circle

The Courts (State or Federal). The courts (state or federal) were ranked seventh in the overall ranking based on the TOTAL means of the survey. It received the highest TOTAL mean of the unrelated groups in the survey. There was no significant difference between this variable and the next (i.e., faculty organizations) in the paired t-test. The courts were placed in the "far circle "along with federal mandates by the cluster analysis. The researcher was surprised to see the courts placed in the "far circle." A review of the literature had indicated that the courts has played only a minor role in higher education issues in Florida. Tukey's HSD test showed no significant differences based on institutional affiliation

Federal Policy Mandates to the States. Federal policy mandates to the states was ranked twelfth in the ranking based on TOTAL means for the survey and was the second of the six unrelated policy groups to be mentioned in the overall ranking. Federal policy mandates to the states were placed in the "far circle" in the cluster analysis. It shared this circle with the courts (state or federal). In the paired t-test with lobbyists from public institutions there was no significant difference. Tukey's HSD test showed significant differences between private universities and colleges and the state university system and 
between the community colleges and the private universities and colleges and the state government. Because the differences in the perception of the influence of federal policy on Florida are significant, it might suggest an area of research to determine the level and kind of impact federal policy is having on state level higher education policy formation.

\section{The Power and Influence Hierarchy: The Sometime Players}

Lobbyists for Public Institutions. Lobbyists for public institutions were considered accredited lobbyists from the community college and state university systenıs. This variable was ranked eighth in the overall ranking based on TOTAL means of the survey and the first of the interest groups to be ranked. This variable showed no significant difference with the next variable, Chief State School Officer, in the paired t-test. The cluster analysis placed in the "sometime players" circle in the cluster analysis. Tukey's HSD test showed significant differences among institutional affiliations. The state government mean was significantly higher than the mean from the community college system. State government officials perceived lobbyists from public institution to be more influential.

Non-Educator Interest Groups. Non-educator interest groups were ranked tenth in the overall ranking based the TOTAL means of the survey. The variable showed no significant difference in its paired t-test with the next variable (i.e., all education interest 
groups combined). It was placed in the "sometime players" circle by the cluster analysis. Tukey's HSD test showed no significant differences based on institutional affiliation.

All the Education Interest Groups. All education interest groups was ranked thirteenth in the TOTAL means of the survey. There was significant difference between this variable and the next, faculty organizations, in the paired t-test. In addition, this variable was the last to be place in the "sometime players" circle in the cluster analysis. There was significant difference between the "sometime players" and "forgotten players" when the means of the variables of these two clusters were compared in a paired t-test. Tukey's HSD test showed significant difference between the community college and state government for this variable.

Lobbyist for Independent Institutions. Lobbyists for independent institutions were considered accredited lobbyists from private universities and colleges and ranked eleventh in the TOTAL means of the survey. There was no significant difference between this variable and the next, the courts, in paired t-test. It was placed in the "sometime players" circles in the cluster analysis. Tukey's HSD test showed no significant differences between institutional affiliation for this variable. 


\section{The Power and Influence Hierarchy: The Often Forgotten Players}

Faculty Organization(s). Faculty organization(s) was ranked fourteenth in the overall ranking of the TOTAL means of the survey. In the cluster analysis, this variable was the first to be included among the "often forgotten players" in the power and influence hierarchy. The ascription for this particular segment of the power and influence hierarchy suggests that the variables in this cluster are perceived to have little or unpredictable impact on higher education policy formation.

Direct Referenda Initiated by Citizens. Direct referenda initiated by citizens was ranked fifteenth in the overall rank order based on the TOTAL means of the survey. There was no significant difference between this variable and the next variable (i.e., student organizations) in the paired t-test. This variable was placed among the "often forgotten players" in the cluster analysis. Tukey's - HSD test showed no significant difference between the means based on institutional affiliation.

Student Organization(s). The interest group with the lowest place in the rank order based on TOTAL means of the survey was student organizations. There was no significant difference between this variable and the next variable (i.e., education research organizations) in the paired t-test. This variable was placed among the "often forgotten players" in the cluster analysis. While Tukey's HSD showed that the mean of the state university system was significantly higher than the mean of the community college system, 
the low ranking of the student groups in the TOTAL ranking and power and influence hierarchy suggest that student groups are perceived to have little impact on state-level policy formation.

Education Research Organizations. Education research organizations were seventeenth in the overall rankings based on the TOTAL means of the survey. While the review of the literature had indicated that government officials rarely use research as the basis for decisions, it was disappointing to this researcher to have its value in Florida higher education policy formation reinforce this conclusion. The ranking suggests that most of the reports and planning efforts mandated by the state legislature and carried out by commissions and local institutions have little impact on higher education policy formation. The low ranking of education research efforts was confirmed in written comments made in the survey.

There was no significant difference between this variable and the next (i.e., producers of education related materials) in the paired t-tests. The variable was placed among the "often forgotten players" by the cluster analysis. Tukey's HSD test showed no significant difference between the means based on institutional affiliation.

Producers of Education Related Materials. The producers of education related materials was ranked last or eighteenth in the rankings based on the TOTAL means of the survey. There was no significant difference between this variable and the next (i.e., 
education research organizations) in the paired t-tests. The variable was placed among the "often forgotten players" in the cluster analysis. Tukey's HSD test showed no significant difference between the means based on institutional affiliation.

\section{$\underline{\text { Summary }}$}

While there were some variation of perception based on institutional affiliation, the data suggests that Florida's higher education leaders recognize a power and influence hierarchy in higher education policy formation. The "insiders" circle of this hierarchy includes five groups. These groups include the state legislature with its leading members and key consultative staff, and the Chancellor and Board of Regents of the State University System. This pattern may indicate that higher education policy is influenced strongly by non-elected legislative staff and full-time professionals in the state capitol who provide support and direction to the concerns and issues articulated by legislators and other elected officials.

The groups included in the "near circle" and "far circle" of the power and influence hierarchy (i.e., The Governor and the Executive Staff, The Chief State School Officer and Senior Staff in the State Department of Education, the courts (state or federal), and federal policy mandates to the states) support Marshall et al.'s (1989) observation that the hierarchy serves to filter the claims of external constituencies from the policy elites who comprise the center of the hierarchy. Of the four groups listed as part of these two circles none have taken an active role in higher education policy formation 
during the time frame of the study. Their positions in the hierarchy suggest that they serve as buffers between higher education's local or institutional leaders and the policy elites found in the state legislature and state coordinating boards.

The placement of all education lobbyists, faculty organization(s), and student organization(s) among the "sometime players" and "often forgotten players" of the hierarchy may indicate the limited influence local institutional leaders have on the statelevel policies that will impact their institutions and personnel. While in the "sometime players" circle, the placement of non-education lobbyists ahead of all education lobbying groups except those from public institutions may be an indication of the potential danger that higher education's unique mission will be compromised by the business or economic interests of the state.

Finally, the low ranking of education research organizations by state government officials and local institutional leaders may be indication of how political the process of policy formation is at the state level. Marshall et al.'s (1989) discussion of feasibility as an important component of policy formation supports this assertion. In addition, the placement of research in its low position in the hierarchy can serve as a warning to those who were hoping that education policy would flow through a rational planning model. While the state legislature may mandate studies and master plans for the two state systems and local institutions from its staff and the Postsecondary Education Planning Commission, the research may indicate that the material will have little impact. However, 
Premfors and Wittrock (1983) assertion that the material could be used for partisan politics may also be supported by this placement in the hierarchy.

\section{Section III of the Survey}

\section{Introduction}

Using open-ended questions, Section III asked respondents to name key policy makers. The respondents who answered this question suggested either specific individuals (Appendix C) or more general categories of "the Governor" or "Senate Higher Education Committee" (Appendix D). The naming of specific individuals and the number of times an individual was mentioned were considered important indicators of a particular individual's influence in higher education policy formation at the state level by this researcher. The more generic list (Appendix D) was used to provide additional insight and commentary on the list of individuals created by the participants' mention of specific names.

Of the 61 survey participants who listed individual(s) (Table 38), the largest group (23) was from the subgroup of state government (Table 39). The second most active subgroup was from the community college system (20). In addition to specific names, several participants provided written observations concerning key policy makers. One higher education administrator commented, "Who could be? The Committee of 100. Education must identity with them and cultivate their support. The real fact is that Florida 
lacks educational leaders" (088). One vice president commented, "During 1994-95, it seems as if major policy persons were legislators" (066). Another vice president

Table 38

Type and Number of Responses to Section III of the Survey

\begin{tabular}{llllll}
\hline $\begin{array}{l}\text { Provided } \\
\text { Information }\end{array}$ & $\begin{array}{l}\text { Private } \\
\text { Institutions }\end{array}$ & $\begin{array}{l}\text { Community } \\
\text { Colleges }\end{array}$ & $\begin{array}{l}\text { State } \\
\text { Universities }\end{array}$ & $\begin{array}{l}\text { Government } \\
\text { Officials }\end{array}$ & TOTAL \\
\hline Yes & 35 & 63 & 20 & 35 & 155 \\
No & 23 & 15 & 7 & 9 & 54 \\
TOTAL & 58 & 78 & 27 & 44 & 209 \\
\hline
\end{tabular}

Table 39

Number of Respondents by Institutional Affiliation who listed the names of individuals they perceived to be key policy makers in Florida higher education

\begin{tabular}{lc}
\hline Institutional Affiliation & No. of Respondents \\
\hline Private Universities/ Colleges & 7 \\
Community College System & 20 \\
State University System & 10 \\
State Government Officials and Accredited Lobbyists & 23 \\
Not Fully Identified & 1 \\
TOTAL & 61 \\
\hline
\end{tabular}


commented, "You left off the Community College Board at the state level and the local boards" (161). Another observed that "the movement of players across interest groups seems peculiar to Florida" (022).

\section{Names of Key Policy Makers}

While the overall list of specific names included 27 individuals (Appendix C), the final list was limited to the individuals who were mentioned by at least three survey participants numbered 17 (Table 40). They included Dr. Charles Reed, the Honorable George Kirkpatrick, Dr. Clark Maxwell, the Honorable Debbie Wasserman Schultz, Mr. John Andrew Smith, Dr. Frank Brogan, Dr. William Proctor, Mr. Edward Woodruff, Dr. John Lombardi, the Honorable J. Keith Arnold, the Honorable Fred Dudley, the Honorable Ken Jenne, the Honorable Ann McKenzie, Mr. Michael O'Farrell, Ms. Linda Collins, and the Honorable Mario Diaz-Balart.

Many of these individuals are leading members of legislative committees or key legislative staff consultants. These two groups were considered "insiders" by the survey participants. They included Senator George Kirkpatrick (24), Senator Ken Jenne (4), Representative Debbie Wasserman Shultz (9), and Representative Mario Diaz-Balart (3). All of whom serve in leadership positions in their respective chambers. Senator Kirkpatrick and Representative Wasserman Shultz serve as Chairs of the Legislator's Higher Education Committees. They were mentioned more often then Senator Jenne, who 
Table 40

Names of Key Policy Makers Mentioned At Least Three Times, Policy Makers Position in State Government or Higher Education and the Total Number of Times Mentioned by Survey Respondents

\begin{tabular}{llc}
\hline Key Policy Maker & \multicolumn{1}{c}{ Position } & Times Mentioned \\
\hline Charles Reed & Chancellor, University System & 27 \\
George Kirkpatrick & Chair, Senate Higher Education & 24 \\
Clark Maxwell & Executive Director, Community College Board & 12 \\
D. Wasserman Schultz Chair, House Higher Education Committee & 9 \\
John Andrew Smith & Staff Director, Senate Ways \& Means & 9 \\
Frank Brogan & Commissioner of Education & 8 \\
William Proctor & $\quad$ Chair, & 8 \\
Edward Woodruff & Staff, Senate Ways \& Means & 5 \\
John Lombardi & President, State University System & 5 \\
J. Keith Arnold & $\begin{array}{l}\text { Representative } \\
\text { Appropriations, Education Committees }\end{array}$ & 4 \\
Linda Collins & Staff, Senate Ways \& Means Committee & 3 \\
Mario Diaz-Balart & Chair, House Appropriations Committee & 4 \\
Ken Jenne & VChair, Senate Ways \& Means Committee & 4 \\
Ann McKenzie & $\begin{array}{l}\text { Representative, } \\
\text { Appropriations, Higher Education Committees }\end{array}$ & 3 \\
\hline & $\begin{array}{l}\text { Staff Director, Senate Higher Education Committee } \\
\text { Michael O'Farrell }\end{array}$ & 3 \\
\hline
\end{tabular}


serves as vice-chair of the Senate Ways \& Means Committee, and Representative DiazBalart, who serves as the chair of the House Appropriations Committee.

Three of the Senate' Ways and Means Committee staff were named by the respondents: Mr. John Andrew Smith (9), its Staff Director; and two staff members, Mr. Edward Woodruff(5) and Ms. Linda Collins (3). Mr. Michael O'Farrell, Staff Director of the Senate Higher Education Committee, was also mentioned by three respondents. Because these individuals are "key legislative staff consultants," they can be considered “insiders".

In addition, two legislators who did not hold legislative committee chairs or vice chairs but who can be considered "insiders" were named by survey participants. Senator Fred Dudley (4) is a member of the Senate Ways and Means Committee. Representative Ann McKenzie (3) is a member of the House Higher Education Committee.

Dr. Charles Reed (27), the Chancellor of the State University System, was mentioned more often by survey participants than any other individual. His office was ranked fourth in the overall ranking and was considered an "insider." Other individuals mentioned who were not part of the insiders were Dr. Frank Brogan, Commissioner of Education (8). The Commissioner of Education and the Governor were placed in the near circle of the influence hierarchy. This placement was consistent with the comments made by respondents and the diffused decision-making process in higher education within Florida state government. The Commissioner is not perceived as a strong advocate for 
higher education even though former Commissioner Betty Castor is President of the University of South Florida.

Finally, the names of several individuals whose positions did not appear on the survey's list of groups were mentioned by the survey participants. These individuals included Dr. Clark Maxwell, Executive Director, Community College Board; Dr. William Proctor, Chair of the Postsecondary Education Planning Commission; and Dr. John Lombardi, President of the University of Florida. Dr. Maxwell was mentioned 12 times and was the third most often mentioned individual on this list of names from Section III. Dr. Proctor was mentioned 8 times. Dr. Lombardi was mentioned three times.

\section{Section IV of the Survey}

\section{Introduction}

Section IV of the survey asked an open-ended question about which documents would be helpful in providing a clearer picture of higher education policy formation in Florida. The respondents were given a 2" space in which to make written comments. This question received the poorest response from the survey participants (Table 41). Only 88 respondents of 209 provided information for this question. Thirty-six of the 88 respondents who supplied information for this question were from the community college system and represented the largest group of respondents to answer this question. 
Table 41

Type and Number of Responses to Section IV of the Survey

\begin{tabular}{llllll}
\hline $\begin{array}{l}\text { Provided } \\
\text { Information }\end{array}$ & $\begin{array}{l}\text { Private } \\
\text { Institutions }\end{array}$ & $\begin{array}{l}\text { Community } \\
\text { Colleges }\end{array}$ & $\begin{array}{l}\text { State } \\
\text { Universities }\end{array}$ & $\begin{array}{l}\text { Government } \\
\text { Officials }\end{array}$ & TOTAL \\
\hline Yes & 16 & 36 & 11 & 23 & 88 \\
No & 42 & 42 & 16 & 21 & 121 \\
TOTAL & 58 & 78 & 27 & 44 & 209 \\
\hline
\end{tabular}

\section{Important Documents}

The list of suggested materials was coded with each respondent's case number, role and institutional affiliation (Appendix E). The documents were than divided into eight groups (Table 42): (a) Articulation Coordinating Committee, (b) Community College System (c) Postsecondary Education Planning Commission, (d) The State Department of Education (e) State Legislative Reports, (f) State Statues, (g) State University System, and (h) Other. Documents from the Postsecondary Education Planning Commission (28 times) and the state legislature ( 24 times) were mentioned most frequently by respondents. In addition, five respondents provided observations about the materials in this section. These comments may provide the most insight into the importance of documents and reports in higher education policy formation in Florida. One respondent wrote, "I don't think that any document has much effect in the year after it is written and promulgated" (041). Another observed that, "nothing will make it clearer" (138). Three 
respondents suggested that it was best to observe the legislative and budget processes.

One of these respondents advised, "walk the halls during legislative session" (156).

Table 42

Source of Materials and Number of Times Mentioned by Respondents by Document's

Origin and Respondent's Institutional Affiliation

\begin{tabular}{|c|c|c|c|c|c|}
\hline $\begin{array}{l}\text { Source of } \\
\text { Materials }\end{array}$ & $\begin{array}{l}\text { Private } \\
\text { Institutions }\end{array}$ & $\begin{array}{l}\text { Community } \\
\text { Colleges }\end{array}$ & $\begin{array}{l}\text { State } \\
\text { Universities }\end{array}$ & $\begin{array}{l}\text { Government } \\
\text { Officials }\end{array}$ & TOTAL \\
\hline $\begin{array}{l}\text { Articulation } \\
\text { Coordinating }\end{array}$ & & & & & \\
\hline Committee & 0 & 1 & 0 & 0 & 1 \\
\hline $\begin{array}{l}\text { Community } \\
\text { College }\end{array}$ & & & & & \\
\hline System & 0 & 9 & 0 & 1 & 10 \\
\hline $\begin{array}{l}\text { Postsecondary } \\
\text { Education } \\
\text { Planning }\end{array}$ & & & & & \\
\hline Commission & 3 & 18 & 0 & 7 & 28 \\
\hline $\begin{array}{l}\text { Department } \\
\text { of Education }\end{array}$ & 0 & 1 & 0 & 0 & 1 \\
\hline Legislative & & & & & \\
\hline Reports & 0 & 12 & 4 & 8 & 24 \\
\hline State Statues & 0 & 0 & 6 & 2 & 8 \\
\hline $\begin{array}{l}\text { State } \\
\text { University }\end{array}$ & & & & & \\
\hline System & 2 & 2 & 4 & 3 & 11 \\
\hline Other & 4 & 2 & 1 & 4 & 11 \\
\hline TOTAL & 9 & 44 & 15 & 25 & 94 \\
\hline
\end{tabular}




\section{Section V of the Survey}

\section{Introduction}

Section $\mathrm{V}$ of the survey instrument asked the respondents to rank their knowledge

of (a) finance, (b) governance, (c) access and choice, and (d) quality assessment using a 7point Likert-type scale. Because the survey was sent to the leading individuals in postsecondary education, their insights and concerns in these four areas could provide valuable information on critical issues in the future.

\section{Finance}

One hundred and ninety respondents rated their level of expertise in higher education finance. Table 43 contains a summary of the overall mean and the means based on institutional affiliation. Private universities and colleges report the lowest mean (4.88), and it is similar to the state government with a mean of 5.00 . The state university system mean for this variable (5.68) was the highest, and it was similar to the community college system mean of 5.61 .

\section{Governance}

One hundred and ninety-one respondents rated their level of expertise in higher education governance. Table 44 contains a summary of the means based on institutional affiliation. Private universities and colleges report the lowest mean (4.82). The state 
government had the highest mean of 5.85 , and it was similar to the community college system mean of 5.74. The state university system mean for this variable 5.44 .

Table 43

Analysis of Variance - a. Finance

\begin{tabular}{llllll}
\hline Institutional Affiliation & $\underline{\mathrm{n}}$ & $\underline{\mathrm{M}}$ & $\underline{\mathrm{SD}}$ & $\underline{\text { F Ratio }}$ & $\underline{\text { F Prob }}$ \\
\hline Private Universities/ Colleges & 52 & 4.88 & 1.63 & & \\
Community College System & 71 & 5.62 & 1.33 & & \\
State University System & 25 & 5.68 & 1.31 & & \\
$\begin{array}{l}\text { State Government Officials } \\
\text { and Accredited Lobbyists }\end{array}$ & 42 & 5.02 & 1.67 & & \\
TOTAL & 190 & 5.29 & 1.52 & 3.4299 & .0182 \\
\hline
\end{tabular}

Table 44

Analysis of Variance - b. Governance

\begin{tabular}{llllll}
\hline Institutional Affiliation & $\underline{\mathrm{n}}$ & $\underline{\mathrm{M}}$ & $\underline{\mathrm{SD}}$ & $\underline{\text { F Ratio }}$ & $\underline{\text { F Prob }}$ \\
\hline Private Universities/ Colleges & 50 & 4.82 & 1.21 & & \\
Community College System & 75 & 5.75 & 1.03 & & \\
State University System & 25 & 5.44 & 1.23 & & \\
$\begin{array}{l}\text { State Government Official } \\
\text { and Accredited Lobbyists }\end{array}$ & 41 & 5.85 & 1.06 & & \\
TOTAL & 191 & 5.49 & 1.18 & 8.8751 & .0000 \\
\hline
\end{tabular}




\section{Access and Choice}

One hundred and ninety-three respondents rated their level of expertise in access and choice. Table 45 contains a summary of the means based on institutional affiliation. Private universities and colleges reported the lowest mean (4.56). The state government had the highest mean of 5.33, and it was similar to the state university system mean of 5.04. The community college system reported a mean of 4.97 .

Table 45

Analysis of Variance - c. Access and Choice

\begin{tabular}{llllll}
\hline Institutional Affiliation & $\underline{\mathrm{n}}$ & $\underline{\mathrm{M}}$ & $\underline{\mathrm{SD}}$ & $\underline{\text { F Ratio }}$ & $\underline{\text { F Prob }}$ \\
\hline Private Universities/ Colleges & 52 & 4.56 & 1.38 & & \\
Community College System & 74 & 4.97 & 1.44 & & \\
State University System & 25 & 5.04 & 1.34 & & \\
$\begin{array}{l}\text { State Government Officials } \\
\text { and Accredited Lobbyists }\end{array}$ & 42 & 5.33 & 1.34 & & \\
TOTAL & 193 & 4.95 & 1.41 & 2.4877 & .0618 \\
\hline
\end{tabular}

\section{Quality and Assessment}

One hundred and eighty-eight respondents rated their level of expertise in quality and assessment. This response was the lowest for the four variables of Section V. Table 46 contains a summary of the means based on institutional affiliation. Private universities and colleges reported a mean of 5.00 , and it was similar to community college system of 
5.03. The state government had the lowest mean of 4.71 . The state university system had the highest mean of 5.40 .

Table 46

Analysis of Variance - d. Quality and Assessment

\begin{tabular}{|c|c|c|c|c|c|}
\hline Institutional Affiliation & $\underline{\mathrm{n}}$ & $\underline{\underline{M}}$ & $\underline{\mathrm{SD}}$ & F Ratio & $\underline{\text { F Prob }}$ \\
\hline Private Universities/ Colleges & 51 & 5.00 & 1.37 & & \\
\hline Community College System & 81 & 5.03 & 1.36 & & \\
\hline State University System & 25 & 5.40 & 1.47 & & \\
\hline $\begin{array}{l}\text { State Government Officials } \\
\text { and Accredited Lobbyists }\end{array}$ & 41 & 4.71 & 1.59 & & \\
\hline TOTAL & 188 & 5.00 & 1.44 & 1.2267 & .3014 \\
\hline
\end{tabular}

Section VI of the Survey

Introduction

One hundred and thirty-seven respondents (66\%) provided written comments for Section VI of the survey instrument (Table 47). This section with its 4" blank space provided an opportunity for respondents to comment on the four areas of policy formation mentioned in Section V. The four categories of (a) finance, (b) governance, (c) access and choice, and (d) assessment and quality were not given specific definitions by the researcher. While the directions for the section directed the respondents to comment "on 
the most pressing issues in the area you feel most knowledgeable," many respondents used the space to comment on a variety of higher education issues or Florida's political culture. A complete listing of comments with the respondent's case number is found in Appendix F. Each survey received a case number that provides the reference citation in parenthesis throughout this study for each participant's written comments.

Table 47

Type and Number of Responses by Institutional Affiliation to Section VI of the Survey

\begin{tabular}{llllll}
\hline $\begin{array}{l}\text { Provided } \\
\text { Information }\end{array}$ & $\begin{array}{l}\text { Private } \\
\text { Institutions }\end{array}$ & $\begin{array}{l}\text { Community } \\
\text { Colleges }\end{array}$ & $\begin{array}{l}\text { State } \\
\text { Universities }\end{array}$ & $\begin{array}{l}\text { Government } \\
\text { Officials }\end{array}$ & TOTAL \\
\hline Yes & 33 & 56 & 14 & 33 & 137 \\
No & 25 & 22 & 13 & 11 & 72 \\
TOTAL & 55 & 78 & 27 & 44 & 209 \\
\hline
\end{tabular}

As a researcher, I am grateful especially that so many respondents took the time to provide candid assessments of the higher education policy formation. Two individuals signed their surveys and one of them asked that I call when I was ready to continue my research. The tone of the responses was one of profound concern for the quality of higher education in Florida and an intense desire on the part of the survey participants to provide the best education to Florida's citizens. 


\section{Emerging Issues in Florida Higher Education}

\section{Introduction}

While the original data analysis plan called for these responses to be coded using Millet's (1988) four categories of (a) governance, (b) finance, (c) access and choice, and (d) quality and assessment or Finitfer et al.'s (1991) three categories of (a) quality, (b) diversity, and (c) budgetary efficiency, the initial review of the participants' comments suggested that a grounded approach would be more appropriate and helpful. The tone and content of the comments reflected a genuine concern of the respondents that the legislature is unclear about its proper role in higher education policy formation. Two patterns emerged from these written comments.

The first pattern emerged from the comments when they were analyzed based on the respondents' institutional affiliation. Differences in perspective surfaced among the representatives from the private institutions and state government officials. A second pattern of common themes did emerged from the respondent's regardless of institutional affiliation. These common themes included: (a) the political nature of state-level policy formation, (b) The role of consultative staff., (c) the competition for state moneys, (d) legislative concern for state-level budgetary efficiency, and (e) legislative attempts to define quality and supervise academic program development for higher education. 


\section{Common Themes}

Theme one: The political nature of state-level policy formation. The largest number of comments involved the role of the state legislature in higher education policy formation. The political nature of state-level policy formation is understood by higher education leaders. Two comments illustrated this understanding. The first concerns the posturing that can take place in a state subculture: "The growth of influence of particular legislators may be effected by desire to appear influential" (022). A second observer concluded: "Florida politics - Player's goals 1. reelection; 2. cutting budgets (de facto pandering to press, business, constituents, etc.; 3 . high visibility statewide (positioning for future, i.e. their personal future). It is a bizarre political scene in Tallahassee" (167).

Theme two: The role of consultative staff. While the role of leading legislators and the legislature overall in higher policy formation was most often mentioned by respondents, the perceived role of legislative consultative staff in the policy formation process was equally important. One observer suggested that the legislative staff was attempting "to close open-door" (078) to legislators. Another lamented that "higher education legislative staffers... too much influence, too uninformed" (126). Another suggested that the legislative staff "are the policy makers" (096). The negative tone continued in the following observation: "the [lack of confidence in faculty and staff] has been precipitated by legislative staff who have faced personal problems with their own 
children in the higher education system" (083). In addition to these comments from Section VI of the survey, eight respondents listed the legislative staff as key policy makers in Section III of the survey and placed the word "unfortunately" afterwards.

Theme three: Competition for state moneys. A third theme focused on the competition between higher education and other groups requesting state funding. The competition is seen as a forced competition brought about by the "misplaced emphases by legislators on law enforcement, prisons, HRS, etc. when education could minimize problems in all those areas. better (and cheaper) to educate than incarcerate!" (128). "We are very concerned for funding of higher education... Rather than finding ways to fund education at a level that will provide for the needed services, legislators, their staff personnel, and state agencies are looking for ways to reduce services to fit within available resources, regardless of the number of citizens to be served" (023).

Theme four: Legislative concern for state-level budgetary efficiency. A fourth issue raised by the survey participants was the legislative attempt to link state-level budgetary efficiency to increased local accountability. This tendency is most often expressed in terms of increased productivity (i.e., concern about faculty workloads or office hours) or decreased access (i.e., limitations on remedial courses or degree requirements). The most general observation in this area concluded that "the legislature tends to micromanage all agencies when revenues are limited" (023). One respondent 
suggested that "the most pressing issue in all areas is removing the Florida legislature from the micromanagement of education" (138). Another respondent used the image of a car driven by remote control to express frustration with the current environment: "The legislature is dictating goals and procedures to institutions in higher education. The squeeze is on ... higher education administrators and faculty are not in the position to manage outcomes and results. The legislature is micro-managing without benefit of knowledge or expertise. Its similar to an automobile being driven by remote control on a busy highway when the driver is without a license" (075).

Theme five: Legislative attempts to define quality and supervise academic program development for higher education. The final theme is a concern that the legislative drive for budgetary efficiency will begin to impact the curricular areas that are the heart and soul of the academy. The state legislature has already limited the number and type of higher education institutions it will support ("Structure," 1990). It reinforces this system through its use of the Articulation Coordinating Committee and the contracting of certain programs to the state's private institution (Laws of Florida, Chapter 95-242). A higher education administrator observed that the "attempt by legislative staff and some legislators to 'standardize' and centralize higher education" (078) is a major concern at the institutional level. Another respondent concluded "in governance area, the legislature is increasingly intrusive in curricular issues. We are headed toward homogeneity which will 
result in mediocrity in the State University System especially as they are forced to common curricula" (034).

\section{Institutional Affiliation and Particular Concerns}

Private Universities and Colleges. Thirty-three respondents from Florida's private universities and colleges provided written comments in the section. While their comments shared many of the concerns of the other subgroups, two issues emerged that were unique to this subgroup. The first was a sense that private universities and colleges are not actively included in the policy formation process at the state level. This observation is supported by Feller (1986) who reported that private institutions in Florida and in Pennsylvania in their evaluations of the State Environmental Management Program complained that they were "unfairly ignored in the formulating of public policies and the awarding of grants that have as a central objective the development of relationships between universities and state government" (p. 109). Section II of the present study also supports this observation. Lobbyists from private institutions were ranked lower than public institutions and non-education groups by all groups. In Section III, survey respondents did mention ICUF (Independent Colleges and Universities of Florida) but did not mention any particular individual from this group that could be considered a key policy maker.

The second concern that emerged from the comments of the administrators from the private institutions was that the current higher education climate may precipitate 
increased conflict between private and public institutions for the resources necessary to maintain institutional programs and improve quality. This concern was captured in several different observations. One official remarked that "competition from public institutions for private funds" was becoming an issue (108). In a similar vain, another observed:

"Increasing competition from public schools/ universities is eroding our ability to operate economically. State institutions should focus on providing access to those unable to pay for private education and to compete (by awarding higher levels of financial aid) for those who can pay" (069). One comment presented the best assessment of the current environment: "Recognition that there must be a reallocation of resources at the university level in order to regain credibility with the taxpayers and the legislators. Then and only then can we address the funding of the cost of a quality education which is so essential to our society if we are to prepare our children for the fiercely competitive future world" (046).

Community College System. Fifty-six of the 78 respondents from the community college system provided a variety of comments and observations. The most pressing issues in this set of comments was finance. One respondent remarked, "The most critical issue facing higher education today in Florida is funding. Education has for the past several years (since the inception of the lottery) received a smaller and smaller piece of the general state revenue. Higher education has suffered the most with community colleges receiving the largest decrease" (020). In addition to funding, the other concern that frequently 
surfaced in this set of comments was local control. One comment argued that "the legislature is imposing curriculum changes upon us -- not within [the legislature's] governance. Should be local decisions" (087). Another commented: "The focus on performance-based incentive funding and performance-based budgeting by the legislature is placing considerable pressure on community colleges to increase the number of graduates and placements" (077).

A similar cautious note was heard in two other comments. The first addressed "the centralization of decision making" (166) and the second was "assessment results are misinterpreted by non-educators" (103). One respondent was critical of the survey instrument: "There are 180,000 students enrolled in the state university system. There 750,000 student enrolled in the community college system. You didn't even include the Executive Director of the State Board of Community Colleges on your list in Part II although you did include the Board of Regents" (097). However, one of the most critical comments in the survey concerned the value of education in Florida: "A more general issue is the widespread contempt of education evidenced among Florida voters/taxpayers. They distrust and resent intellectual inquiry and refuse to pay for improvement of lives. The state is a poisonous atmosphere for education" (034).

State University System. Thirteen of the 27 respondents from the state university system offered comments and suggestions concerning higher education policy formation. The most balanced comment suggested: "Higher education must communicate, based on 
objective evidence; that we are about quality and can measure our effectiveness. The legislature and their staff perceive that too much energy is diverted toward 'self-serving' activities by faculty and staff -- particularly in the public sector" (083). This concern for effectiveness was echoed in another suggestion that "colleges/universities need to develop institutional effectiveness plans to ensure that students are receiving quality education services and that the professorate is committed to providing quality instruction using the latest technology as appropriate in the delivery of undergraduate education" (005). Another respondent warned: "The demand for accountability and productivity has begun and will intensify. As such, we, higher education, will be required to demonstrate to our clients (students) and tax payers (public institutions) that expenditures are justify in carrying out the academic mission. Consequences of not doing this will be reduced funding at a time few of us can afford it" (054).

Like the community college system, the issue of funding dominated the comments made by the state university personnel. One respondent warned: "State revenues will not meet state needs and commitments during the next 5 years. Program cuts appear inevitable" (119). A constant theme across the higher education personnel was the competition with other state services for state moneys was captured in the comment: "decrease in funding [for education] due to increase in funding for prisons" (065).

State Government and Accredited Lobbyists. Eleven of 44 respondents from the state government or accredited lobbyists offered comments. The two issues of 
productivity and remediation were unique to state governmental officials. One respondent observed: "With declining state revenues, providing access to qualified students will be difficult. Productivity of universities and students in using available resources (providing faculty, classroom sets, increasing student loads per term, improving student advising). Improving articulation among community colleges, public universities and private institutions" (002). Another expressed concern about "graduate and job acquisition as compared to graduation rate, retainability of information gathered in college and quality of the product and accountability for that product" (205).

Six respondents also expressed a similar concern about the need for "remediation" at the post secondary level. No respondent from the other subgroups in this study mentioned remediation as a problem within higher education. Comments about "productivity" from the other subgroups tended to focus on issues of quality. One respondent from this subgroup expressed similar frustration with the current unstable and unpredictable state-level environment: "The most pressing issue is full recognition of Tallahassee-based staff and conservative Senate leadership of the need to invest in postsecondary education to strengthen Florida's competitiveness in the world marketplace. Excess attention to efficiency and accountability is misplaced. Florida should be focusing on building capacity (access) and quality to prepare Floridians for the 21 st century" (170). 


\section{Summary}

Two hundred and nine surveys were returned or $72 \%$ of the 290 in the original list. Respondents were generous in completing the six sections of the survey that were divided between quantitative and qualitative type questions. One hundred and twenty-nine offered sufficient and complete data in Section II to create the model of a power and influence hierarchy. The three hypotheses and several research questions that guided this research centered on the recognition by Florida's higher education leaders of the presence of a power and influence hierarchy among those individuals or groups that attempt to influence higher education policy formation at the state level.

The higher education leaders do recognize a power and influence hierarchy among those who attempt to influence state level higher education policy formation. Of the eighteen groups selected for the survey there was no significant difference in perceptions for 14 groups. However, there were differences in the perception of influence based on institutional affiliation for four groups listed in Section II of the survey. The subgroups differed in their perceptions of the influence of key legislative staff consultants, all education interests groups combined, lobbyists from public institutions and student organizations. The similarities and differences in the perceptions of influence based on institutional affiliation can provide useful information on the emerging pattern of influence in higher education policy formation in Florida. Section III of the survey provided an open-ended question about key policy makers in Florida that provided additional insight and clarification to Section II's quantitative information. In addition to individuals who 
represented the groups listed in Section II, the respondents indicated that the Executive Director of the State Board of Community Colleges and the Chair of the Postsecondary Education Planning Committee and presidents of some local institutions had the ability to influence policy formation.

In addition to the material from Section II of the survey, respondents provided information that was used to construct a tentative profile of Florida's higher education leadership (Section I). This profile indicates that the leadership is dominated by white males who are between 40 and 59. Women and minorities have made inroads into all areas of higher education leadership but are still underrepresented in these positions. A surprise to this researcher was the similarity in political orientation based on institutional affiliation. With a small variation in respondents from the public university system, higher education leaders from state government and local institutions shared the same conservative to moderate political orientation.

Section IV of the survey was another open-ended question that asked the respondents to identify key documents that would give insight into higher education policy formation. While documents from eight different sources were mentioned, the impression that these documents provided little insight into policy formation surfaced in the written comments. This feeling was supported by the document analysis based on the originating source of the document. The most-often mentioned source (28 times) of referenced materials was from the Postsecondary Education Planning Commission. These materials were cited most often by community college leaders ( 18 of the 28 ). However, the power 
and influence hierarchy indicated that education research was considered an "often forgotten player" in higher education policy formation.

Sections V and VI of the survey asked quantitative (Section V) and qualitative (Section VI) questions about the emerging issues in higher education policy formation in Florida. The analysis of Section V's quantitative data indicated that the subgroups had the least amount of expertise in the area of quality and assessment. Only the academic vice presidents indicated a high level of expertise in this area.

Section VI's quantitative data proved to be a rich source of insights that continued to clarify the researcher's understanding of Florida's higher education policy formation. One hundred and thirty-seven respondents from the four subgroups provided written comments for this section. The original research plan to code the comments using Millet's (1987) four categories or Finifter et al.'s (1991) three categories was revised because of the number of respondents who answered the question and the richness of their responses.

Two patterns emerged from the comments. The first pattern showed some variation in concerns based on institutional affiliation. Private institutional leaders and state government officials raised unique concerns from their particular perspectives. In addition, five themes common to the four subgroups emerged from the data. These concerns recognition of the higher education leadership of the political nature of state-level policy formation, the role of consultative staff, the competition for state moneys, the legislative concern for state-level budgetary efficiency, and the legislative attempts to define quality and supervise academic program development for higher education. 


\section{DISCUSSION}

\section{Introduction}

The research for study was conducted as planned with a minor delay in the mailing schedule and the addition of Senator Kirkpatrick's letter of support to legislators and legislative staff at the time of the fourth mailing. Data analysis used quantitative and qualitative methods to organize and interpret the respondents' answers to the six sections of the survey. This discussion will be organized into three sections. In the first section, the response rate for the survey will be assessed. In the second section, the three hypotheses and seven research questions that guided this research will be discussed. In the last section, conclusions and implications for Florida's higher education environment and the politics of higher education research will be outlined.

The Response Rate

\section{Introduction}

Respondents were very generous in completing the surveys. Two hundred and nine of 290 surveys were returned for a response rate of $72 \%$. The researcher especially welcomed the seven additional letters of regret from individuals who declined to participate in the survey. Several other respondents wrote short notes supporting either the research effort or the timeliness of the topic. In addition, the respondents' written comments for the three open ended questions (Sections III, IV, VI) added to the quality and depth of the quantitative research (Sections I, II, V). 


\section{Response for Each Section of the Survey}

In Section I, respondents were asked to indicate their institutional role (Question

a) and institutional affiliation (Question b). The highest response rate by role was from legislative staff (166\%) where 6 staff members were included on the initial list but 10 legislative staff responded to the survey. This response may be an indication of the interest of legislative staff in the research. The presidents (87\%), academic vice presidents $(86 \%)$ and administrative vice presidents (83\%) also had high response rates. The members of the executive branch had a response rate of $50 \%$ and the legislators had a response rate of $39 \%$. The addition of Senator Kirkpatrick's letter of support in the last mailing may have increased the response rate from the legislators and legislative staff who received it. Nine of the 32 survey participants from these categories responded during the fourth mailing period. The poorest response rate based on role was from accredited lobbyists and journalists. Of the 39 who were sent surveys only $8(21 \%)$ responded. This response may be indicative of the fact that many accredited lobbyists represent several constituencies in Tallahassee and sometimes serve as lobbyists on a part-time basis.

The response rate based on institutional affiliation showed some variation. The community college system had the best response rate of $93 \%$. The state university system followed with a response rate of $93 \%$. The private universities and colleges had a similar response rate of $85 \%$. Only the state government officials and accredited lobbyists and journalists had a dissimilar response rate of $41 \%$. 
In Section II, 129 responses that contained no missing data were used to develop the TOTAL rank order and the power and influence hierarchy. Data from these responses was used to test two of the study's hypotheses. Data from the 209 cases was used to test the third hypothesis. The number of cases was sufficient for data analysis.

In Section III, 153 respondents (73.9\%) provided information concerning who they felt should be surveyed as a key policy maker. The individuals who were named specifically by the respondents were considered influential in state policy higher education by this researcher. Of the 153 respondents, 61 provided the names of specific individuals. While the positions or groups were also named in this section, the researcher used the information for supportive purposes.

In Section IV, 86 individuals (41.5\%) provided information concerning documents that would help in understanding the process of policy formation in Florida. Due to the fluid nature of Florida's political environment, content analysis of documents other than budgetary and general legislation related to higher education may provide limited information about policy formation activity.

The quantitative data from Section $V$ was not as informative as the written comments found in Section VI but it did reveal one important insight. Of the four areas mentioned, the two areas of access and choice, and quality and assessment were given the lowest means by all subgroups. With 193 responses for access and choice, the mean for this area was 4.95 . It was the lowest of the four means. With 188 responses for quality and assessment, the mean for this area was 5.00 and was very similar to the mean for 
access and choice. Only a review of the data based on professional role revealed that mean of the academic vice presidents in the area of quality and assessment was higher. With issues related to these two areas so critical to the current dialogue within higher education, the researcher had hoped that the higher education leaders would have had a greater level of expertise in these two areas.

In Section VI, 136 individuals (65.7\%) provided comments on the areas of finance, governance, access and choice, and quality and assessment. The comments from this final section also provided perceptions of the Florida political culture and the state's higher education "system."

\section{Summary}

While a total of 209 individuals returned surveys, not all sections of the survey and not all questions of a section were completed by each respondent. While the researcher can not be sure why a particular respondent chose to complete one question and ignored another, three observations can be made. First, survey participants may have felt that no additional information was needed or could be supplied for the open-ended questions of Sections III, IV, and VI and chose to leave the answer spaces blank. Second, respondents may have found the format for some questions in Sections I and II confusing. Finally, others may have had objections to the tone or content of a particular question.

Some conclusions might be drawn from the response rate to the survey.

Interest in the research topic appears to be the single most important factor in the response rate. This conclusion is supported by number of respondents (over $70 \%$ ) who indicated on 
their reply postcard that they wished a summary of the dissertation after it was defended. The other factor that appears to have influenced the response rate is the use of several mailings to increase the rate. The fourth mailing was critical in achieving a $72 \%$ response rate for the survey.

The three letters of introduction appear to have had little impact on the response rate. The postcard reminder used as the second mailing had little impact on the response rate (Cote, Grinnell \& Tompkins, 1986). A concern raised by the response rate is the lack of participation in the survey by state government officials and accredited lobbyists. While two legislators indicated their philosophies towards survey research, it would be interesting to know how other legislators view this kind of activity. An indication of the lack of regard for education research is the low ranking received in this study by education research organizations. Education research was perceived by this survey's participants to have little influence on higher education policy formation in Florida.

\section{Hypotheses and Research Questions}

\section{Hypothesis One}

The hypothesis stated that "there is at least one statistically significant difference among the various groups that seek to influence higher education policy." Correlated $t$ tests showed significant difference with three pairs of variables from the 18 variables that were included in the analysis. These pairs included: (a) the state legislature and Chancellor of the State University System, (b) the Board of Regents and the Governor, and (c) all the 
education interest groups and faculty organizations. The differences occurred between variables with high and low means in the TOTAL overall ranking. The state legislature, Chancellor, the Board of Regents and the Governor with means ranging from 5.89 to 4.78 were considered high means in the TOTAL overall ranking. All the education interest groups with a mean of 4.12 and faculty organization(s) with a mean of 3.58 were considered low means in the TOTAL overall ranking. The differences in these three pairs of variables and their placement in the overall ranking suggest that Florida's higher education leaders recognize various levels of influence between the various groups that attempt to influence higher education policy. While not all paired $t$-tests showed significant difference in the TOTAL overall ranking of the variables, at critical points in the ranking significant differences did occur. This pattern was consistent with Marshall et al.'s (1989) study that found not all differences were significant.

\section{Hypothesis Two}

The second hypothesis asserted that "there is at least one statistically significant difference between the clusters that form a power and influence hierarchy in the state-level context of higher education policy formation." Hierarchical cluster analysis allows any number of variables to be clustered into any number of predetermined clusters. The eighteen variables were clustered into five or six clusters in an effort to break the "insider circle" with its five variables. This break did not occur until the number of clusters was increased to seven. This procedure suggests that Florida's higher education leaders 
recognize a power and influence hierarchy that protects some groups' influence and filters other groups away from the policy formation process.

The means of variables assigned to a cluster by the hierarchical analysis were then combined to create a mean for the cluster. Correlated t-tests were then performed on the pairs of clusters of the power and influence hierarchy to determine if significant differences between clusters existed. The tests indicated that significant differences between clusters in the hierarchy occur at two critical points: (a) between the "insiders" and "near circle" and (b) between the "sometime players" and "often forgotten players." The significant differences occurred at important points in the power and influence hierarchy. Near the center of the hierarchy, there is a significant break between the influence of the board of regents as the last "insiders" and the governor as the first member

of the "near circle." At the outer limits of the circle, there is a significant break between the lobbyists for private institutions as the last group of the "sometime players" and faculty organization(s) as the first group of the "often forgotten players." Differences between the "near circle," the "far circle," and the "sometime players" of the hierarchy were not significant. This pattern of significance was consistent with Marshall et al.'s research (1989).

\section{Hypothesis Three}

The last hypothesis suggested "there is one statistically significant difference in the perceptions of power and influence of higher education leaders based on the institutional affiliation of the observer." An initial MANOVA determined that differences based on 
institutional affiliation did occur within the 18 variables of Section II of the survey. An analysis of variance was performed with each variable to determine which contained significant differences based on institutional affiliation. In addition, a post-hoc Tukey's HSD was conducted for each variable.

Of Section II's eighteen variables, five were shown to have differences based on institutional affiliation. These variables included: (a) key legislative staff consultants, (b) all education interests groups combined, (c) lobbyists for public institutions, (d) student organizations, and (e) federal mandates to the states. The differences most often occurred between state government officials and representatives from the public institutions.

The community college and state university personnel gave key legislative staff consultants higher means then either the state government officials or the representatives from private institutions. This difference may indicate that legislative staff consultants are perceived to have more influence on policy formation by the representatives from public institutions. This conclusion is supported by the comments found in Sections III, IV and VI of this survey. An important question emerged from the data in this analysis. What is the exact role of the legislative staff in the higher policy formation process?

Differences in perception between the community college personnel and state government officials were also reported for all education groups combined and lobbyists from public institutions. The state government officials reported a mean that suggests their perceptions of the impact of education groups on policy formation is greater than the 
perceptions of community college administrators. The data suggested one question. What role do the lobbyists from higher education play in policy formation?

Differences between community college, state university, and private institutions occurred with student organization(s) and federal mandates to the states. While student organization(s) were placed among the "often forgotten players" of the hierarchy, state university personnel perceived the impact of student organization(s) to be greater than community college representatives. In the area of federal mandates, community college administrators differed with state university representatives on the impact of these mandates, with community college representatives giving the variable a higher mean. Government officials gave the variable a lower mean than representatives from private institutions. In fact, government officials gave this variable the lowest mean of all subgroups. The analysis of the data suggested two questions. Why do leaders of local institutions perceive the impact of federal mandates to be so influential? Why do state government leaders feel that the impact of federal mandates is less?

\section{Research Question One}

Data from Section II of the survey was used to answer the question: "Do the higher education leaders agree on the presence of a power and influence hierarchy?" The data generated by the participants' answers to the survey's questions suggested that Florida's higher education policy leaders do agree on the presence of a power and influence hierarchy. While there are some differences in perceptions based on a 
respondent's institutional affiliation of the influence of particular groups, the differences raised interesting questions but do not appear to effect the model that has been generated by the data.

\section{Research Question Two}

Data from Section II of the survey was used to answer this question: "How do their perceptions differ based on institutional affiliation?" Differences in perception based on institutional affiliation touched four clusters of the power and influence hierarchy. For the "insiders," the means of the community colleges and state university personnel were significantly higher than the means of the state government officials and the private university personnel. In the "far circle," differences surfaced on the influence of federal policy mandates between personnel from the community colleges, government officials, and state university staff, and between private institutional administrators and state university personnel.

In the "sometime players" circle, variations occurred for lobbyists for public institutions and all education interests groups. State officials perceive lobbyists to be more influential than representatives from the community colleges. In the "often forgotten players" circle, government officials' mean was significantly higher than the mean from the respondents from the community colleges. 


\section{Research Question Three}

Data from Section II of the survey was used to answer this question: "Who are the policy elites that form the 'insiders' and 'near circle' of the power and influence hierarchy?" According to Marshall et al. (1989) groups that are clustered into the insiders and near circle of the power and influence hierarchy can be considered the policy elites in a particular policy subculture. They also suggested that elected or appointed state-level government officials occupy these circles in the K-12 policy subculture of the state capital

The data from the survey indicated that similar patterns can be found in the statelevel higher education policy subculture. The policy elites who comprise these two circles of the power and influence hierarchy are elected or appointed state government officials. The "insiders" included the leading members of legislative committees, consultative staff, the legislature, the Chancellor of the State University System, and the Board of Regents. The committees mentioned most often were Senate Ways \& Means, Higher Education and Education, and House Appropriations, Higher Education, and Education. The Governor and Commissioner of Education, who were placed in the "near circle" of the influence hierarchy, were not considered as influential in this area of policy formation.

With five groups listed as part of the "insiders," this cluster is very crowded.

This crowding and the inclusion of the Executive Director of the State Community College Board and the Chair of the Postsecondary Planning Commission in list of key policy makers in Section III may indicate the unstable conditions at the state level in academic governance. The Governor and the Commissioner of Education comprised the 
much smaller "near circle" of the power and influence hierarchy. Their roles may serve as a filter that distances the influence of other groups from state level policy formation. Gove's (1987) analysis of the governor's role in higher education and Marshall et al.'s (1989) study of influence suggest that the governor's interest in higher education policy can impact the policy formation process but only if a particular governor chooses to devote attention to this policy arena. While influence is centered in the state legislature, it appears that individuals such as the leading members of the legislature and key staff consultants appear to have more influence than the legislature as a whole.

\section{$\underline{\text { Research Question Four }}$}

The fourth question asked about the groups that are marginalized from the statelevel higher education policy formation process: "Who are the 'sometime players' and ‘forgotten players' in this model?" Lobbyists from public institutions, non-education interest groups, all education interest groups and lobbyists from private institutions comprised the "sometime players" circle of the hierarchy. According to Marshall et al. (1989), these groups are involved in the policy formation process but have little influence. Because many of the local institutions include their presidents as lobbyists, the data suggests that presidents have little impact on state-level higher education policy formation.

The last circle of the hierarchy is called the "often forgotten players." According to Marshall et. al (1989), groups that are placed in this circle rarely participate in the policy formation process and have little influence on it. Faculty organizations, direct referenda 
initiated by citizens, student organizations, education research organizations, and producers of education related products were placed in this circle in the data analysis based on the survey participants' responses to Section II. The placement of faculty and student organizations who represent two of the three traditional internal interests groups of the academy among the "often forgotten players" suggests that concerns about local institution autonomy and identity are not unfounded.

\section{Research Question Five}

Data from Section VI provided information to answer the research question: Do higher education leaders perceive that academic governance is shared in Florida's higher education policy formation? The overall ranking of the various groups and their placement in a power and influence hierarchy suggest that higher education policy formation at the state level filters away the input and concerns of the academy's three primary internal groups of administrators, faculty, and students. While the analysis of variance showed that state government officials, when compared to the community college personnel, perceive the influence of lobbyists from public institutions to be greater, the analysis does not suggest how the state government officials interact with these lobbyists from public institutions to create this influence. This slight variation in the influence pattern does not change the overall conclusion that the academy's traditional internal interests groups have little impact on higher education policy formation at the state level. 


\section{$\underline{\text { Research Question Six }}$}

Data from Section IV provided information to answer the research question:

"What reports or documents can provide insight into Florida's higher education policy formation?" While documents from seven different sources did emerge, the Postsecondary Education Planning Commission's work was mentioned most frequently (28 times). However 18 of the 28 respondents who mentioned this commission's work were from community college system, and no respondent from the university system mentioned this commission's work. While this information suggests that personnel from the community college system perceive the Postsecondary Education Planning Commission work to be important, the respondents' written comments from Section VI of the survey indicate that many of the projects recommended by the Commission have remained unfunded by the legislature.

A variety of state legislature reports (24 times) were mentioned by community college personnel and state government officials. These reports included a variety of mandated studies (Appendix E). While various state statutes are mentioned by survey respondents, Senate Bill 2330 (Laws of Florida, Chapter 95-242) is considered the most important document by this researcher. This statute contains the legislation that mandates the Articulation Committee to strengthen articulation in the state and Board of Regents and Community College Board to limit graduation requirements to 60 credits for an associates degree and 120 credits for a baccalaureate. Comments in Section VI of the survey reveal a very different perspective on this legislation. Comments from state 
government officials suggest that this legislation is part of a larger legislative commitment to accountability. Comments from state university and community college personnel indicate that this statute is an excellent example of the local institutional leaders' assertion that the legislature is attempting to micromanage higher education and to create a homogenized curriculum. Leaders from private institutions suggest that private higher education has limited participation in the legislative dialogue about higher education policy formation.

\section{Research Question Seven}

Data from Sections V and VI was used to answer the seventh research question. "How do the four subcultures perceive the various policy issues facing higher education in Florida?" Section $\mathrm{V}$ provided quantitative information on governance, finance, access and choice, and quality and assessment. Two conclusions are suggested by the information. Within the four subgroups, the respondents were more comfortable with the issues of governance and finance and least comfortable with the areas of access and choice and quality and assessment.

There was a slight variation is this pattern, vice presidents for academic affairs rating themselves more knowledgeable in the area of quality and assessment then other respondents. The relatively low levels of knowledge in the areas of quality and assessment can have important implications in the current environment. The number of state legislative initiatives based on a concern for quality and assessment takes on new meaning 
when the individuals responsible for this legislative activity indicate a relatively low level of understanding in this area.

The areas of finance and governance showed significant difference based on institutional affiliation. Private universities/ colleges appear to have little knowledge in the financial and governance issues facing public higher education in Florida. This situation may be the result of low impact that state financial commitments have on private education.

\section{Conclusions and Implications}

\section{The Florida Higher Education Environment}

The following broad generalizations might be drawn from the data collected in this study:

1. Higher education policy formation is an unstable political reality in Florida dominated by the legislature. This instability may be the result of the unstable tax base used by the state legislature to fund its educational, human services, and criminal justice activities. In addition, the continued growth of the state's population and its demand for higher education is exacerbating a tense situation.

2. In addition to the power and influence hierarchy created through analysis of the data from this study's survey, there appear to be two other "hierarchies" operating within 
the Florida's higher education political culture. The first hierarchy suggested by the study's information is that the Senate takes the lead in higher education and the House follows that lead. This conclusion is supported by the comments made by survey participants in Section III and Section IV.

The second hierarchy suggested by the data is found within the higher education institutions, with the state university system having the most influence, followed by the community college system and ending with the private institutions. This observation is supported by comments in Section VI of the survey and a review of the literature. Within this overall hierarchy, it also appears that the University of Florida, Florida State University, Florida A\&M, and the University of South Florida dominate the entire higher education culture. This observation is supported by comments made in Section III and Section VI of the survey.

3. Attempts to provide for a rational system of higher education within the state continue to suffer. The conflict (Mautz, 1982) and distrust (Augenblick et al., 1990) reported in earlier research continues to thwart the good intentions and personnel integrity of the individuals concerned for Florida and its institutions of higher education. This level of mistrust and miscommunication can only make future collaborative efforts which are so critical to higher education difficult or impossible. 
4. Two of the three traditional internal interests groups of the academy are perceived to be often forgotten players in the process. Faculty and student organizations were ranked among the lowest in relative influence by the survey participants. Even the third of the internal interest groups, the administrators, were seen as "sometime players" in the process who must compete with non-education interests groups for input into higher education policy decisions.

5. Several respondents commented on negative public perceptions of higher education. The solution that higher education leaders spend more time with the general public is problematic. The legislature protects its prerogatives. The Board of Regents' attempt to gain constitutional status in the early 1980 s was defeated in referendum. The legislature responded to the initiative by creating the Postsecondary Education Planning Commission and strengthening each local institution's board of trustees. More recently, Dr. Lombardi's attempts to raise issues of the state funding of higher education in the public forum of the press received sharp criticism from members of the legislature and the Board of Regents (Negron, 1995).

6. While all the respondents were concerned that the current and anticipated growth in higher education are outstripping the state's current financial arrangements, the legislative solution of less financial support but more accountability and efficiency was not shared by the higher education professionals. This division between higher education 
professionals and state government officials is unfortunate because the expertise of the both groups is needed to provide an adequate higher education system for the state's citizens.

\section{Politics of Higher Education Research}

This study began with the conviction that to identify and study the patterns of power and influence among higher education leaders at the state level was important. Mortimer and McConnell's (1978) concept of academic governance with its four variables provided a suitable conceptual framework for this study:

1. The "what" of higher education policy formation at the state level is unstable with little agreement among the various policy actors. While the traditional state concern for budgetary efficiency dominated the comments, the new concerns about quality, diversity, assessment and linking economic development and higher education also surfaced. The comments revealed little agreement or consensus on these areas.

2. The "who" of higher education policy formation at the state level came into sharper focus. The state level is dominated by the state legislature, its staff, and appointed boards and commissions. While local institutional leaders must adjust to the regulatory and budgetary decisions of the legislature, there is little indication that they have real participation in the policy formation process that creates these expectations. 
3. The "how" of higher education policy formation was not the direct focus of this research, but the information gathered from the surveys indicates that a clear and careful investigation of the process of policy formation is needed. A study of the origin and legislative process that lead to the creation of SB 2330 and its eventual passage by the legislature may be most helpful.

Marshall et al.'s (1989) concepts of assumptive worlds and power and influence hierarchy are important research tools in investigating the political culture of higher education:

1. The concept of the power and influence hierarchy provided a way to capture the fluid quality of political influence at a particular moment. It helped to identify not only policy elites but also the marginalized policy actors.

2. Survey participant responses provided information to construct a profile of higher education leadership in Florida.

3. Survey participant responses provided information about key policy makers, important documents and emerging issues in Florida higher education. 
4. The survey's response rate suggests that a multi-state study of perceptions of influence might be undertaken to determine patterns of influence within higher education.

5. The survey provided a tentative list of names of individuals who might be considered the policy elites among higher education and state governmental leaders in Florida. It also provided information that could be used to construct an interview protocol to investigate the operational code of the policy elites.

6. The survey's results suggest that a study of how the higher education lobby is organized in Florida and how to make it more effective might be helpful.

\section{Summary}

As a researcher, I was especially grateful that so many respondents took the time to provide candid assessments of Florida's higher education policy formation process. Two individuals signed their surveys and one of them asked that I call when I was ready to continue my research. The tone of the responses was one of profound concern for the quality of higher education in Florida and an intense desire to provide the best education to Florida's citizens.

Three hypotheses and seven research questions directed this research on the power and influence structures and emerging issues in state-level higher education policy formation. It was proposed that there would be a significant difference in at least one of 
the 19 variables listed on the survey. Of the policy groups that were used for the analysis, significant differences were shown by correlated t-tests on the individual variables pairwise from highest to lowest means for five of the 18 variables. Significant differences were shown by correlated t-tests on the five clusters of the power and influence hierarchy for two of the five clusters. Finally, variations in the perceptions of the four subgroups were analyzed using an analysis of variance for each variable and Tukey's HSD to determine if there were differences in perceptions of influence based on institutional affiliation. These tests showed significant variance according to institutional affiliation for five of the eighteen variables.

The seven research questions provided the researcher with the opportunity to probe more deeply into the perceptions of power and influence in state level higher education policy formation. Guided by these questions, the researcher was able to determine that not only the policy elites but also the higher education leaders perceive a power and influence hierarchy in state level higher education policy formation. Their perceptions did differ on relative influence of key legislative consultative staff, the value of lobbyists from all education interests groups and public institutions, the role of student organizations, and the impact of federal mandates on state policy. The power and influence hierarchy suggested that faculty and student organizations and education research have limited to little impact on policy formation at the state level.

The low ranking and common agreement on the value of education research calls into question the value of any report or mandated study, especially the work of the 
Postsecondary Education Planning Commission and the numerous master and five year plans produced by local institutions and the state-wide coordinating bodies. The clusters of the power and influence hierarchy and the written comments by the survey participants suggest that the unstable and unpredictable atmosphere of state-level higher policy formation is a highly political environment where any attempt at rational planning will be frustrated. While Florida's higher education policy leaders share many of the same concerns, they have been unable to establish the trust and communication necessary to find common solutions.

Mortimer and McConnell's (1978) concept of academic governance as a multifaceted process with various constituencies and issues but four common variables proved useful in grounding this study. Marshall et al.'s (1989) assumptive worlds concept with its model of a power and hierarchy proved was useful in capturing a snap shot of the relative power and influence of those individuals and groups who attempt to influence higher education policy at the state level. While not included in their original work, Marshall et al.'s (1989) concept of a power and influence hierarchy can provide information to support a critical analysis of the relative influence of various groups, especially the marginalized. 


\section{REFERENCES}

Ah Nee-Benhan, M. K. (1993). Political and cultural determinants of educational policymaking: Their effects on native Hawaiians. (Doctoral Dissertation, University of Hawaii, 1993). [CD-ROM]. Abstract from: ProQuest File: Dissertation Abstracts Item: ACC 9325013

Almanac Issue. (1995). The Chronicle of Higher Education, XLII(1).

Alpert, D. (1985). Performance and paralysis: The organizational context of the American research university. Journal of Higher Education, 56(3), 241-281.

Altbach, P. G. \& Berdahl, R. O. (Eds.). (1987). Higher education in American society (Rev. ed.). Buffalo, NY: Prometheus Books.

Aper, J. \& Hinkle, D. (1991). State policies for assessing student outcomes: A case study with implications for state and institutional authorities. Journal of Higher Education, 62(5), 539-555.

Aspen Institute. (1992). American higher education: purposes, problems and public perceptions. Queenstown, MD: Author.

Atkinson, A. J. (1995). A cultural analysis of values and education policymaking: A case study of Virginia, 1990-1994. (Doctoral dissertation, Virginia Commonwealth University, 1995). [CD-ROM]. Abstract from: ProQuest File: Dissertation Abstracts Item: ACC 9535043

Augenblick, Van De Water \& Associates. (1990). An examination of the overall structure for the delivery of public postsecondary education in Florida. In Florida State Postsecondary Education Commission, The structure of public postsecondary education in 
Florida: Report and recommendations of the Postsecondary Education Planning

Commission, 1990 (Appendix A). Tallahassee, FL: Florida Postsecondary Education

Planning Commission. (ERIC Document Reproduction Service ED 318 520)

Austin, A. (1990, Winter). Faculty culture, faculty values. New Directions in Institutional Research, 68, 61-74.

Banta, T. W. \& Fisher, H. S. (1990). An international perspective on assessing baccalaureate program outcomes. Evaluation Practice, 11(3), 167-175.

Benjamin, R. (1993). The redesign of governance in higher education. Santa Monica, CA: Rand Corp. (ERIC Document Reproduction Service No. ED 363 210)

Berdahl, R. O. \& Studds, S. M. (1990). The selective enhancement of quality education: The tension between excellence and equity. In R. O. Berdahl \& B. A. Holland (Eds.), Developing state fiscal incentives to improve higher education (pp. 13-34). College Park, MD: National Center for Postsecondary Governance and Finance.

Bok, D. (1992, July/ August). Reclaiming the public trust. Change, 13-19.

Breneman, D. W. \& Finn, C. E., Jr. (Eds.). (1978). Public policy and private higher education. Washington, DC: The Brookings Institution.

Brofenbrenner, U. \& Hamilton, S. F. (1978). School effectiveness in ecological perspective. (ERIC Reproduction Document Service No. ED 182 371)

Buchbinder, H. (1993). The market oriented university and the changing role of knowledge. Higher Education, 26(3), 331-347. 
Burrell, G. \& Morgan, G. (1988). Sociological paradigms and organizational analysis: Elements of the sociology of corporate life. Portsmouth, NH: Heinemann Educational Books, Inc.

Cameron, K. S. \& Tschirhart, M. (1992). Postindustiral environments and organizational effectiveness in colleges and universities. Journal of Higher Education, $\underline{63}(1), 87-108$.

Capper, C. A. (1992). Mulitparadigm perspectives of administration: Informing theory and practice. San Francisco, CA: Annual Meeting of the American Education Research Association, April 20-24, 1994. (ERIC Document Reproduction Service No. ED 346565$)$

Carnegie Foundation for the Advancement of Teaching (1988, March/ April). Public support of private colleges. Change, 35-40.

Carson, R. J. (1992). Perceptions of educational and political leaders of the creation of a state-operated school district in New Jersey. (Doctoral dissertation, Temple University, 1992). [CD-ROM]. Abstract from: ProQuest File: Dissertation Abstracts Item: ACC 9134928

Challenges, realities, strategies: The master plan for Florida postsecondary education for the 21st century. (1993). Tallahassee, FL: Florida State Postsecondary Education Planning Commission. (ERIC Document Reproduction Service ED 370 470)

Cherryholmes, C. H. (1988). Power and criticism: Poststructural investigations in education. New York: Teachers College Press. 
Clark, B. R. (1987). The insulated Americans: Five lessons from abroad. In P. G.

Altbach \& R. O. Berdahl (Eds.), Higher education in American society (Rev. ed., pp. 315326). Buffalo, New York: Prometheus Books.

Clegg, S. (1994). Power, narrative and democracy in social theory. Sydney, Australia: Annual Meeting of the International Communication Association, July 11-15, 1994. (ERIC Document Reproduction Service No ED 374 473)

Cobb, C. \& Edmonds, R. (1995, September). A system at risk. Florida Trends, $60-64$.

Conrad, C. F. \& Blackburn, R. T. (1985). Program quality in higher education: A review and critique of the literature and research. In J. C. Smart (Ed.), Higher education: Handbook of theory and research, Vol. 1 (pp. 283-308). New York: Agathon Press, Inc.

Corey, D., Jackson, D., \& Pritchard, B. (1983). What's on the horizon? Trends impacting higher education. Warren, MI: Macomb County Community College. (ERIC Document Reproduction Service No. ED 231 270)

Cote, L., Grinnel, R., \& Tompkins, L. (1986). Increasing response rates to mail surveys: The impact of adherence to Dillman-like procedures and techniques. The Review of Higher Education, 9(2), 229-242.

Davies, G. K. (1991). The influence of public policy on the quality of higher education. In D. H. Finifter, R. G. Baldwin, \& J. R. Thelin (Eds.), The uneasy public triangle in higher education: Quality, diversity and budgetary efficiency (pp. 37-44). New York: Macmillan Publishing Company. 
Doyle, D. P. (1991). Higher education quality: The eye of the beholder. In D. H.

Finifter, R. G. Baldwin, \& J. R. Thelin (Eds.), The uneasy public triangle in higher education: Quality, diversity and budgetary efficiency (pp. 54-62). New York: Macmillan Publishing Company.

Dye, T. R. (1991). Public policy in Florida: Education and welfare. In R. J. Huckshorn, Government and politics in Florida (284-303). Gainesville, FL: University Presses of Florida.

Dye, T. R. (1995). Politics in the sunshine state. Englewood Cliffs, NJ: Prentice Hall.

Easton, D. (1965). A systems analysis of public life. Chicago, IL: University of Chicago Press.

Eddy, E. (1985, Summer). Theory, research, and application in educational anthropology. Anthropology and Educational Quarterly, 16, 83-104.

El-Khawas, E. (1995). Campus trends 1995. Washington, DC: American Council on Education.

Englert, R. M. (1986). Higher education's evaluation politics. In S. Gove \& T. Stauffer (Eds.), Policy controversies in higher education (pp. 100-124). New York: Greenwoood Press.

Etzioni, A. (1964). Modern organizations. Englewood Cliffs, NJ: Prentice-Hall. Eulau, H. \& Quinley, H. (1987). Legislators and academicians. In L. E. Goodall (Ed.), When colleges lobby states: The higher education/ state government connection. 
(Rev. ed., pp. 88-99). Washington, DC: American Association of State Colleges and Universities.

Ewell, P. (1990). State policy on assessment: The linkage to learning. Denver, CO: Education Commission of the States. (ERIC Document Reproduction Service ED $333800)$.

Feller, I. (1986). Universities and state governments: A study in policy analysis. New York: Praeger.

Ferris, J. M. (1991). Contracting and higher education. Journal of Higher Education, 62(1), 1-24.

Fetterman, D. (1987). Ethnographic auditing: A new approach to evaluating management in higher education. Washington, DC: Annual Meeting of the American Educational Research Association, April 20-24, 1987. (ERIC Document Reproduction Service ED 283 839).

Finifter, D., Baldwin, R., \& Thelin, J. R. (Eds.). (1991). The uneasy public policy triangle in higher education: Quality, diversity and budgetary efficiency. New York: Macmillan Publishing Company.

Fischer, F. J. (1990, January/ February). State financing of higher education: A new look at an old problem. Change, 42-56.

Fisher, L. A. (1988). State legislatures and the autonomy of colleges and universities: A comparative study of legislation in four states, 1900-1979. Journal of Higher Education, 59(2), 133-162. 
Floyd, C. E. (1985). Faculty participation in decision making: Necessity or luxury?

(ASHE-ERIC Higher Education Report No. 8). Washington, DC: Association for the Study of Higher Education. (ERIC Document Reproduction Service No. ED 267 694)

Fonte, R. (1989). Financial governance patterns among two year

colleges. Atlanta, GA: Annual Meeting of the Association for the Study of Higher Education, November 2-5, 1989. (ERIC Document Reproduction Service No. ED 313 990)

Foster, W. (1986). Paradigms and promises. Buffalo, NY: Prometheus Books.

Foster, W. (1991) A model of agency for postgraduate education. In W. G.

Tierney (Ed.), Culture and ideology in higher education: advancing a critical agenda (pp. 107-128). New York: Praeger Publishers.

Freeman, C. E. (1992). Missouri and Oklahoma: A comparative study of state higher education policy and political culture. San Francisco, CA: Annual Meeting of the American Education Research Association, April 20-24, 1992. (ERIC Document Reproduction Service No. ED 347 888)

Gardner, J. W., Atwell, R. H., \& Berdahl, R. O. (Eds.). (1985). Cooperation and conflict: The public and private sectors in higher education. Washington, DC: Association of Governing Boards of Universities and Colleges.

George, J. (1992). Policy formation of the Commonwealth of Pennsylvania's special education regulations and standards: A case analysis. (Doctoral dissertation, University of Pittsburgh, 1992). [CD-ROM]. Abstract from: ProQuest File: Dissertation Abstracts Item: ACC 9209391 
Gilley, J. W. (1991). Thinking about American higher education: The 1990s and beyond. New York: Macmillan Publishing Company.

Ginsburg, A. L. \& McLaughlin, M. A. (1991). Improving minority postsecondary outcomes: The need for a comprehensive approach. In D. H. Finifter, R. G. Baldwin, \& J. R. Thelin (Eds.), The uneasy public triangle in higher education: Quality, diversity and budgetary efficiency (pp. 91-108). New York: Macmillan Publishing Company.

Gioia, D. A. \& Pitre, E. (1990). Multiparadigm perspectives on theory building. Academy of Management Review, 15(4), 584-602.

Gomez, A. S. (1982). Legislative influence on curriculum: A case study of the state of Florida's problems. Miami, FL: Miami-Dade Community College. [ERIC Document Reproduction Service No. ED 216756$]$

Goodall, L. E. (Ed.). (1987). When colleges lobby states: The higher education/ state government connection (Rev. ed.). Washington, DC: American Association of State Colleges and Universities.

Gove, S. K. (1987). Governors and higher education. In L. E. Goodall (Ed.). When colleges lobby states: The higher education/ state government connection, (Rev. ed., pp. 41-52). Washington, DC: American Association of State Colleges and Universities.

Gove, S. K. \& Floyd, C. E. (1975). Research on higher education administration and policy: An uneven report. Public Administration Review, 111-118.

Gove, S. K. \& Solomon, B. W. (1968). The politics of higher education: A bibliographic essay. Journal of Higher Education, 39(4), 181-195. 
Gove, S. K. \& Stauffer, T. M. (Eds.). (1986). Public controversies in higher education. New York: Greenwood Press.

Gove, S. K. \& Welch, S. (1987). The influence of state constitutional conventions on the future of higher education. In L. E. Goodall (Ed.), When colleges lobby states: The higher education/ state government connection (Rev. ed., pp. 5-15). Washington, DC: American Association of State Colleges and Universities.

Green, K. C. (1986). Government responsibility for quality and equality in higher education. In S. Gove \& T. Stauffer (Eds.), Policy controversies in higher education (pp. 87-99). New York: Greenwoood Press.

Greene, M. (1991). The demands of diversity: Implications for public policy. In D. H. Finifter, R. G. Baldwin, \& J. R. Thelin (Eds.), The uneasy public triangle in higher education: Quality, diversity and budgetary efficiency (pp. 26-32). New York: Macmillan Publishing Company.

Greer, D. G. (1986). Politics and higher education: The strategy of the state-level coordination and policy implementation. In S. Gove \& T. Stauffer (Eds.), Policy controversies in higher education (pp. 27-49). New York: Greenwoood Press.

Griffin, E. (1991). A first look at communication theory. New York: McGrawHill, Inc.

Gumport, P. (1993). The contested terrain of academic program reduction. Journal of Higher Education, 64(3), 283-311.

Gutmann, A. (1991). What counts as quality in higher education?. In D. H. Finifter, R. G. Baldwin, \& J. R. Thelin (Eds.), The uneasy public triangle in higher 
education: Quality, diversity and budgetary efficiency (pp. 45-53). New York: Macmillan Publishing Company.

Hartmark, L. S. \& Hines, E. R. (1986). Politics and policy in higher education: Reflections on the status of the field. In S. K. Gove \& T. M. Stauffer (Eds.), Public controversies in higher education (pp. 3-26). New York: Greenwood Press.

Harvey, J. (1994). First impressions and second thoughts: Public support for higher education. Washington, DC: American Council on Education.

Harvey, J. \& Immerwahr, J. (1995a). Goodwill and growing worry: Public perceptions of American higher education. Washington, DC: American Council on Education.

Harvey, J. \& Immerwahr, J. (1995b). The fragile coalition: Public support for higher education in the 1990s. Washington, DC: American Council on Education.

Hassard, J. (1991). Multiparadigms and organizational analysis: A case study. Organizational Studies, 12(2), 275-299.

Hines, E. R. \& Hartmark, L. S. (1980). Politics of Higher Education. Washington, DC: American Association for Higher Education.

Hook, S., Kurtz, P, \& Todorovich, M. (Eds.). (1978). The university and the state: What role for government in higher education? Buffalo, NY: Prometheus Books.

Johnson-Howard, D. K. (1991). School board member value shift and policy change: Consequences of community dissatisfaction. (Doctoral dissertation, Washington State University, 1990). [CD-ROM]. Abstract from: ProQuest File: Dissertation Abstracts Item: ACC 9116568 
Joint Legislative Management Committee (u.n.) Registered Legislative Lobbyists 1992-1994 Biennium. Tallahassee, FL: Legislative Information Division.

Jones, R. C., Oberst, B. S., \& Lewis, C. S. (1990, May/ June). Building U. S. economic competitiveness: The land-grant model. Change, 11-17.

Kaplin, W. A. (1989). The law of higher education: A comprehensive guide to legal implications of administrative decision making (2nd ed.). San Francisco, CA: JosseyBass Publishers.

Kaplin, W. A. \& Lee, B. A. (1990). The law of higher education 1985-1990 update. San Francisco, CA: National Association of College and University Attorneys.

Karelis, C. H. (1991). Price as a lever in higher education reform. In K. M. Borman, P. Swami, \& L. D. Wagstaff(Eds.), Contemporary issues in U.S. education (pp. 148-157). Norwood, NJ: Ablex Publishing Corporation.

Kean, T. K. (1991). Foreword. In D. H. Finifter, R. G. Baldwin, \& J. R. Thelin (Eds.), The uneasy public policy triangle in higher education: Quality, diversity, and budgetary efficiency (pp. vii-viii). New York: Macmillan Publishing Company.

Kerlin, S. P. \& Dunlap, D. M. (1993). For richer, for poorer: Faculty morale in periods of austerity and retrenchment. Journal of Higher Education, 64(3), 348-

Kerr, C. (1994). Troubled times for American higher education: the 1990s and beyond. Albany, NY: State University of New York Press.

Kimbrough, R., Alexander, K., \& Wattenbarger, J. (1984). Government and education. In M. Dauer (Ed.), Florida politics and government (2nd ed., pp. 422-447). Gainesville, FL: University Presses of Florida. 
Klebs, K. J. (1995). School board decision making: Factors and influences.

(Doctoral Dissertation, University of Illinois at Urbana-Champaign, 1994) [CD-ROM]. Abstract from: ProQuest File: Dissertation Abstracts Item: ACC 9512430

Langenberg, D. N. (1992). (R)evolution in American higher education. Chicago, IL: David Dodds Henry Lecture sponsored by Illinois University, December 4, 1992. (ERIC Document Reproduction Service No ED 362 111)

Laws of Florida, Volume 1, Part Three, Chapter 95-243. (1995).

Levin, H. M. (1991). Raising productivity in higher education. Journal of Higher Education, 62(3), 241-261.

Levy, D. C. (1986). Policy controversies in higher education finance: Comparative perspectives on the U.S. private-public debate. In S. Gove \& T. Stauffer (Eds.), Policy controversies in higher education (pp. 237-262). New York: Greenwoood Press.

Lincoln, Y. S. (Ed.). (1985). Organizational theory and practice. Beverly Hills, CA: SAGE Publications, Inc.

Lincoln, Y. S. (1991). Advancing a critical agenda. In W. G. Tierney (Ed.), Culture and ideology in higher education: advancing a critical agenda (pp. 17-34). New York: Praeger Publishers.

Lynn, Jr., L. (1987). Managing public policy. Boston: Little Brown, Company. Marshall, C., Mitchell, D., \& Wirt, F. (1985). Influence, power and policy making. Peabody Journal of Education, 62(4), 61-89.

Marshall, C., Mitchell, D., \& Wirt, F. (1986). The context of state-level policy formation. Educational Evaluation and Policy Analysis, 8(4), 347-378. 
Marshall, C., Mitchell, D., \& Wirt, F. (1989). Culture and education policy in the American states. Philadelphia, PA: The Falmer Press.

Martorana, S. V. \& Nespoli, L. A. (1986). Regionalism and institutional proximity in statewide planning: Coordination concepts and principles to counter chaos. In S. Gove \& T. Stauffer (Eds.), Policy controversies in higher education (pp. 50-66). New York, NY: Greenwoood Press.

Mautz, R. (1982). The power game: Governance of higher education in Florida. Tallahassee, FL: Florida State University Institute for Studies in Higher Education. (ERIC Document Reproduction Service No. ED 231 413)

McKinnon, J. D. (1995, July). Tallahassee report. Florida Trend, 22- 25.

Millett, J. (1987). State government. In P. Altbach \& R. Berdahl (Eds.), Higher education in American society (Rev. ed., pp. 183-205). Buffalo, NY: Prometheus Books.

Moos, M. \& Rourke, F. E. (1987). The state story: Administrative centralization. In L. E. Goodall (Ed.), When colleges lobby states: The higher education/ state government connection (Rev. ed., pp. 72-82). Washington, DC: American Association of State Colleges and Universities.

Morgan, A. W. (1992). The politics and policies of selective funding: The case of state-level quality incentives. The Review of Higher Education, 15(3), 289-306.

Morgan, A. W. \& Mitchell, B. L. (1985). The quest for excellence: underlying policy issues. In J. C. Smart (Ed.), Higher education: Handbook of theory and research, Vol. 1 (pp. 309-348). New York: Agathon Press, Inc. 
Mortimer, K. P. \& McConnell, T. R. (1978). Sharing authority effectively:

Participation, interaction, and discretion. San Francisco, CA: Jossey-Bass.

Munitz, B. \& Lawless, R. (1986). Resource allocation policies for the eighties. In S. Gove \& T. Stauffer (Eds.), Policy controversies in higher education (pp. 67-87). New York, NY: Greenwoood Press.

National Commission on Excellence in Education. (1983). A nation at risk: The imperative for educational reform. Washington, DC: U. S. Department of Education.

Negron, E. (1995, December 17). Lombardi case raises issue of university control. Sun-Sentinel, pp. 1F-2F.

1995 Know your legislators. (1995). Tallahassee, FL: Associated Industries of Florida Service Corporation.

Parker, M. \& McHugh, G. (1991). Five texts in search of an author: A response to John Hassard's 'multiple paradigms and organizational analysis.' Organizational Studies, 12(3), 451-456.

Parsons, M. (1992). Power and politics in higher education policy arena. Minneapolis, MN: Annual Meeting of the Association for the Study of Higher Education, October 29- November 3, 1992. (ERIC Document Reproduction Service ED 352 917)

Penny, S. (1986). Accreditation: issues for the eighties. In S. Gove \& T. Stauffer (Eds.), Policy controversies in higher education (pp. 125-136). New York: Greenwoood Press.

Popkewitz, T. S. (1984). Paradigm and ideology in education research: The social functions of the intellectual. Philadelphia, PA: The Falmer Press. 
Premfors, R. \& Wittrock, B. (1983). R\&D and public policy-making. R\&D for Higher Education, 1. Stockholm, Sweden: National Swedish Board of Universities and Colleges, Research and Development Unit. (ERIC Document Reproduction Service ED 232 515)

Rhoades, G. (1993). Retrenchment clauses in faculty union contracts: Faculty rights and administrative discretion. Journal of Higher Education, 64(3), 312-347.

Richardson, J. (1985). Do policy actors benefit from research of themselves? Peabody Journal of Education, 62(4), 116-118.

Robb, C. S. (1982, May/ June). A governor's view-higher education, the new federalism, and the states. Change, 38-42.

St. John, E. P. (1991). A framework for reexamining state resource-management strategies in higher education. Journal of Higher Education, 62(3), 263-287.

Satterlee, B. (1992). Program review and evaluation: A survey of contemporary literature. (ERIC Reproduction Document Service No. ED 356 261)

Schaeffer, W. (1990). Education without compromise: From chaos to coherence in higher education. San Francisco, CA: Jossey-Bass Inc., Publishers.

Schmitz, C. C. (1993). Assessing the validity of higher education indicators. Journal of Higher Education, 64(5), 503-521.

Sederburg, W. (1989, January/ February). A legislator looks at academe. Change, 31-38. 
Sergiovanni, T. J. \& Corbally, J. E. (Eds.). (1984). Leadership and organizational culture: New perspectives on administrative theory and practice. Chicago, IL: University of Illinois Press.

Shulman, C. H. (1972). State aid to private higher education. Washington, DC: American Association for Higher Education.

Simmons, H. L. (1986). The influence of accreditation on the development of traditionally black colleges in the middle states region. In S. Gove \& T. Stauffer (Eds.), Policy controversies in higher education (pp. 137-153). New York: Greenwoood Press.

Simsek, H. \& Louis K. (1994). Organizational change as paradigm shift. Journal of Higher Education, 65(6), 670-695.

Sirotnik, K. A. \& Oakes, J. (Eds.). (1986). Critical perspectives on the organization and improvement of schooling. Boston: Kluwer-Nijhoff Publishing.

Skolink, M. L. \& Jones, G. A. (1992). A comparative analysis of arrangements for state coordination of higher education in Canada and the United States. Journal of Higher Education, 63(2), 121-142.

Slaughter, S. (1988). Academic freedom and the state: Reflections on the uses of knowledge. Journal of Higher Education, 59(3), 241-261.

Slaughter, S. (1990). The Higher learning and high technology. Albany, NY: State University of New York Press.

Slaughter, S. (1993). Retrenchment in the 1990s: The politics of prestige and gender. Journal of Higher Education, 64(3), 250-282. 
Solmon, L. C. \& Zumeta, W. (1986). U. S. science manpower and r \& d capacity: New problems on the horizon. In S. Gove \& T. Stauffer (Eds.), Policy controversies in higher education (pp. 186-214). New York: Greenwoood Press.

Spears, J. D. (1989). State policy and rural access to adult education. (Doctoral Dissertation, Kansas State University, 1988). [CD-ROM]. Abstract from: ProQuest File: Dissertation Abstracts Item: ACC 8911098

Stout, R. T. (1985). Paradigms of state politics. Peabody Journal of Education, 62(4), 1-6.

The structure of public postsecondary education in Florida: Report and recommendations of the Postsecondary Education Planning Commission, 1990. (1990). Tallahassee, FL: Florida State Postsecondary Education Commission. (ERIC Document Reproduction Service ED 318 520)

Ten public policy issues for higher education in 1995. (1995). Washington, DC: Association of Governing Boards of Universities and College.

Tierney, W. G. (1988). Organizational culture in higher education. Journal of Higher Education 59(1), 2-21.

Tierney, W. G. (Ed.). (1990, Winter). Assessing Academic Climates and Cultures. New Directions in Institutional Research, 68.

Tierney, W. G. (1991a). Border crossings: Critical theory and the study of higher education. In W. G. Tierney (Ed.), Culture and ideology in higher education: advancing a critical agenda (pp. 3-16). New York: Praeger Publishers. 
Tierney, W. G. (Ed.). (1991b). Culture and ideology in higher education:

Advancing a critical agenda. New York: Praeger Publishers.

Tierney, W. G. (1992). An anthropological analysis of student participation in college. Journal of Higher Education, 63(6), 603-618.

U.S. Department of Education. (1995). 1995 Digest of Education Statistics. Washington, DC: National Center for Education Statistics. [On-Line]. Available: WWW URL: http://www.ed.gov/NCES/pubs/D95/dtab209.html

Volkwein, J. F. (1989). Changes in quality among public universities. Journal of Higher Education, 60(2), 136-151.

Webb, J. (1992). The process of 'powering down': The politics and culture of change. (Doctoral Dissertation, The University of North Carolina at Chapel Hill). [CDROM]. Abstract from: ProQuest File: Dissertation Abstracts Item: ACC 9235041

Weiler, H. N. (1986). "The hot and the cold wind of politics": Planning higher education in Africa. In S. Gove \& T. Stauffer (Eds.), Policy controversies in higher education (pp. 215-236). New York: Greenwoood Press.

White, A. E. (1990). Organizational structure and design in higher education: A literature review of organizational structures in higher education with a focus on the coexistence of academic and non-academic structures. (ERIC Document Reproduction Service No 319 354)

Whitson, L. J. \& Hubert, F. W. R. (1982). Interest groups and the department chairperson. Journal of Higher Education 53(2), 163-176. 
Wiedman, D. (1990). University accreditation: Academic subcultural and organizational responses to directed change. Studies in Third World Societies, 42, 227246.

Wiedman, D. (1992). Effects on academic culture of shifts from oral to written traditions: The case of university accreditation. Human Organization, 51(4), 398-407.

Wildavsky, A. (1987). Choosing preferences by constructing institutions: A cultural theory of preference formation. American Political Science Review, 81(1) 3-12.

Williams, R. L. (1991). The origins of federal support for higher education: George W. Atherton and the land-grant college movement. University Park, PA: The Pennsylvania State University Press.

Wilson, R. (1991). Barriers to diversity and the myth of equal access. In D. H. Finifter, R. G. Baldwin, \& J. R. Thelin (Eds.), The uneasy public triangle in higher education: Quality, diversity and budgetary efficiency (pp. 91-108). New York: Macmillan Publishing Company.

Wolfe, A.W. \& Jreisat, J. E. (1995, November). Opinion: Why Florida's governor...gets no respect. Change, $64-65$.

Yin, R. K. (1984). Case study research: Design and methods. Beverly Hills, CA: Sage Publications.

Young, K. (1977). 'Values' in the policy process. Policy and politics, 5, 1-22.

Zemsky, R. (1991). The goal of diversity: Access and choice in academia. In D. H. Finifter, R. G. Baldwin, \& J. R. Thelin (Eds.), The uneasy public triangle in higher 
education: Quality, diversity and budgetary efficiency (pp. 67-81). New York: Macmillan Publishing Company.

Zumeta, W. (1992). State policies and private higher education. Journal of Higher Education, 63(4), 363-417.

Zumeta, W. (1996). Meeting the demand for higher education without breaking the bank: A framework for the design of state higher education policies in an era of increasing demand. Journal of Higher Education, 67(4), 367-425. 


\section{APPENDIX A}

List of 290 Higher Education Leaders Sent Surveys

$\underline{\text { Private College and University Systems }}$

Barry University

Sr. Jeanne O'Laughlin, OP, PhD, President

Dr. J. Patrick Lee, Vice President for Academic Affairs

Mr. Timothy H. Czerniec, Vice President for Business Affairs

Bethune-Cookman College

Dr. Oswald P. Bronson, Sr., President

Dr. Anne Taylor, Vice President for Academic Affairs

Mr. Ernest C. Cook, Vice President for Fiscal Affairs

Clearwater Christian College

Dr. George D. Youstra, President

Dr. David D. Moore, Dean of Academic Affairs

Dr. James Munroe, Vice President of Administrative Affairs

Eckerd College

Dr. Peter H. Armacost, President

Dr. Lloyd W. Chapin, Vice President and Dean of Faculty

Mr. James A. Christison, Vice President for Finance

Edward Waters College

Dr. Jesse L. Burns, President

Dr. Leenette Penington, Vice President for Academic Affairs

Mr. Stanley Williams, Manager for Business and Finance

Embry-Riddle Aeronautical University

Dr. Steven M. Silwa, President

Dr. Ira D. Jacobson, Vice President, Academics

Mr. Robert A. Jost, Vice President for Administration

Flagler College

Dr. William L. Proctor, President

Dr. William T. Abare, Jr., Executive Vice President

Mr. K. S. Russom, Treasurer and Director for Business and Finance

Florida Institute of Technology

Dr. Lynn E. Weaver, President

Dr. Andrew W. Revay, Jr., Vice President for Academic Affairs 
Mr. Robert C. Bowie, Vice President for Financial Affairs and Treasurer

Florida Memorial College

Dr. Albert E. Smith, President

Dr. Karl Wright, Vice President for Academic Affairs

Mr. Willie Kemp, Acting Vice President for Business and Fiscal Affairs

Florida Southern College

Dr. Thomas L. Reuschling, President

Dr. Ben F. Wade, Vice President and Dean of the College

Mr. Brunner R. Hunt, Vice President for Finance \& Business Manager

Jacksonville University

Dr. James J. Brady,President

Dr. Jesse S. Robertson, Vice President for Academic Affairs

Mr. Jerry Goodman, Vice President for Operations

Lynn University

Mr. Donald E. Ross, President

Dr. Jennifer Braaten, Provost

Mr. Gerald Carvelle, Executive Vice President

Nova Southeastern University

Dr. Ovid C. Lewis, President

Dr. Elizabeth A. McDaniel, Vice President for Academic Affairs

Mr. Jeffrey Schneider, Vice President for Finance

Palm Beach Atlantic College

Dr. Paul R. Corts, President

Dr. E. Eugene Hall, Provost

Mr. Charles Harwell, Vice President of Finance

Ringling School of Art and Design

Pres. Arland F. Christ-Janer, President

Ms. Johnette L. Isham, Vice President for Academic Affairs

Mr. Donald L. Nolt, Vice President for Business Affairs

Rollins College

Dr. Rita Bornstein, President

Dr. Charles M. Edmondson, Vice President for Academic Affairs and Provost

Mr. Louis Morrell, Vice President for Finance and Treasurer 
St. Leo College

Msgr. Frank M. Mouch, President

Dr. Edwin J. Doran, Vice President for Academic Affairs

Mr. John Weicherding, Vice President for Business Affairs

St. Thomas University

Rev. Msgr. Franklyn M. Casale, Office of the President

Rev. Gary N. McCloskey, OSA, PhD, Vice President for Academic Affairs

Mr. Norman Blair, Vice President for Administration and Treasurer

Stetson University

Dr. H. Douglas Lee, President

Dr. Eugene S. Lubot, Provost

Ms. Ann Graham, Vice President for Business \& Finance

University of Miami

Dr. Edward T. Foote, II, President

Dr. Luis Glaser, Provost \& Executive Vice President

Mr. David A. Lieberman, Senior Vice President Business \& Finance

University of Tampa

Dr. Robert Vaughn, President

Dr. Thomas J. Hegarty, Provost

Mr. Clark Rogers, Vice President for Administrative Affairs

Warner Southern College

Dr. Gregory V. Hall, President

Dr. William Rigal, VP for Academic Affairs

Mr. Robert Hall, Vice President for Business Affairs

Webber College

Mr. Rex Yentes, President

Dr. Deborah M. Fuschetti, Dean of Academic Affairs

\section{Community College System}

Brevard Community College

Dr. Maxwell C. King, President

Dr. Adelbert J. Purga, Vice President for Academic Affairs

Mr. Stephen J. Megregian, Vice President for Business Affairs

Broward Community College

Dr. Willis N. Holcombe, President 
Dr. Jean E. Hunter, Vice President for Academic Affairs

Mr. Kirk Murray, Vice President for Human, Financial, and Information Resources

Central Florida Community College

Dr. William J. Campion, President

Mr. Richard Ray Kinsey, Vice President, Business Services

Chipola Junior College

Dr. Dale O'Daniel, President

Mr. Charlton Keen, Dean-Academic Affairs

Mr. Ron Ward, Dean-Admin. \& Business Services

Daytona Beach Community College

Dr. Philip R. Day, Jr., President

Dr. Norman Will, Vice President Academic Affairs

Dr. Chuck Mojock, Vice President, Administrative Affairs

Edison Community College

Dr. Kenneth P. Walker, President

Dr. James A. Slusher, Vice President, Operations

Dr. Robert R. Jones, Vice President, Management \& Budget

Florida Community College at Jacksonville

Dr. Charles C. Spence, President

Dr. Edgar C. Napier, Executive Vice President of College Operations

Mr. Jackson L. Spears, Vice President of Administrative and Business Services

Florida Keys Community College

Dr. William A. Seeker, President

Dr. Richard Parker, Vice President

Mr. E. Nelson Read, Dean, Administrative \& Business Services

Gulf Coast Community College

Dr. Robert L. McSpadden, President

Dr. Linda B. Adair, Vice President, Instructional Services

Mr. John W. Morris, Vice President, Business and Finance

Hillsborough Community College

Dr. Andreas A. Paloumpis, President

Dr. William Scheuerle, Acting Vice President Academic Affairs

Dr. Leo Diaz, Acting Vice President Administative Affairs

Indian River Community College

Dr. Edwin R. Massey, President 
Dr. John W. Muir, Vice President of Academic Affairs

Mr. Barry A. Keim, Vice President of Administration and Finance

Lake City Community College

Dr. Muriel Kay Heimer, President

Dr. Deborah Hecht, Vice President, Instruction

Mr. Homer Masingil, Vice President, Business Services

Lake-Sumter Community College

Dr. Robert W. Westrick, President

Dr. Sylvia Thomasson, Vice President Education Services

Dr. Kenneth Stack, Vice President Administrative Affairs

Manatee Community College

Dr. Stephen J. Korcheck, President

Dr. Roy H. Raines, Vice President of the College

Dr. Bobby J. Ballard, Vice President of Business Affairs

Miami-Dade Community College

Dr. Robert H. McCabe, President

Dr. Jon J. Alexiou, Vice President for Education

Dr. Robert J. Blood, Vice President for Business Affairs

North Florida Community College

Dr. William H. McCoy, President

Dr. John W. Maguire, Vice President/Academic Dean

Ms. Amelia A. Mulkey, Dean of Administrative Services

Okaloosa-Walton Community College

Dr. James R. Richburg, President

Dr. James A. Durham, Vice President Instructional Services

Mr. Jeffrey Schembera, Vice President for Administrative Services

Palm Beach Community College

Dr. Edward M. Eissey, President

Dr. Patricia Dyer, Vice President Academic Affairs

Dr. Tony Tate, Vice President Administrative \& Business Affairs

Pasco-Hernando Community College

Dr. Robert W. Judson, Jr., President

Dr. Paul J. Szuch, Provost/Dean of Instruction

Mr. John Harrison, Dean of Business Affairs

Pensacola Junior College 
Dr. Horace E. Hartsell, President

Dr. Charles Atwell, Exec. Vice President Academic Affairs

Dr. Randy Spiwat, Vice President of Business Affairs

Polk Community College

Dr. Maryly Vanleer Peck, President

Mr. William Swinford, Dean of Instruction

Mr. William Ryan, Dean of Institutional Advancement

St. Johns River Community College

Dr. Robert L. McLendon, Jr., President

Mr. Edward B. Wiley, Vice President Academic Affairs

Mr. William Kirkland, Vice President Business Affairs

St. Petersburg Junior College

Dr. Carl M. Kuttler, Jr., President

Dr. Robert Sullins, Vice President for Educational \& Student Services

Mr. Mac Cunningham, Vice President for Business Services

Santa Fe Community College

Dr. Lawrence W. Tyree, President

Dr. Patricia Grunder, Dean of Academic Affairs

Dr. Robert Myers, Vice President of Academic Affairs

Seminole Community College

Dr. Earl S. Weldon, President

Dr. James Sawyer, Executive Vice President

Mr. Andrew Vavreck, Vice President of Administration \& Finance

South Florida Community College

Dr. Catherine P. Cornelius, President

Dr. W. Aurbrey Gardner, Vice-President, Academic Affairs

Mr. Robert S. Austin, Jr., Vice-President, Business Affairs

Tallahassee Community College

Dr. T.K. Wetherell, President

Mr. William T. Hanna, Vice President Administrative Affairs

Ms. Debra Austin, Interim Vice President of Educational Services

Valencia Community College

Dr. Paul C. Gianni, Jr., President

Dr. W. Carolyn Allen, Provost of the East Campus

Dr. William Michael Hooks, Vice President Planning \& Educational Services

Mr. Jack C. Crawford, Vice President for Administrative Services 


\section{$\underline{\text { State University System }}$}

Florida A\&M University

Dr. Frederick S. Humpries, President

Dr. Richard A. Hogg, Sr., Vice President for Academic Affairs

Dr. Robert D. Carroll, Vice President for Administration

Florida Atlantic University

Dr. Anthony J. Catanese, President

Dr. Richard Osburn, Vice President Academic Affairs

Dr. Marie McDemmond, Vice President Administration \& Finance

Florida International University

Dr. Modesto A. Maidique, President

Dr. James A. Mau, Provost and Vice President

Dr. Leonard Rodriguez, Vice President for Business and Finance

Florida State University

Dr. Talbot D'Alemberte, President

Dr. Larry Able, Provost \& Vice President for Academic Affairs

Mr. John Canaghi, Vice President for Finance \& Admin. Affairs

Gulf Coast University

Dr. Roy Tarnaughan, President

Ms. Suzanne Richter, Vice President for Academic Affairs

Ms. Linda Bennion, Controller

University of Central Florida

Dr. John C. Hitt, President

Dr. Gary Whitehouse, Provost \& Vice President for Academic Affairs

Dr. John Bolte, Vice President for Admin. \& Finance

University of Florida

Dr. John V. Lombardi, President

Dr. Andrew Sorensen, Provost \& Vice President Academic Affairs

Mr. Gerald Schaffer, Vice President for Administrative Affairs

University of North Florida

Dr. Adam W. Herbert, Jr., President

Dr. Charles Galloway, Acting VP of Academic Affairs

Mr. Robert Fagin, Vice President Administration \& Finance 
University of South Florida

Dr. Betty Castor, President

Dr. Thomas J. Tighe, Provost \& Exec. VP of Admin. Affairs

Mr. Eric Walden, Controller

The University of West Florida

Dr. Morris L. Marx, President

Dr. Douglas Friedrich, Provost \& Vice President for Academic Affairs

Mr. John G. Martin, Vice President for Administrative Affairs

\section{$\underline{\text { State Government Officials }}$}

The Honorable Charles H. Bronson, Jr.

Senate Higher Education Committee

The Honorable Ginny Brown-Waite

Senate Ways \& Means Committee

The Honorable Mario Diaz-Balart

Senate Ways \& Means Committee

The Honorable Fred R. Dudley

Senate Ways \& Means Committee

The Honorable John H. Dyer

Senate Ways \& Means Committee

The Honorable John S. Grant

Senate Education Committee

The Honorable Katherine Harris

Senate Higher Education Committee

The Honorable Jim Horne

Senate Education Committee

The Honorable Kenneth C. Jenne

Senate Ways \& Means Committee

The Honorable Karen Johnson

Senate Education Committee 
The Honorable Daryl L. Jones

Senate Higher Education Committee

The Honorable George G. Kirkpatick, Jr.

Senate Higher Education Committee

The Honorable Jack Latvala

Senate Education Committee

The Honorable John McKay

Senate Education Committee

The Honorable Matthew J. Meadows

Senate Education Committee

The Honorable William G. Myers, MD

Senate Higher Education Committee

The Honorable Donald C. Sullivan, MD

Senate Education Committee

The Honorable William H. Turner

Senate Education Committee

The Honorable Charles Williams

Senate Ways \& Means Committee

Ms. Linda Harkie

Senate Education Committee

Mr. Mike O'Farrell

Senate Higher Education Committee

Mr. John Andrew Smith

Senate Ways \& Means Committee

The Honorable William F. Andrews

House Education Committee

The Honorable Keith J. Arnold

House Education Committee

The Honorable Annie Betancourt

House Higher Education Committee 
The Honorable F. Allen Boyd, Jr.

House Education Committee

The Honorable Rudolph Bradley

House Higher Education Committee

The Honorable Larcenia J. Bullard

House Education Committee

The Honorable Jerrold Burroughs

House Higher Education Committtee

The Honorable James Bush, III

House Education Committee

The Honorable Lisa Carlton

House Education Committee

The Honorable Cynthia Moore Chestnut

House Education Committee

The Honorable Faye B. Culp

Senate Education Committee

The Honorable Jim Davis

House Education Committee

The Honorable Willye F. Clayton Dennis

House Higher Education Committee

The Honorable Lori Edwards

House Appropriations Committee

The Honorable Josephus Eggelletion, Jr.

House Education Committee

The Honorable Mike Fasano

House Education Committee

The Honorable Mark G. Flanagan

House Higher Education Committee

The Honorable Rodolfo Garcia, Jr. 
House Appropriations Committee

The Honorable Greg Gay

House Higher Education Committee

The Honorable Addie L. Greene

House Higher Education Committee

The Honorable Sally A. Heyman

House Higher Education Committee

The Honorable Debbie Horan

House Education Committee

The Honorable Suzanne Jacobs

House Higher Education Committee

The Honorable James E. King, Jr.

House Appropriations Committee

The Honorable Ralph L. Livingston

House Higher Education Committee

The Honorable Evelyn J. Lynn

House Higher Education Committee

The Honorable Anne MacKenzie

House Higher Education Committee

The Honorable John Morroni

House Education Committee

The Honorable John C. Rayson

House Education Committee

The Honorable Buzz Ritchie

House Appropriations Committee

The Honorable Jorge Rodriguez-Chomat

House Higher Education Committee

The Honorable Debbie Wasserman Schultz

House Higher Education Committee 
The Honorable Jeff Stabins

House Education Committee

The Honorable Joe G. Tedder

House Education Committee

The Honorable John Thrasher

House Education Committee

The Honorable Jack N. Tobin

House Education Committee

The Honorable Allen Trovillion

House Higher Education Committee

The Honorable Majorie R. Turnbull

House Higher Education Committee

Ms. Cynthia Burt

House Education Committee

Ms. Linda Bradley-Long

House Higher Education Committee

Mr. David Coburn

House Appropriations Committee

Mr. Chuck Sanders

Acting Advisor on Education

The Honorable Lawton Chiles

Office of the Governor

Dr. Charles Reed

Chancellor

State University Systems of Florida

Mr. Clark Maxwell

Executive Director

Division of Community Colleges

Mr. Frank T. Brogan

Commissioner of Education 
Dr. Linda Owens

Post Secondary Education Director

\section{Accredited Lobbyists and Journalists}

Ms. Sharon Crow

Daytona Beach Community College

Mr. Don F. Lamonica

Gulf Coast Community College

Mr. Warren Johnson

Hillsborough Community College

Mr. Bernie Parrish

Indian River Community College

Mr. John C. Davis, Sr.

Lake City Community College

Ms. Muriel Kay Heimer

Lake City Community College

Mr. Robert "Duffy" Soto

Lake City Community College

Mr. Jack Abstein

Miami-Dade Community College

Mr. Claymore Schnitker

North Florida Junior College

Mr. Jeff Schembera

Okalossa-Walton Community College

Mr. Larry Bracken

Pensacola Junior College

Mr. Louis Kalivoda

Santa Fe Community College

Mr. Edwin A. Johnson

Seminole Community College 
Mr. Carl M. Kuttler, Jr.

St. Petersburg Junior College

Mr. Michael L. Richardson

St. Petersburg Junior College

Mr. William T. Hanna

Tallahassee Community College

Mr. Thomas M. Henkel

Valencia Community College

Mr. Jeffrey A. Moler

Valencia Community College

Mr. Eugene Stinson

Edward Waters College

Mr. Jim Davis

Florida A\&M University

Ms. Karen Moore

Florida International University

Dr. Stephen Sauls

Florida International University

Mr. Gene "Hal" Johnson

Nova Southeastern University

Mr. Thomas F. Panza

Nova Southeastern University

Mr. Joel H. Mullenix

Pensacola Christian College

Mr. Robert G. Kauzlarich

University of Miami

Mr. Russell H. Klenet

University of Miami/ School of Medicne

Mr. William D. Rubin 
University of Miami/ School of Medicne

Mr. Richard H. Sites

SGA-UWF Bldg 22/204

Mr. David S. Thompson

SGA-UWF Bldg 22/204

Ms. Mary Hanley

Adult and Community Educators, FL

Ms. Joan R. Humphries

American Association of University Professors

Mr. Daniel F. Moore

Association of Accredited Private Schools, FL

Mr. L. Frank Casey

Association of Community Colleges, FL

Mr. Howard G. Burke

Christian Colleges \& Schools, FL

Ms. Kristine L. Anderson

FTP-NEA

Mr. William L. Boyd

Independent Colleges and Unviersities of Florida

Ms. Kappie Spencer

American Association of Unviversity Women

Mr. Jack Wheat

The Florida Press Center 


\section{PERSONAL DATA}

Check appropriate box in category.

a. Role:
$\square$ University/College President
$\square$ University/College VP for Academic Affairs
$\square$ University/College VP for (Business) Administrative Affairs
$\square$ Executive Branch
$\square$ Legislator
$\square$ Legislative Staff
$\square$ Interest Group Representative

b. Institution Identification:
$\square$ Private University/College
$\square$ Florida Community College System
$\square$ State University System of Florida
$\square$ Other
c. Time in Present Position: $\quad 1-3$ yrs. $\square \quad 4-6$ yrs. $\square \quad 7-9$ yrs. $\square \quad 10$ yrs. $+\square$
$\begin{array}{llllll}\text { d. Age: } & \text { Under } 29 \square & 30-39 \square & 40-49 \square & 50-59 \square & 60-69\end{array} \quad 70+$

e. Gender: $F \square \mathrm{M} \square$

f. Ethnicity: White/NonHispanic $\square$ Hispanic $\square$ African-American $\square$ Black/Other $\square$ Asian-American $\square \quad$ Other (Please Specify)

g. Highest Degree Earned:

Bachelor/ Area (Please specify)
Masters/ Area (Please specify)
Doctorate/ Area (Please specify)

h. Do you possess one of the following?

Yes $\square$ No $\square$ Teacher Certification

Yes $\square$ No $\square$ Administrator's Certification

Yes $\square$ No $\square$ Law License

i. Family Income: Less than $\$ 49,000$ $\$ 50,000-\$ 65,000$

Greater than $\$ 65,000$

j. Political Orientation: Liberal

Moderate

Conservative $\square$

k. Political Party Affiliation: Democrat Republican Independent

Other (Please specify) 


\section{PERCEPTIONS OF INFLUENCE IN STATE-LEVEL POLICYFORMATION FOR HIGHER EDUCATION IN FLORIDA.}

Please circle a number from 1 to 7 to indicate the level of influence over higher education policy initiatives in Florida exercised by the following individuals or groups between 1989 and 1994:

Very Very

Low High

a. The Governor and the Executive Staff

1234567

b. The Chief State School Officer and Senior

Staff in the State Department of Education

1234567

c. The State Board of Regents

1234567

d. Chancellor of State University System

1234567

e. The State Legislature

1234567

1. Leading Members of Legislative Committees

1234567

2. Key Legislative Staff Consultants

1234567

f. All the Education Interests Groups

1234567

1. Faculty Organization(s)

1234567

2. Lobbyist from Independent Institutions

1234567

3. Lobbyist from Public Institutions

1234567

4. Student Organization(s)

1234567

g. Non-Educator Interest Groups (business leaders,

1234567

taxpayers groups, etc.)

h. Producers of Education Related Products

1234567

(textbook manufacturers, test producers, etc.)

i. Direct Referenda Initiated by Citizens

1234567

j. The Courts (State or Federal)

1234567

k. Federal Policy Mandates to the States

1234567

1. Education Research Organizations

1234567

m. Any Others:

1234567 
III. WHO ARE THE KEY POLICY-MAKERS IN FLORIDA HIGHER EDUCATION POLICY FORMATION THAT YOU FEEL I SHOULD SURVEY?

IV. ARE THERE ANY REPORTS OR OTHER DOCUMENTS YOU THINK WOULD BE HELPFUL TO ME IN GETTING A CLEARER PICTURE OF HIGHER EDUCATION POLICY FORMATION IN FLORIDA?

V. WHICH OF THE FOLLOWING AREAS OF POLICY FORMATION DO YOU FEEL THE MOST KNOWLEDGEABLE?

Least Most
a. Finance
1234567
b. Governance
1234567
c. Access \& Choice
1234567
d. Quality \& Assessment
1234567

VI. IN THE AREA YOU FEEL MOST KNOWLEDGEABLE, PLEASE COMMENT ON THE MOST PRESSING ISSUES IN THAT AREA? 


\section{Florida International University}

January 3, 1996

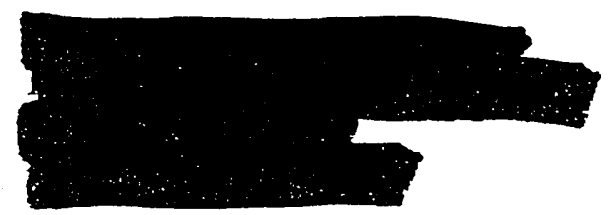

Dear

America's colleges and universities are today experiencing unprecedented change and challenge. In such an environment, it is essential that educational scholars and practitioners engage in the type of disciplined inquiry that will contribute to more effective policy formation and implementation.

At Florida International University, we encourage our doctoral students in Higher Education Administration to explore problems and issues related to postsecondary education at various levels. Edward Blackwell, a student in our doctoral program, has chosen as his dissertation topic the area of state-level policy formation and implementation.

His enclosed survey is an attempt to identify who are the individuals and groups who have influence over the direction of higher education policy in Florida. I ask that you take the time necessary to complete the survey. A special feature of Mr. Blackweil's survey method is his use of a separate return postcard with your name and address that guarantees you anonynuty while allowing him to keep a record of respondents. expertise.

Thank you for your participation in this study and for sharing with us your knowledge and

Sincerely,

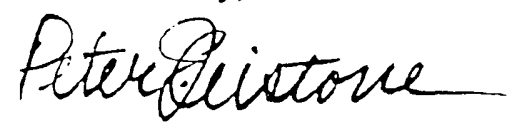

Peter J. Cistone, PhD

?rofessor

?JC/ams 
January 3, 1996

1

2 -

$3 \sim$

4 -

Dear 5 is not.

While all votes are equal in a democratic society, influence

If we are to better understand how policy formation and implementation take place, we need to investigate the varying degrees of influence that individuals and groups have in its formation. As a leader in higher education in Florida, I ask you to complete the enclosed survey.

The questionnaire is designed to help us better understand the individuals, groups and issues that are important in higher policy formation in florida. The survey is easy to follow and will take a Iimited amount of time to complete. To protect your anonymity, I have enclosed a separate postcard to be returned to a different address. In addition to the postcard and survey, I have enclosed a self-addressed, stamped envelope for the completed survey.

I look forward to your response and your assistance in helping us better understand who shapes state-level higher education policies in Florida.

Sincerely,

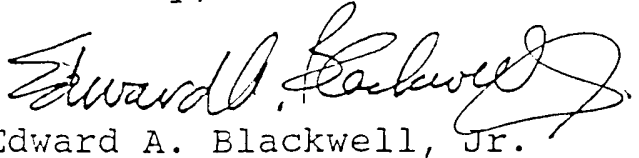

Edward A. Blackwell, Jr.

Director of Campus Ministry

EAB : ams

P.S. If you would like to receive a summary of the research, please be sure to check the "yes" line on the return postcard. 


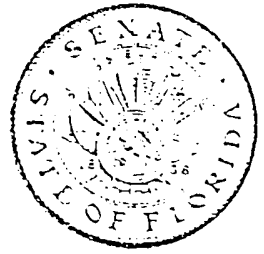

¿ENATOR GEORGE KIRKPATRICK

5 th District

EIEID (1)

\section{THE FLORIDA SENATE}

Tallahassee, Florida 32399-1100

$$
\text { January 1, } 1996
$$

COMMITTEES:

Higher Education,

Chairman

Ways and Means,

Sub. B (Education)

Rules and Calendar

Education

Community Affairs

JOINT COMMITTEE:

Advisory Council on Environmental Education Legislative Auditing

Recently, we all received a request to participate in a research study from peter J. Cistone,. Bh.D. His letter explained:

"Arierica's colleges and universities are today experiencing unprecedented change and challenge. In such an environment, it is essential that educational scholars and practitioners engage in the type of disciplined inquiry that will contribute to more effective policy formation and implementation.

Ft Florida International university, we encourage our doctoral students in Higher Education Administration to explore problem: and issues related to postsecondary education at various levels. Eciward Blackweli, a student in our doctoral program, has chosen as ris dissertation topic the area of state-level policy
formation and implementation."

Fecently, I had the opportunity to visit st. Thomas University as part of my tour of our state's private colleges and universities. During the visit, I had a delightful conversation with Eci Blackwell who is the doctoral student at F.I.U. The conversation focused on the purpose and meaning of higher education in Florida. I was impressed with his depth of knowiecige and passion for education.

I would like to invite you to complete the enclosed questicrnaire that is part of Ed's investigation of influence and policy formation in Florida. I have completed my copy of the 
Pôge 2.

survey and found that it is clear and straightforward with a place for personal comments about policy formation. Another feature of Ed's study is the separate return card that allows him to acknowledge your participation in the study and keep your responses completely confidential.

All of us are committed to the improvement of the quality of our state's postsecondary education system. Our ability to share our interest and concerns can help us improve the quality of our decisions and increase the effectivexhss of our efforts. Ed's study is part of that larger procesf and I encourage you to participate. I hope you will make/f special effort to complete the survey and return it as soon fo you have time.

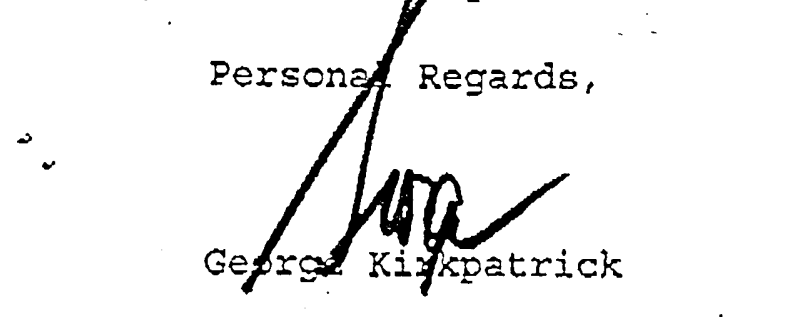

GGK:pas 
Dear Ed:

I have returned my answers to your survey in the self-addressed, stamped envelope that you provided.

Yes $\square \quad$ Please send me a summary of the research after you have defended your dissertation. 
APPENDIX C

Names of Key Policy Makers

by Respondents' Professional Role and Institutional Affiliation

with Number of Times Mentioned,

Policy Maker's Position in Florida Higher Education,

Ranking in TOTAL Rank Order and Cluster Location in Power and Influence Hierarchy

Presidents of Private Universities/ Colleges

\begin{tabular}{|c|c|c|c|c|}
\hline Key Policy Maker & $\begin{array}{l}\text { Times } \\
\text { Mentioned }\end{array}$ & Position & Rank & Cluster \\
\hline George Kirkpatrick & 3 & $\begin{array}{l}\text { Chair, Senate } \\
\text { Higher Education }\end{array}$ & 1 & INSIDER \\
\hline Mario Diaz-Balart & 1 & $\begin{array}{l}\text { Chair, House } \\
\text { Appropriations }\end{array}$ & 1 & INSIDER \\
\hline Debbie Wasserman Shultz & 1 & $\begin{array}{l}\text { Chair, House } \\
\text { Higher Education }\end{array}$ & 1 & INSIDER \\
\hline Ken Jenne & 1 & $\begin{array}{l}\text { VChair, Senate } \\
\text { Higher Education }\end{array}$ & 1 & INSIDER \\
\hline John Andrew Smith & 1 & $\begin{array}{l}\text { Staff, Senate } \\
\text { Ways \& Means }\end{array}$ & 2 & INSIDER \\
\hline Michael O'Farrell & 1 & $\begin{array}{l}\text { Staff, Senate } \\
\text { Higher Education }\end{array}$ & 2 & INSIDER \\
\hline Fred Dudley & 1 & Legislator & 3 & INSIDER \\
\hline J. Keith Arnold & 2 & Legislator & 3 & INSIDER \\
\hline Greg. A. Gay & 1 & Legislator & 3 & INSIDER \\
\hline Anne McKenzie & 1 & Legislator & 3 & INSIDER \\
\hline Buzz Ritchie & 1 & Legislator & 3 & INSIDER \\
\hline Peter Rudy Wallace & 1 & Legislator & 3 & INSIDER \\
\hline James Scott & 1 & Legislator & 3 & INSIDER \\
\hline Charles Reed & 2 & Chancellor,SUS & 4 & INSIDER \\
\hline William Proctor & 3 & Chair, PEPC & & \\
\hline
\end{tabular}


Academic Vice Presidents of Private Universities/Colleges

\begin{tabular}{|c|c|c|c|}
\hline Key Policy Maker & $\begin{array}{l}\text { Times } \\
\text { Mentioned }\end{array}$ & Position & Cluster \\
\hline T.K. Weatherall & 1 & $\begin{array}{l}\text { President, } \\
\text { Community College System }\end{array}$ & \\
\hline Betty Castor & 1 & $\begin{array}{l}\text { President, } \\
\text { State University System }\end{array}$ & \\
\hline
\end{tabular}

Presidents of the Community College System

\begin{tabular}{|c|c|c|c|c|}
\hline Key Policy Maker & $\begin{array}{l}\text { Times } \\
\text { Mentioned }\end{array}$ & Position & Rank & Cluster \\
\hline George Kirkpatrick & 4 & $\begin{array}{l}\text { Chair, Senate } \\
\text { Higher Education }\end{array}$ & 1 & INSIDER \\
\hline John Andrew Smith & 1 & $\begin{array}{l}\text { Staff Dir., Senate } \\
\text { Ways \& Means }\end{array}$ & 2 & INSIDER \\
\hline Edward Woodruff & 2 & $\begin{array}{l}\text { Staff, Senate } \\
\text { Ways \& Means }\end{array}$ & 2 & INSIDER \\
\hline Charles Reed & 3 & Chancellor, SUS & 4 & INSIDER \\
\hline William Proctor & 2 & Chair, PEPC & & \\
\hline Clark Maxwell & 5 & Director, SBCC & & \\
\hline John Lombardi & 1 & $\begin{array}{l}\text { President, } \\
\text { State University S }\end{array}$ & & \\
\hline
\end{tabular}

Academic Vice Presidents of the Community College System

\begin{tabular}{lllll}
\hline Key Policy Maker & $\begin{array}{l}\text { Times } \\
\text { Mentioned }\end{array}$ & Position & Rank & Cluster \\
\hline
\end{tabular}

\begin{tabular}{|c|c|c|c|c|}
\hline George Kirkpatrick & 4 & $\begin{array}{l}\text { Chair, Senate } \\
\text { Higher Education }\end{array}$ & 1 & INSIDER \\
\hline Mario Diaz Balart & 1 & $\begin{array}{l}\text { Chair, House } \\
\text { Appropriations }\end{array}$ & 1 & INSIDER \\
\hline Debbie Wasserman Schultz & 1 & $\begin{array}{l}\text { Chair, House } \\
\text { Higher Education }\end{array}$ & 1 & INSIDER \\
\hline John Andrew Smith & 2 & $\begin{array}{l}\text { Staff Dir., Senate } \\
\text { Ways \& Means }\end{array}$ & 2 & INSIDER \\
\hline
\end{tabular}




\begin{tabular}{|c|c|c|c|c|}
\hline Michael O'Farrell & 1 & $\begin{array}{l}\text { Staff Dir., Senate } \\
\text { Higher Education }\end{array}$ & 2 & INSIDER \\
\hline Edward Woodruff & 2 & $\begin{array}{l}\text { Staff, Senate } \\
\text { Ways \& Means }\end{array}$ & 3 & INSIDER \\
\hline Charles Reed & 3 & Chancellor, SUS & 4 & INSIDER \\
\hline James Tulley & 1 & Lobbyist/ Public & 8 & $\begin{array}{l}\text { SOMETIMES } \\
\text { PLAYER }\end{array}$ \\
\hline Frank Brogan & 2 & CSSO & 9 & $\begin{array}{l}\text { NEAR } \\
\text { CIRCLE }\end{array}$ \\
\hline Clark Maxwell & 2 & Director, SBCC & & \\
\hline
\end{tabular}

Administrative Vice Presidents of the Community College System

\begin{tabular}{|c|c|c|c|c|}
\hline Key Policy Maker & $\begin{array}{l}\text { Times } \\
\text { Mentioned }\end{array}$ & Position & Rank & Cluster \\
\hline George Kirkpatrick & 1 & $\begin{array}{l}\text { Chair, Senate } \\
\text { Higher Education }\end{array}$ & 1 & INSIDER \\
\hline Fred Dudley & 1 & Legislator & 3 & INSIDER \\
\hline Peter Rudy Wallace & 1 & Legislator & 3 & INSIDER \\
\hline Charles Reed & 2 & Chancellor, SUS & 4 & INSIDER \\
\hline William Proctor & 1 & Chair, PEPC & & \\
\hline Clark Maxwell & 2 & Director, SBCC & & \\
\hline Phil Day & 1 & $\begin{array}{l}\text { President, } \\
\text { Community Colle }\end{array}$ & stem & \\
\hline
\end{tabular}

Presidents of the State University System

\begin{tabular}{|c|c|c|c|c|}
\hline Key Policy Maker & $\begin{array}{l}\text { Times } \\
\text { Mentioned }\end{array}$ & Position & Rank & $\mathrm{Clu}$ \\
\hline George Kirkpatrick & 2 & $\begin{array}{l}\text { Chair, Senate } \\
\text { Higher Education }\end{array}$ & 1 & INSIDER \\
\hline John Andrew Smith & 1 & $\begin{array}{l}\text { Staff Dir., Senate } \\
\text { Ways \& Means }\end{array}$ & 2 & INSIDER \\
\hline Linda Collins & 1 & $\begin{array}{l}\text { Staff, Senate } \\
\text { Ways \& Means }\end{array}$ & 2 & INSIDER \\
\hline Ken Jenne & 1 & Legislator & 3 & INSIDER \\
\hline Charles Reed & 3 & Chancellor & 4 & INSIDER \\
\hline James Heekin, Jr. & 1 & Chair, Regents & 5 & INSIDER \\
\hline Jon Moyle & 1 & $\begin{array}{l}\text { Member, Regents } \\
226\end{array}$ & 5 & INSIDER \\
\hline
\end{tabular}


Academic Vice Presidents of the State University System

\begin{tabular}{lrlrl}
\hline Key Policy Maker & $\begin{array}{l}\text { Times } \\
\text { Mentioned }\end{array}$ & Position & Rank & Cluster \\
\hline George Kirkpatrick & 2 & $\begin{array}{l}\text { Chair, Senate } \\
\text { Higher Education }\end{array}$ & 1 & INSIDER \\
Charles Reed & 1 & Chancellor, SUS & 4 & INSIDER \\
James Heekin, Jr. & 1 & Chair, Regents & 5 & INSIDER \\
Jon Moyle & 1 & Member, Regents & 5 & INSIDER \\
\hline
\end{tabular}

Academic Vice Presidents of the State University System

\begin{tabular}{lrlll}
\hline Key Policy Maker & \multicolumn{1}{l}{$\begin{array}{l}\text { Times } \\
\text { Mentioned }\end{array}$} & Position & Rank & Cluster \\
\hline Mario Diaz Balart & 1 & $\begin{array}{l}\text { Chair, House } \\
\text { Appropriations } \\
\text { Staff Dir., Senate }\end{array}$ & 2 & INSIDER \\
John Andrew Smith & 2 & $\begin{array}{l}\text { Ways \& Means } \\
\text { Chancellor, SUS } \\
\text { Commissioner, } \\
\text { Education }\end{array}$ & 4 & INSIDER \\
Frank Brogan & 2 & 9 & NEAR \\
CIRCLE & $\begin{array}{l}\text { President, } \\
\text { State University System } \\
\text { Fredident, }\end{array}$ & \\
John Lombardi & 1 & State University System & \\
\hline
\end{tabular}

Members of the Executive Branch

\begin{tabular}{|c|c|c|c|c|}
\hline Key Policy Maker & $\begin{array}{l}\text { Times } \\
\text { Mentioned }\end{array}$ & Position & Rank & $\mathrm{Clu}$ \\
\hline George Kirkpatrick & 1 & $\begin{array}{l}\text { Chair, Senate } \\
\text { Higher Education }\end{array}$ & 1 & INSIDER \\
\hline Ken Jenne & 1 & Leading Member & 1 & INSIDER \\
\hline Daryl Jones & 1 & Leading Member & 1 & INSIDER \\
\hline
\end{tabular}




\begin{tabular}{|c|c|c|c|c|}
\hline Debbie Wasserman Schultz & 1 & $\begin{array}{l}\text { Chair, House } \\
\text { Higher Education }\end{array}$ & 1 & INSIDER \\
\hline John Andrew Smith & 1 & $\begin{array}{l}\text { Staff Dir., Senate } \\
\text { Ways \& Means }\end{array}$ & 2 & INSIDER \\
\hline Linda Collins & 1 & $\begin{array}{l}\text { Staff, Senate } \\
\text { Ways \& Means }\end{array}$ & 2 & INSIDER \\
\hline Edward Woodruff & 1 & $\begin{array}{l}\text { Staff, Senate } \\
\text { Ways \& Means }\end{array}$ & 2 & INSIDER \\
\hline Fred Dudley & 1 & Legislator & 3 & INSIDER \\
\hline J. Keith Arnold & 1 & Legislator & 3 & INSIDER \\
\hline
\end{tabular}

$\underline{\text { Legislators }}$

\begin{tabular}{|c|c|c|c|c|}
\hline Key Policy Maker & $\begin{array}{l}\text { Cimes } \\
\text { Mentioned }\end{array}$ & Position & Rank & Cluster \\
\hline George Kirkpatrick & 4 & $\begin{array}{l}\text { Chair, Senate } \\
\text { Higher Education }\end{array}$ & 1 & INSIDER \\
\hline Debbie Wasserman Shultz & 2 & $\begin{array}{l}\text { Chair, House } \\
\text { Higher Education }\end{array}$ & 1 & INSIDER \\
\hline Michael O'Farrell & 1 & $\begin{array}{l}\text { Staff Dir., Senate } \\
\text { Higher Education }\end{array}$ & 2 & INSIDER \\
\hline Greg A. Gay & 1 & Legislator & 3 & INSIDER \\
\hline Anne McKenzie & 1 & Legislator & 3 & INSIDER \\
\hline Danny Webster & 1 & Legislator & 3 & INSIDER \\
\hline Charles Reed & 2 & Chancellor, SUS & 4 & INSIDER \\
\hline Frank Brogan & 5 & $\begin{array}{l}\text { Commissioner, } \\
\text { Education }\end{array}$ & 9 & $\begin{array}{l}\text { NEAR } \\
\text { CIRCLE }\end{array}$ \\
\hline
\end{tabular}

$\underline{\text { Legislative Staff }}$

\begin{tabular}{lllll}
\hline Key Policy Maker & $\begin{array}{l}\text { Times } \\
\text { Mentioned }\end{array}$ & Position & Rank & Cluster \\
\hline
\end{tabular}

\begin{tabular}{|c|c|c|c|c|}
\hline George Kirkpatrick & 2 & $\begin{array}{l}\text { Chair, Senate } \\
\text { Higher Education }\end{array}$ & 1 & INSIDER \\
\hline Debbie Wasserman Shultz & 3 & $\begin{array}{l}\text { Chair, House } \\
\text { Higher Education }\end{array}$ & 1 & INSIDER \\
\hline Michael O'Farrell & 1 & $\begin{array}{l}\text { Staff Dir., Senate } \\
\text { Higher Education }\end{array}$ & 2 & INSIDER \\
\hline Fred Dudley & 1 & Legislator & 3 & INSIDER \\
\hline Anne McKenzie & 1 & $\begin{array}{l}\text { Legislator } \\
228\end{array}$ & 3 & INSIDER \\
\hline
\end{tabular}




\begin{tabular}{|c|c|c|c|c|}
\hline Cynthia Chestnut & 1 & Legislator & 3 & INSIDER \\
\hline J. Keith Arnold & 1 & Legislator & 3 & INSIDER \\
\hline Buzz Ritchie & 1 & Legislator & 3 & INSIDER \\
\hline Charles Reed & 3 & Chancellor & 4 & INSIDER \\
\hline T. K. Weatherall & 1 & $\begin{array}{l}\text { President, } \\
\text { Community }\end{array}$ & ystem & \\
\hline Betty Castor & 1 & $\begin{array}{l}\text { President, } \\
\text { State Univer }\end{array}$ & & \\
\hline John Lombardi & 2 & $\begin{array}{l}\text { President, } \\
\text { State Univer }\end{array}$ & & \\
\hline Sandy D'Alemberte & 1 & $\begin{array}{l}\text { President, } \\
\text { State Univer }\end{array}$ & & \\
\hline
\end{tabular}

Accredited Lobbyists and Journalists

\begin{tabular}{|c|c|c|c|c|}
\hline Key Policy Maker & $\begin{array}{l}\text { Times } \\
\text { Mentioned }\end{array}$ & Position & Rank & Cluster \\
\hline George Kirkpatrick & 1 & $\begin{array}{l}\text { Chair, Senate } \\
\text { Higher Education }\end{array}$ & 1 & INSIDER \\
\hline Debbie Wasserman Shult & ltz & $\begin{array}{l}\text { Chair, House } \\
\text { Higher Education }\end{array}$ & 1 & INSIDER \\
\hline John Andrew Smith & 2 & $\begin{array}{l}\text { Staff Dir., Senate } \\
\text { Ways \& Means }\end{array}$ & 2 & INSIDER \\
\hline David Coburn & 1 & $\begin{array}{l}\text { Staff, Senate } \\
\text { Ways \& Means }\end{array}$ & 2 & INSIDER \\
\hline Linda Collins & 1 & $\begin{array}{l}\text { Staff, Senate } \\
\text { Ways \& Means }\end{array}$ & 2 & INSIDER \\
\hline Cynthia Chestnut & 1 & Legislator & 3 & INSIDER \\
\hline Anne McKenzie & 1 & Legislator & 3 & INSIDER \\
\hline Rudy Garcia & 1 & Legislator & 3 & INSIDER \\
\hline Charles Reed & 3 & Chancellor, SUS & 4 & INSIDER \\
\hline Debbie Gally & 1 & Staff, Chancellor & 4 & INSIDER \\
\hline Frank Brogan & 1 & $\begin{array}{l}\text { Commissioner, } \\
\text { Education }\end{array}$ & 9 & $\begin{array}{l}\text { NEAR } \\
\text { CIRCLE }\end{array}$ \\
\hline Clark Maxwell & 1 & Director, SBCC & & \\
\hline William Proctor & 1 & Chair, PEPC & & \\
\hline John Lombardi & 1 & $\begin{array}{l}\text { President, } \\
\text { State University Sy }\end{array}$ & & \\
\hline
\end{tabular}




\section{APPENDIX D}

\section{Summary for Section III}

$\underline{\text { Key Policy Makers by Title or Position with Survey's Case Number References }}$

The State Legislature: 023, 032, 058, 087, 103, 138, 146, 154, 176, 197, 199

Legislature: "Senate first, House second": 075

Key Members: 006

Committee Chairs: 072, 114, 159

Higher Education Committee Chairs: 115

Staff: 032. 042, 048, 050, 077, 078, 096, 103, 106, 108, 121, 137. 156, 206

"the shadow government" 032; "unfortunately" 078; "unfortunately" 042

Key: 006, 182

Committees: 155

Appropriations: 059

Higher Education: 126, 175

"too much influence, too uninformed" 175

The Senate

The President of the Senate: 011, 058, 080, 111, 112, 147, 206

Leadership: 025

Committee Chairs: 175

Relevant Committees \& Subcommittees: 064

Staff: 055, 089, 184

Senate Ways \& Means Committee

Chair: 042, 080, 111, 112, 114, 116, 129, 209

Members: 018, 045, 196

Staff: 031, 045, 081, 109, 111, 112, 121, 129, 169, 193, 209

Senate Higher Education Committee

Chair: 020, 051, 111, 112, 114, 116, 129, 147, 189, 203, 209

Members: 008, 071, 121, 143, 151, 160, 174, 190

Staff: 091, 111, 112, 121, 129, 151, 185, 181, 209

Senate Education Committee

Chair: 020, 068, 086, 128, 209

Members: 045, 143, 172

Staff: 020, 045, 081, 091, 193, 209 
The House of Representatives

The Speaker of the House: 011, 058, 080, 111, 112, 122, 147, 206,

Leadership: 025

Committee Chairs: 175

Relevant Committees \& Subcommittees: 064

Staff: 055,184

House Appropriations Committee

Chair: 042, 080, 111, 112, 114, 116, 129, 147, 209

Members: 018, 045, 160, 167, 196

Staff: 031, 045, 081, 091, 111, 112, 121, 129, 169, 193, 209

House Higher Education Committee

Chair: 020, 051, 111, 112, 114, 129, 147,189, 203, 209

Members: 008, 071, 143, 172, 174, 181, 190

Staff: 091, 121, 129, 181, 185, 209

House Education Committee

Chair: 020, 068, 086, 114, 128, 209

Members 045, 172, 193

Staff: 020, 045, 081, 091, 209

Governor: $011,089,108,111,112,176,189$

Governor's Staff: 072, 123

Governor's Higher Education Staff: 181

Department of Education: 174, 176

Commissioner: 111, 112, 114, 172, 209

Staff: $123,172,188$

Higher Eucation Staff: 191

Division of Community Colleges: 070, 081, 174

Staff: 081

Postsecondary Education Planning Commission

Members: 053, 077, 078, 108, 111, 112, 114, 190, 195

Staff: 181

State University System

Chancellor: 009, 020, 072, 089, 108, 120, 121, 123, 131, 152, 160, 166 Staff: 065

Board of Regents

Chair: 160

Members: 005, 008, 009, 035, 045, 053, 059, 078, 092, 111, 112, 114, $119,131,143,152,166,174,209$ 
Staff: 005, 081, 172

Institutional Presidents: 008, 035, 065, 072, 078, 119, 209

Iinstitutional Administrators: 008

State Board of Community Colleges

Director: 020, 108, 111, 112, 121, 122, 131, 161, 166,

Members: 007, 059, 077, 078, 111, 112, 166, 190

Staff: 034, 108

Institutional Board of Trustees: 059, 131, 161

Institutional Presidents: 007, 062, 119

Independent Colleges and Universities of Florida

Board of Trustees: 059

Presidents: 026, 123

Members: 150

Local Institutions

Presidents: 023, 048, 063, 142, 143, 144, 159

Vice Presidents: 142

Facultyt Senate Presidents: 035

Lobbies

Teacher Union: 196

Higher Education: 023

Edcuation: 158

Others

Old-Time Politicos: 009

President's Council: 121

The Committee Of 100: 088

CIA/ Council of Presidents: 201

Reporters: 181

NAACP: 197

City Officials: 197 


\section{APPENDIX E}

Florida Higher Education Documents of Interest

\section{General Comments from Section IV}

I don't think that any document has much effect in the year after it is written and promulgated." (041)

"Nothing will make it clearer." (138)

\section{Comments about the Legislative Process}

"Study the '95 Legislation" (050)

"Walk the halls during leg[islative] session" (153)

"1995-96 Legislative Session" (042)

"Budget process" (015)

\section{Source of Document with Respondent Case Numbers}

(a) Articulation Coordinating Committee:

Reports: 078

(b) Community College System

State Board of Community Colleges

Mission Statement: 066

Master or Five-Year: 111, 112 ,127, 190

Capital Improvement Plan: 070

Minutes or Reports: 020, 034, 070, 182

(c) Postsecondary Education Planning Commission

Mission Statement: 066

Master or Five-Year Plan: 11, 112, 190

Agenda or Minutes: 078, 080

Reports: 012 014, 018, 020, 033, 034, 042, 055, 059, 067, 068, 077,

091, 098, 103, 136, 137, 181, 191

Publications: 080

(d) The State Department of Education

K-12 Master Plan: 127

(e) State Legislative Reports*

Budget-Related Materials: 033 , 111, 112

Mandated Studies: 
Legislative Studies: 059, 177, 143, 181, 205

Staff Documents: 075

* A respondent may have listed more than one document in these areas.

(f) State Statues

General Statues: 005

Appropriations Bill: 016, 128, 143

Proviso Language in Appropriations Bill: 045, 096, 175

Education-Related Legislation: 152

Specific Legislation

1991 FAU/ Broward Legislation: 006

1987-1988 12-hr Law for Faculty: 006

1995120 Credit-hr legislation: 006, 038

(g) State University System

Mission Statement: 066

Master or Five Year Plan: 005, 111, 112, 127, 147

Publications: 119

Board of Regents

Mission Statement: 066

Master or Five Year Plan: 083, 160

Agenda or Minutes of Meetings: 080, 175

Materials or Publications: 018, 082

(h) Other Sources:

State Documents

Demographic Studies: 088

Planning Documents: 143

1980 Reports for the Joint Executive \& Legislative Commission on

Higher Education in Florida: 195

Blueprint 2000: 016, 034

Newspapers

“Miami Herald's “ Annual Lawmaker Rating: 022

Interest Groups

Friends for Education Committee 022

Tax Watch: 147

Independent Colleges and Universities of Florida Documents:

Florida Council of 100 Report:

Other

California Study on Higher Education (152) [Respondent did not specify the particular study.] 


\section{APPENDIX F \\ Summary of Comments from Section VI}

002 Natural resources, = a) water quality and management, b)Land management, purchases and preservation, $c$ ) air emissions

005 Need for colleges/ universities to develop institutional effectiveness plans to ensure that students are receiving quality education services.

005 Need to ensure the professorate is committed to providing quality instruction using the latest technology as appropriate in the delivery of undergraduate education.

005 Need to provide educational services for a diverse student body.

005 Need to provide distance learning opportunities for students who cannot attend traditional programs.

006 Funding by FTE [full-time equivalent]

006 Expenditure analysis \& cost per delivery of credit hours

006 [Number] of credit hours for Florida FTE!

009 Florida lacks the tax base to fund adequately higher education and the most influential people do no value even the cost-savings to the state that assistance to independent institutions could accomplish.

012 How the state will deal with the 80,000 additional qualified high school graduates seeking admission for Florida's colleges by the end of this decade

012 Individual boards of trustees at the State University System institutions.

014 With declining state revenues, providing access to qualified students will be difficult.

014 Productivity of universities and students in using available resources (providing faculty, classroom seats, increasing student loads per term, improving student advising)

014 Improving articulation among community colleges, public universities and private institutions.

015 Revenue shortfalls and reduction of state funding

016 Future structure of Florida's educational community - decline of $2+2$ system

016 Decline of financing for education

018 Funding of private/ ind and how that affects access and choice. - more funding needed. 
020 The most critical issues facing higher education today in Florida is funding. Education has for the past several years (since the inception of the lottery) received a smaller and smaller piece of the general state revenue. Higher education has suffered the most with community colleges receiving the largest decrease.

022 The Miami Herald rates effectiveness of lawmakers. It is based on some statewide assessment. [from Section IV]

022 A look at the Friends for Education Committee Chairs/ Members may be helpful. [from Section IV]

022 The growth of influence of particular legislators may be effected by desire to appear influential. [from Section IV]

022 Affordability as it relates to access \& choice.

022 Need for ways for institutions to present a report card of its quality and assessment

023 We are very concerned for funding of higher education. Legislature tends to micromanage all agencies when revenues are limited. Rather then finding ways to fund education at a level that will provide for the needed services, legislators their staff personnel, and state agencies are looking for ways to reduce services to fit within available revenues, regardless of the number of citizens to be served.

027 State support for private education through student assistance.

029 Adequate financial support

029 Continuing erosion of local/ institutional control

030 The management of resources by legislation undermines local decisions and causes wasteful use of funds

033 Funding enrollment growth in light of state revenue caps.

033 Preserving student financial assistance, especially Pell Grants and deferred interest loans.

033 Access to higher education - especially open door for community colleges \& availability of hugh demand programs at the university.

033 Preserving local governance of community colleges and reducing state reports and other bureaucratic requirements.

034 In governance area, the legislature is increasingly intrusive in curricular issues. We are headed towards homogeneity which will result in mediocrity in State University System especially as they are forced to common curricula. 
034 A more general issue is the widespread contempt for education evidenced among Florida voters/ taxpayers. They distrust and resent intellectual inquiry and refuse to pay for improvement of lives. The state is a poisonous atmosphere for education.

035 Accountability - taxpayer desire to know that funds are being spent efficiently \& effectively

035 Remediation in post-secondary institutions

035 Students want to prevent tuition increases while increasing access.

035 State revenue availability is decreasing. Universities want to raise tuition.

038 Maintaining or improving student access in the face of a decreasing percentage of public revenue being appropriated to higher education.

039 Accountability to customers - students, employees \& public

039 Preparing students for global competition

041 I don't think that any document has much effect in the year after it is written and promulgated. [from Section IV]

041 We need to stop playing games and insist that people/ schools do what they say that they will do. To that end, better definitions of quality and more sensitive (and workable) instruments of assessment are needed.

042 Insufficient funding \& a desire by legislature to base education policy on ability to fund education rather than the greater need of an educated population.

046 Recognition that there must be a reallocation of resources at the university level in order to regain credibility with the taxpayers and the legislators. Then and only then can we address the funding of the cost of an quality education which is so essential to our society if we are to prepare our children for the fiercely competitive future world.

049 Maintaining accurate projection of income generated by enrollment (tuition \& fees)

049 Constructing a budget that serves and supports the mission of the college.

050 All of the above issues are inter-related the finance component is currently the most dominant. The other areas are being compromised by inadequate funding

051 Financial restrictions prevail over needs assessment - studies \& logical proposals.

052 The state government has placed so many mandates on the local school boards and, at the same time, restricted the local boards in so many other ways. 
053 I don't directly deal with Florida issues in these categories - as a private institution $\mathrm{CFO} / \mathrm{CBO}$ [Chief Financial Officer/ Chief Business Officer], I deal with local and national issues and trends, not state government very much.

054 The demand for accountability and productivity has begun and will intensify. As such, we, higher education, will be required to demonstrate to our clients (students) and tax payers (public institutions) that expenditures are justified in carrying out the academic mission. Consequences of not doing this will be reduced funding at a time few of us can afford it.

057 Finance - revenue cap effects on colleges/ universities

057 Funding sources - limited

057 Postsecondary Education Planning Commission needs far exceed funding capability

057 Enrollment increases projected for the next several years will exceed funding capability

058 There has been a continuing decline in general revenue support of community colleges. Current and future appropriations for corrections/ prisons will adversely affect all levels of education in Florida.

059 Finance

060 The state must find a way to include private colleges and universities in the "higher education solution." More state money can be allocated to students attending private colleges and state universities should be allowed to manage tuition costs to generate a larger part of their revenue.

062 Legislature vs local control

062 Outside agencies determining curriculum and enrollments

063 How are institutions assessing the quality of education

064 The most pressing issue is the whole complex of issues growing out of the apparent conflict between the drive for program efficiency and local governance and program quality.

065 Decrease in funding due to increases in funding for prisons

066 Developmental/ preparatory classes in postsecondary education.

066 The recent trend to set up policies so that students have to follow rigid steps toward graduation. Proposed plans to penalize students \& universities who/ that allow students to experiment with courses. Finances really directing curriculum. 
069 Increasing competition from public schools/ universities is eroding our ability to operate economically. State institutions should focus on providing access to those unable to pay for private education and to compete (by awarding higher levels of financial aid) for those who can pay.

070 Lack of general revenues

070 Declining student base

070 Inadequate technology

070 Outdated facilities

071 Access due to increase admissions \& over enrollment

071 Admission requirements for community colleges

071 Decreased funding

072 How we fund enrollment growth!

073 Standardization within public institutions

075 The legislature is dictating goals and procedures to institutions in higher education. The squeeze is on ... higher education administrators and faculty are not in the position to mange outcomes and results. The legislature is micro-managing without the benefit of knowledge or expertise. Its similar to an automobile being driven by remote control on a busy highway when the driver is without a license.

077 The focus on performance-based incentive funding and performance-based budgeting by the legislature is placing considerable pressure on community colleges to increase the number of graduates and placements.

077 Demographic changes will greatly influence ethnicity diversity in Florida colleges

078 Finance - clearly inadequate funding

078 Governance - attempt by legislative staff \& some legislators to "standardize" and centralize higher education

078 Attempt by legislative staff to close the open door

080 Higher Education: budget funding

080 Access and growth

080 Tuition differential issues

081 Accountability measurers \& impact of recent legislation (60/120 credit rule, etc.)

082 How to provide for an additional 80,000 students per year in Florida within the budget constraints $\&$ competing priorities of the state! 
083 Higher education must communicate, based on objective evidence that we are about quality and can measure our effectiveness. The legislature and their staff perceive that too much energy is directed toward "self-serving" activities by faculty and staff -- particularly in the public sector.

083 This [situation] has been precipitated by legislative staff who have faced personal problems with their own children in the higher education system.

083 Further, with tight funding, there is a politically driven feeling that unit costs can and should be down -- that higher education is [ ] a business and they want to buy more spaces for students with less cost!!

084 Lottery revenue vs. education budget. Lottery was to be added to education budget. It has not been.

085 Funding at all levels. Funds to support new programs and to support implementation of high technology (high cost)!

086 cultural diversity

086 Government encroachment - higher ed[ucation]

086 Lack of responsiveness on the part of Fla. Dept. of Ed. officials

087 Not enough state money available to not only fund more adequately higher education but the agencies of the state

087 The legislature is imposing curriculum changes upon us -- not within the governance -- should be local decisions.

088 Who could be? The Committee of 100. Education must identify leaders in the legislature and work with them and cultivate their support. The real fact is that Florida lacks educational leaders. [from Survey's Section III]

089 Additional funds for higher ed[ucation]

090 Charter Schools

091 Frankly, having served in higher education in Florida since 1962 (both public and independent) I think I am knowledgeable about all of the above areas. There are pressing issues in each one. If you wish to contact me by phone, I will be pleased to discuss these matters. Signed by Respondent

092 Lack of funds for capital facilities (Postsecondary Education Planning Commission

092 Inadequate financing per FTE [full-time equivalent] student

092 Interference in University curriculum by legislature

092 Restrictive laws \& rules 
094 As a state legislator, I would hope my expertise would be weighted on the governance side more than any other. We need to run government as efficiently as we can with what we have to work with, without raising taxes at this time.

095 Maintaining local control (governance) of community colleges

096 Legislative staff. They are the policy makers. [from Section III]

096 Increased (increasing) "accountability" (also called bureaucracy) while budget is shrinking.

097 Yes! - There are 180,000 students enrolled in the State University System. There are 750,000 students enrolled in the Community College System. You didn't even include the Exec[utive] Director or the SBCC [State Board of Community Colleges] on your list in Part II although you did include the BOR [Board of Regents \& Chancellor. [from Section IV]

097 Furthermore - the Comm[issioner] of Ed[ucation] is really a K-12 office - could care less about higher ed! [from Section IV]

097 Performance-based funding - a real challenge to get the measures right!

097 Funding - funding - funding - how to survive - Who's going to be cut off from higher ed[ucation]

098 Maintaining local control

100 Revenue cap

100 Rainy day fund requirements

100 Funding of prisons and $85 \%$ rule

100 Low tuition rates

100 Quality of Florida's education delivery systems and its relationship to funding

101 I will be working on a bill for school flexibility. It will give individual schools and districts the ability to ask the Commissioner of Ed[ucation] for permission to waive certain statutes so that those schools can reach their individual goals for Blueprint 2000. It gives them an incentive to be creative in deciding how to obtain what they, individually, need in their school

103 SBCC [State Board of Community Colleges] staff who help write the proviso language. [from Section III]

103 We are depriving students of access, [the] $60 \mathrm{hr}$. rule does not allow students to explore various fields legislative mandates do not allow colleges to spend money on what the college deems appropriate.

103 Assessment results are misinterpreted by non-educators.

104 Being able to deliver quality educational services in a timely manner. 
106 The decreasing revenue and increasing accountability facing community colleges in the foreseeable future.

107 The need for tax reform in order that education, and all needs of state government, can be adequately funded.

108 State university system is overwhelmed. The SUS [State University System] is becoming an elitist system. How do we make the SUS more accessible \& more open to all the population?

110 Clearly the most pressing is the issue of access. Decreasing resources will (already do) force colleges to limit access. Currently, we are unable to offer the courses needed when they are needed to serve students appropriately - It will get worse in 1996-97.

111 The struggle to secure adequate funding to meet the explosive higher education needs of the state.

113 Student loan reductions

113 Competition from public institutions for private funds

113 Access to State University System

114 Defining quality

114 Accountability measures

114 Student outcomes assessment

115 Full funding for current \& incoming students; less state-required paperwork

116 The changing population

116 The increasing costs \& the mood of the taxpayers

116 The changes in education

118 We are entering a decade in which it will be extremely difficult to guarantee continued access to a high-quality education.

118 Many of the most vocal persons addressing this topic seem to have little understanding of valid measures of quality.

119 State revenues will not meet state needs and commitments during the next 5 years. Program cuts appear inevitable.

121 Inability to provide consistency by following a set funding formula. 
121 Basically the relative priority and lack of commitment to funding higher education.

122 Mission of community college - open door or not

122 University vs community articulation and enrollment

126 Higher ed[ucation] leg[i]s[lative] staffers. too much influence, too uninformed. [from Section III]

127 Funding will be tight

127 State and federal micro management

127 Changes occurring in EA/EO

127 Proof of quality

128 Reductions in proportion of state funding going to education;

128 Use of unpredictable lottery revenues to supplant - rather than enhance - general revenue sources

128 Misplaced emphasis by legislators on law enforcement, persons, HRS, etc. when education could minimize problems in all those areas. Better (and cheaper) to education than incarcerate!

129 Revenue [ ]

129 [ ] of policy making at [ ] state level

129 Lack of civic leadership for education

131 Remedial education is one of the most significant problems. It should be greatly reduced at the $\mathrm{CC}$ level. The structure of the $\mathrm{CC}$ governance should be examined closely to make sure it is the effective way to run the system.

136 Declining revenues are killing higher education. Prisons, juvenile justice, and welfare get too much funding and education suffers.

136 The lottery has proven not to be the answer.

137 Simply put - adequate financing without further state (legislative) control.

138 Nothing will make it clear or clearer. [from Section IV]

138 The most pressing issue in all areas is removing the Florida legislature from the micromanagement of education.

140 We must generate more gross receipt taxes to fund much needed Postsecondary Education Planning Commission projects.

140 Student growth is clearly outstripping general revenue and lottery funds.

140 Revenue cap (budgetary growth) must be granted relief.

144 Shrinking state financial support in the face of increasing student enrollment 
145 Which factors count, i.e. value added by institutions to enhance competencies.

148 Accountability in education is pivotal. There has to be a way of measuring the performance of our student \& finding ways of competing against the major universities from the rest of the country.

149 Sufficient revenue to meet growing demands

149 Availability of slots for students (related to revenue)

150 We must do something with the problems in national accrediting bodies.

151 You cannot operate a quality higher ed[ucation] program at the current funding level.

151 In addition, you cannot operate the $3 \mathrm{rd}$ most populous state on a limited $6 \%$ sales tax, a small corporation tax, dog racing, and lottery.

152 Identifying alternative sources of income

152 Accountability

152 Admission standards, graduate requirements, tuition

152 Limited resources, larger class sizes

153 Funding must be accompanied by clear objectives, reporting, and accountability for results.

156 Walk the halls during a legislative session [from Section IV]

156 Funding [ ]

156 Division of responsibility among SUS, CC and public schools

158 Utilization of resources from independent institutions and public/ private partnerships to deliver an education product.

158 Develop outcome assessments

159 Technology and market forces will continue to create huge changes in the Florida postsecondary educational system. Fewer dollars and more students will require large increases in productivity and accountability. The taxpayer at all levels is looking for a much larger ROI (return on investment) in outcomes -- products not process as in the past.

160 The absence of a stable funding source to support higher education.

160 The inability for legislative "long-range" planning.

160 The continued existence of "crisis" fiscal policy. 
161 Privatization of public education - probably will come in some form or another over the years.

164 Federal \& State Aid

165 Maintaining affordability and value (i.e. quality) of private college education cost to the students. need blind admission -- access.

166 Erosion of education budget in the total state budget picture.

166 Centralization in decision-making

166 Republican efforts to reduce access for needy student

166 Resources for technology

167 Florida politics - Player's goals 1. reelection; 2. cutting budgets (de facto pandering to press, business, constituents, etc); 3 . high visibility statewide (positioning for future, i.e. their personal future). It is a bizarre political scene in Tallahassee. signed by respondent

168 Equitable funding across all segments of education.

170 Most pressing issue is full recognition of Tallahassee-based staff and conservative Senate leadership of the need to invest in postsecondary education to strengthen FL's competitiveness in the world marketplace. Excess attention to efficiency and accountability is misplaced. FL should be focusing on building capacity (access) and quality to prepare Floridians for the 21 st century.

172 Problems/ concerns related to excellence and access

172 Testing \& access, especially in CC's [Community Colleges]

172 Articulation agreements and their impact - reception at S[enio]r college/ universities

174 Need more top school officials coming from business area -- Education is a business and could, in my opinion, be administered best by people with business background -- especially in light of expected dwindling resources.

175 Future sources for student growth

175 Tuition policy - getting families, students to pay more of cost since other state revenues aren't available

175 Access given limited enrollment for $\mathrm{B}+$ students to 4 year education

175 Articulation with CC programs

175 Poor graduation rates and legislative expectations

179 Equitable funding of a. community colleges vis-a-vis K-12, b. community colleges vis-a-vis state university system, and c. small community colleges 
179 Undermining of general revenue appropriations since lottery education "enhancement funding"

179 Block grants and performance-based funding program loopholes

181 Abuses/misuse of technology and distance learning funds

181 Greater concern for numbers of students admitted or graduated rather than on quality.

181 Increasing privatization and its impact on access for working and middle class students

182 If local community college BOT's [Board of Trustees] have local control or it the legislature and SBCC [State Board of Community Colleges] erode this authority.

184 Lack of it!!

185 Equitable funding among the public community colleges

188 Need for autonomy for state universities, e.g., recent Lombardi issue

190 Shrinking local control

190 Micro management by the state legislature

191 Return system to 2+2 [ ]

191 Permit the 3 senior institutions - UF [University of Florida], USF [University of South Florida] - FSU [Florida State University] to function under local control [ ]

193 The legislature, as a result of inability to fully fund education, social programs, corrections, etc. are enacting laws that effect educational purely as cost reduction measures without concern for their consequences (educational).

195 Lack of designated funding source for $\mathrm{H}$ [igher] E[ducation] needs of the state's public institutions

195 Threat from within the state bureaucracy to the local control of community college.

196 FRFP changes to reflect more fairness

196 Higher ed[ucation] \$ [money] to expand facilities to allow larger [numbers] \#'s of students

197 In Jacksonville, it is time to settle the integration issue. 
198 Whether the university system structure is flexible enough to allow campuses a sense of institutional identity and direction, and whether a more appropriate balance between legislative power and regents' authority can be derived.

199 A need for more funding for private college and universities from state funds

199 More voice from the private college sector in the governance of higher education in Florida

201 Curriculum

203 Standards for admission

203 Remediation

203 High school graduation requirements

203 Ability to finish university in 4 years

204 Tuition flexibility

204 Remediation

205 Graduate and job acquisition as compared to graduation rate

205 Retainability of information gathered in college.

206 Quality of the product and accountability for that product.

207 Pre-K through 12th grade funding including capital outlay. 
VITA

Edward A. Blackwell, Jr.

1972

B. A., Sociology

Bloomsburg University

Bloomsburg, PA

1976

Ordained to Priesthood

Diocese of Harrisburg

Harrisburg, PA

1979

M. A., Theology

Mt. St. Mary's Seminary

Emmitsburg, MD

1980-1988

Director of Young Adult Ministry

Diocese of Harrisburg

Harrisburg, PA

Director of Campus Ministry

Millersville University

Millersville, PA

1988 to Present

Director of Campus Ministry

St. Thomas University

Miami, FL

1989

Member of Master Long Range Planning

1991

Member of SACS Steering Committee

Editor of Self-Study

1992

Member of Strategic Planning

1993

Doctoral Candidate

Florida International University

Miami, FL 